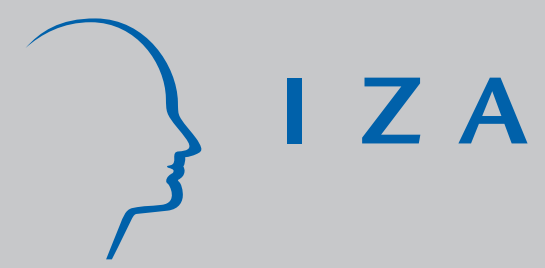

IZA DP No. 8786

Are Recipients of Social Assistance 'Benefit Dependent'?

Concepts, Measurement and Results for Selected

Countries

Herwig Immervoll

Stephen P. Jenkins

Sebastian Königs

January 2015 


\title{
Are Recipients of Social Assistance 'Benefit Dependent'? \\ Concepts, Measurement and Results for Selected Countries
}

\author{
Herwig Immervoll \\ $O E C D$ and IZA \\ Stephen P. Jenkins \\ LSE and IZA \\ Sebastian Königs \\ $O E C D$ and IZA
}
Discussion Paper No. 8786
January 2015

IZA

P.O. Box 7240

53072 Bonn

Germany

Phone: +49-228-3894-0

Fax: +49-228-3894-180

E-mail: iza@iza.org

\begin{abstract}
Any opinions expressed here are those of the author(s) and not those of IZA. Research published in this series may include views on policy, but the institute itself takes no institutional policy positions. The IZA research network is committed to the IZA Guiding Principles of Research Integrity.

The Institute for the Study of Labor (IZA) in Bonn is a local and virtual international research center and a place of communication between science, politics and business. IZA is an independent nonprofit organization supported by Deutsche Post Foundation. The center is associated with the University of Bonn and offers a stimulating research environment through its international network, workshops and conferences, data service, project support, research visits and doctoral program. IZA engages in (i) original and internationally competitive research in all fields of labor economics, (ii) development of policy concepts, and (iii) dissemination of research results and concepts to the interested public.
\end{abstract}

IZA Discussion Papers often represent preliminary work and are circulated to encourage discussion. Citation of such a paper should account for its provisional character. A revised version may be available directly from the author. 


\section{ABSTRACT}

\section{Are Recipients of Social Assistance 'Benefit Dependent'? Concepts, Measurement and Results for Selected Countries ${ }^{1}$}

Means-tested Social Assistance (SA) benefits play an important role as social protection floors supporting households in financial difficulties. This paper presents evidence on the patterns of SA benefit receipt in a selection of OECD and EU countries. It provides an overview of the role of SA benefits in social protection systems and assesses the generosity of benefit payments. It then studies the dynamics of SA benefit receipt based on micro-level data describing trends in aggregate receipt and transition rates and presenting new evidence on spell durations and repeat spells. The final part of the paper summarizes recent empirical evidence on state dependence (or 'scarring effects') in benefit receipt and discusses its possible sources and policy implications.

JEL Classification: I38, J60, J64, C23

Keywords: social assistance, welfare benefits, state dependence, benefit dependence, scarring

Corresponding author:

Sebastian Königs

OECD

2, rue André Pascal

75775 Paris Cedex 16

France

E-mail: Sebastian.Koenigs@oecd.org

\footnotetext{
${ }^{1}$ This report was produced with the assistance of the European Union, as part of the joint OECD/EU project "Multi-country Database on Benefit Recipients and Analysis of Recipiency Patterns" (2010-13). The authors thank Monika Queisser for guidance and detailed drafting suggestions and Ross Finnie for providing results on benefit receipt in Canada. Jenkins' research was partially supported by core funding of the Research Centre on Micro-Social Change at the Institute for Social and Economic Research by the University of Essex and the UK Economic and Social Research Council (award RES518-28-001). This report is also released as OECD Social, Employment and Migration Working Paper 162. Sections 2 and 3 are available as Statistics Norway Discussion Paper (Königs, 2015).

The usual disclaimer applies. In particular, the views expressed in this paper should not be reported as representing the official views of the European Union or the OECD, or of their member countries. The opinions expressed and arguments employed are those of the author(s).
} 


\section{Table of contents}

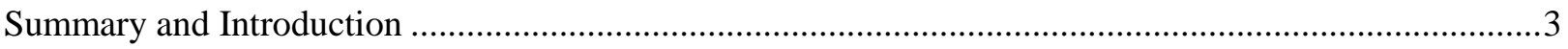

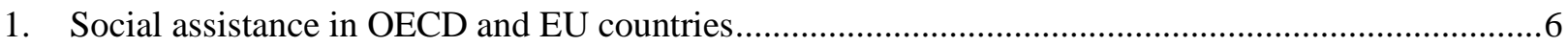

A typology of social assistance benefits: scope and links with other transfer programmes.....................

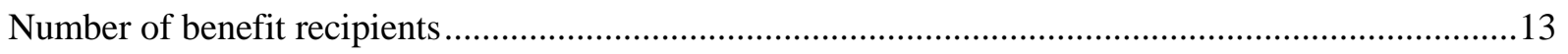

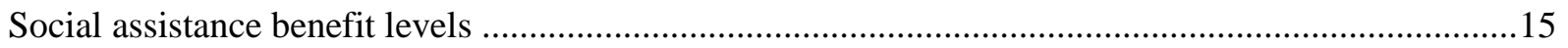

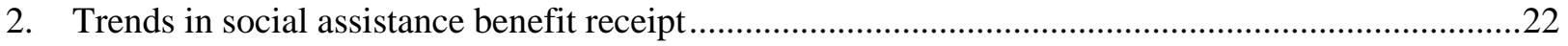

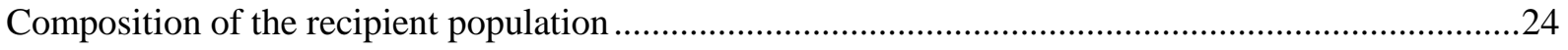

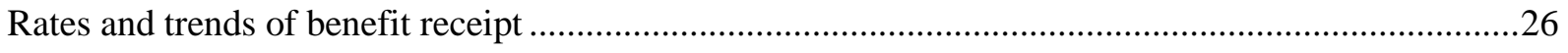

Benefit transition rates and the relative importance of entries vs. exits .................................................

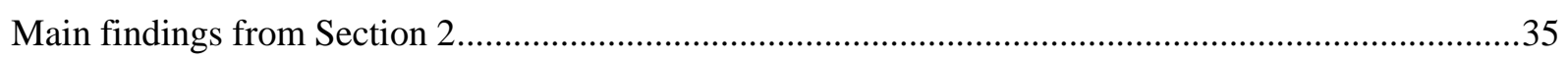

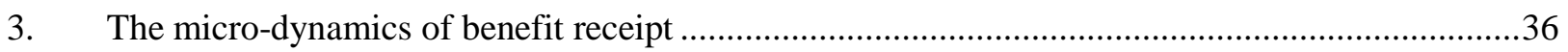

Duration of benefit spells $(1)$ - evidence from long panels ....................................................................

Duration of benefit spells (2) - a cross-sectional perspective .............................................................

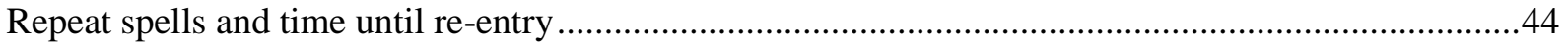

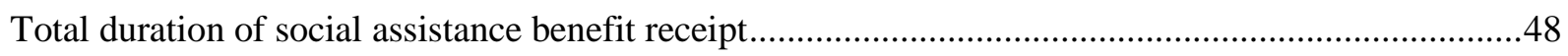

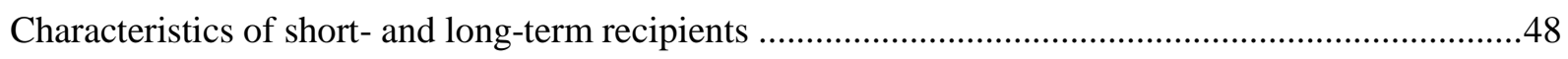

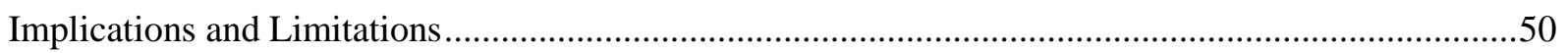

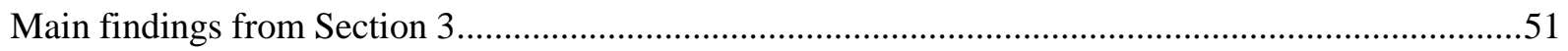

4. State dependence in benefit receipt: Do past benefit spells make continued receipt more likely?.53

Heterogeneity, genuine, and spurious state dependence ……..........................................................53

Estimates of the degree of state dependence, spurious and genuine ...................................................55

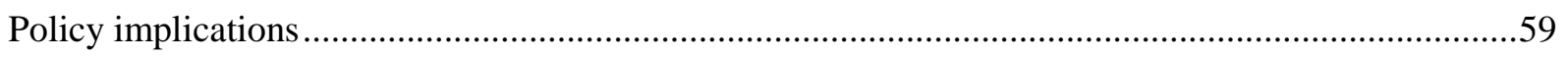

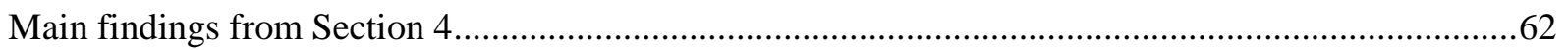

Annex 1.A. Social Assistance programmes included in the recipiency statistics reported in Section 1...64

Annex 4.A. Issues complicating assessments of state dependence: model specification ........................66

Annex 4.B. Issues complicating assessments of state dependence: data and definitions ........................71

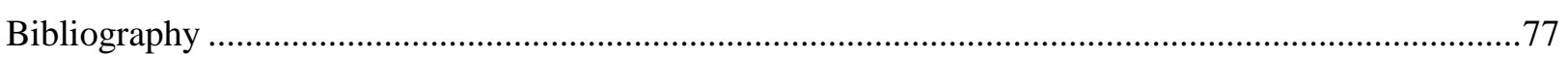




\section{Summary and Introduction}

Almost all OECD and EU countries operate comprehensive means-tested benefit programmes for workingage individuals and their families. These benefits have a major role as Social Protection Floors, either providing last-resort safety-net income support alongside primary income-replacement benefits or acting as a principal instrument for delivering income support. Government spending on such benefits is a substantial budget item in OECD and EU countries.

More generally, patterns of social assistance benefit receipt are of significant social policy concerns, and have become more so in recent years. As for other parts of social protection, the aftermath of the 'Great Recession' has created not only greater demand for social support but also increased pressures to reduce or control spending. A greater focus on targeting limited resources to the poorest families has shifted the balance of insurance versus assistance benefits in some countries, and created pressures to rely more heavily on social assistance and other benefits of 'last resort'. Also, the nature of last-resort benefits has been changing over time, e.g., as a consequence of the 'welfare to work' reforms introduced in countries such as the USA, the UK, Australia, New Zealand, and Germany; these reforms may affect the extent of income support that these benefits can provide, the transitions into and out of benefit receipt, and the levels, trends and composition of social spending.

The aim of this paper is to review a number of the most important aspects in light of current economic and social developments. It gives an overview of social assistance (SA) policies across OECD and EU countries and presents new evidence on the duration of SA benefit receipt, and related indicators of 'benefit dependence'. While related results are available from earlier studies for a few individual countries, a key objective of this paper is to provide a comparative perspective and analyse benefit receipt patterns using a unified conceptual framework and measurement approach.

Section 1 situates SA benefits in relation to countries' overall income support programmes, proposes a typology to support cross-country comparisons, and draws attention to the diversity in the types of SA programmes. It summarises key features of SA programmes, including the number of recipients and the income situation and likely poverty status of benefit recipients. Finally, since debates of means-tested benefits often centre on work-incentive issues, this part also compares SA amounts to the incomes of minimum-wage earners and to the income levels typically provided by unemployment benefits.

The remaining parts of the paper present evidence on the dynamics of SA benefit receipt. Here, the perspective is distinctively longitudinal and analysis is based on micro-level panel data that permit following the same set of individuals over extended periods of time. Two different types of dynamics are considered:

- Trends over time in the prevalence of receipt and turnover for national populations: this is an aggregate perspective, referred to as 'macro dynamics';

- Evidence on the persistence or turnover in benefit receipt at the recipient level: this is an individual perspective, referred to as 'micro dynamics'.

Section 2 discusses macro dynamics of SA benefit receipt tracing benefit receipt rates of working-age individuals and their families from the 1990s through to the late 2000s / early 2010s. The discussion focusses on a range of OECD and EU countries for which suitable data were available: Canada, Germany, Latvia, Luxembourg, the Netherlands, Norway, Sweden, and the United Kingdom. Key results include the following:

- Annual rates of benefit receipt initially vary substantially across countries but, in the 2000s, often converge to around $4-6 \%$ of the working-age population. In any given month, about $2-4 \%$ of 
working-age individuals receive SA benefits. The gap between annual and average monthly rates of benefit receipt is a measure of the extent to which people move into and out of benefit receipt ('turnover'). Measured in this way, the beneficiary population in a selection of five countries is found to be the most static in Luxembourg and the Netherlands, while turnover is highest in Norway.

- An analysis of the drivers of trends in beneficiary stocks shows that changes in the annual rate of benefit receipt tend to be primarily driven by changes in entry rates, which in most countries declined to around $1 \%$ per year in the 2000 s.

- Exit rates are less powerful as a determinant of aggregate beneficiary counts: Year-on-year exit rates from benefits change remarkably little over time even though policies often focus on moving benefit recipients on a path towards self-sufficiency and despite numerous policy changes during the observation period.

- Year-on-year exit rates do, however, differ a lot between countries. In Luxembourg, only around $14 \%$ of benefit recipients stop receiving benefits in a given year. Exit rates are more than twice as high in Norway and Sweden, and three times as high in Latvia. Low exit rates are a first indication of long expected spell durations, an aspect discussed in more detail in Section 3.

- Perhaps surprisingly, there is no evidence for strong seasonal changes in benefit receipt. In countries where monthly data are available, both aggregate rates of benefit receipt and transition rates show little systematic month-to-month variation.

Although most official statistical summaries of benefit receipt describe macro dynamics, information about the individual-level dynamics, the subject of Section 3, is often more useful for understanding the determinants of the benefit receipt process. First, annual aggregate data usually do not allow determining for how long individual recipients remain on benefits. Second, aggregate transition rates into and out of benefits say little about whether benefit leavers are likely to return to claim benefits again later on (and if so, how quickly).

While the exact individual paths into and out of benefit receipt are informative for policy purposes, the data requirements for analysing them are considerable. Section 3 therefore focuses on five countries for which high-quality longitudinal data were made available, allowing individuals to be tracked month by month over a longer period of time: Latvia, Luxembourg, the Netherlands, Norway, and Sweden.

- The five countries fall into two groups with distinct patterns of benefit receipt dynamics: for Latvia, Norway, and Sweden, the duration of benefit spells is typically very short (median spell durations of 2-3 months) but a majority of benefit recipients have multiple spells during the observation period. In the Netherlands and Luxembourg, by contrast, median spell durations tend to be very long ( 9 and 15 months, respectively) but benefit leavers are unlikely to return to benefits.

- When adding up all spells of a given individual, the total duration spent on benefits is longer in the 'longer but fewer spells' countries (Netherlands and Luxembourg).

- Within countries, benefit spell durations are very heterogeneous, indicating that averages can be a poor guide for policies targeted at specific groups. In Norway and Sweden, a very small minority ( $2 \%$ and $4 \%$ ) of recipients stay on benefits for extended periods of time of more than 24 months. In Luxembourg, the majority of spells also last shorter than 2 years, but longer spell durations beyond 2 years are much more common here (38\%). 
- Given this heterogeneity between benefit recipients, the factors associated with individual receipt patterns are a crucial question for policy. There is evidence that, especially in Norway and Sweden, immigrants are over-represented among recipients with very long benefit spells. However, this assessment is very partial as the monthly data used in this part of the paper provide only little information on key characteristics of benefit recipients and therefore do not allow a more systematic assessment of the incidence of long-term benefit receipt.

The final Section 4 zooms in on benefit trajectories of specific individuals to investigate the extent to which benefit receipt in one period makes future benefit receipt more likely (so-called 'state dependence'). A starting point is the observation that, in a given year, benefit receipt rates are much higher for individuals who received benefits already in the previous year, than for individuals who were non-recipients. This suggests that recipients might be 'stuck' in a situation of benefit receipt.

However, in and of itself, an observation of apparent 'benefit traps' is not sufficient for informing policies to prevent them. There are two sets of drivers that can explain a strong association between benefit receipt across periods. It may indeed be past benefit receipt per se, that raises the likelihood of benefit receipt in later periods (the technical term for this is genuine state dependence). But alternatively, the association may arise simply because some individuals have characteristics (such as being a lone parent or having low education) that are associated with lower incomes and a greater need for support, regardless of the features of the benefit system (spurious state dependence). The distinction is crucial because a finding of genuine benefit traps suggests that benefit dependence results from factors that are somehow inherent in the benefit system, while spurious dependence typically points to other policy levers for promoting self-sufficiency (e.g., childcare for lone parents, second-chance schooling for low-skilled individuals).

Section 4 first discusses these concepts in more detail and critically surveys the most important statistical approaches that researchers have employed to measure state dependence. Acknowledging a number of complications that arise in such assessments, it then summarises and compares available evidence for six countries (Britain, Canada, Germany, the Netherlands, Norway, and Sweden), based on rich household panel data:

- The degree of observed state dependence is substantial: In the six countries analysed, compared with an individual who does not receive SA, someone who is currently receiving it is 60 to 80 percentage points more likely to be a recipient in the next period. The smallest difference (and, hence the smallest extent of observed state dependence) is found for non-refugee immigrant women in Sweden (58 percentage points) and the largest for women and non-EU migrants in the Netherlands ( 85 percentage points).

- Empirical studies that report results in broadly comparable formats also find statistically significant genuine state dependence. The size of this effect is however only a fraction of the level of observed state dependence, indicating that the largest part of continued benefit receipt among those receiving benefits in a given period can be attributed to recipients' personal and household characteristics. From these results, it appears that benefit receipt per se explains only a smaller, yet quantitatively important, part of apparent 'benefit traps'. The magnitude of genuine state dependence varies strongly across countries, recipient groups, and benefit programmes. The smallest effects are reported for native women in Sweden ( 5 percentage points), while genuine benefit traps seem to be largest (35 percentage points) in Canada and for some groups (EU-born immigrants) in the Netherlands. Typically, state dependence appears to be a bigger issue among migrants than natives.

- Turning to policy implications, a number of possible behavioural mechanisms may underlie these quantitative findings, including financial work disincentives arising from benefit receipt, the po- 
tential loss of labour market networks, adverse effects on individuals' motivation or feeling of self-control, or future employers perceiving past benefit receipt as a negative productivity signal.

- Existing empirical evidence says nothing or very little about the relevance of each of these different channels. It is likely, however, that a substantial part of state dependence in SA benefit receipt may be attributable to persistence in unemployment, poverty, or low pay, rather than SA benefit receipt per se. This calls for further research, as the identification of drivers of state dependence is a crucial prerequisite for effective targeting and design of policy measures (for instance, persistence of poverty may be addressed through transfers, while benefit dependence obviously cannot). In other cases, however, the distinction may be less consequential and existing results as presented in this paper can be a useful guide for policy (for instance, when strengthening employment support policies may be a suitable policy response for reducing persistence of poverty, unemployment or benefit receipt).

\section{Social assistance in OECD and EU countries}

Almost all OECD countries operate comprehensive means-tested benefit programmes for working-age individuals and their families, either as last-resort safety nets alongside primary income replacement benefits, or as the principal instrument for delivering social protection. These social assistance benefits (henceforth, SA) aim at providing an acceptable standard of living for families unable to earn sufficient incomes from other sources. As anti-poverty measures, they reduce income disparities at the bottom of the income spectrum and, as such, represent important building blocks of redistribution policies. Equally important, they act as safety nets for individuals experiencing low-income spells and, hence, help to smooth income levels over time.

This section provides a broad overview of current SA programmes in OECD and EU countries. ${ }^{2}$ In the policy debate, as well as in economic models, such transfers are occasionally characterised as simple income floors. Yet, while benefit levels are important, the extent to which they shape distributional outcomes also depends on many other factors.

One important factor is the way in which benefits of last resort are embedded in the wider social policy framework. For example, their significance as a redistribution instrument evidently differs between countries where they complement other benefits that provide powerful first-tier safety nets (as in much of continental Europe) and those where they represent the main benefit (as in Australia, New Zealand). Consequently, reforms of higher-tier benefits will often have implications for SA programmes in terms of spending levels, the number and characteristics of benefit recipients, and how best to support them.

The remainder of this section first proposes a simple typology for situating different types of SA programmes as elements of the overall redistribution system (Section 1.1). It then presents new comparative data on the number of benefit claimants (Section 1.2) and compares benefit levels, and the likely income of benefit recipients, to median household incomes and commonly used relative poverty thresholds (Section $1.3)$.

2. This section is based on, and updates, Immervoll (2012a). Earlier reviews of social assistance policies in different countries include Eardley et al. (1996), OECD (1998a; 1998b; 1999) as well as Adema et al. (2003). In-depth information on, and analyses of, policies in individual countries is available in the OECD's Benefits and Wages series which includes information on policy institutions and parameters, as well as indicators on income adequacy and work incentives (www.oecd.org/els/social/workincentives). Activation policies, including for SA recipients, are the subject of on-going OECD policy reviews and other analytical work (see www.oecd.org/els/employment/almp). 
The aim of the overview in this section is to provide important contextual information on SA policies that aid in interpreting the results of longitudinal analyses of SA receipt in later sections of this paper. Those analyses generally cover periods prior to the onset of the economic and financial crisis in 2008. For consistency, data in this first descriptive section therefore also relate to SA programmes that were in place prior to the crisis. However, it is important to keep in mind that the scope of the contextual information is, for two reasons, not fully congruent with the concept of SA adopted in the later analytical sections. First, the concept of SA used here is more comprehensive (i.e., may cover a greater number of benefits) than may be feasible or useful in the later analysis of receipt patterns using household micro-data. Second, descriptions of SA programmes relate to one particular year, while the longitudinal analyses necessarily cover longer periods (that is, 2007 SA policy rules may differ significantly from programmes that were in place during earlier years). Most of the data sources that are cited do, however, allow easy backdating/updating to earlier/later years.

\section{A typology of social assistance benefits: scope and links with other transfer programmes}

Last-resort benefits mean different things in different countries and for different population groups, and the terminology used to describe these programmes therefore varies across countries. For the purpose of this paper, SA programmes are broadly defined as public cash or in-kind transfers that aim at preventing extreme hardship and employ a low-income criterion as the central entitlement condition. Benefits of last resort therefore include broad minimum-income benefits ('non-categorical' SA), as well as other meanstested assistance payments that are typically received by families with no other income sources (although, as discussed below, the same benefits can to some extent also top up the incomes of low-paid workers and other low-income groups). Examples are means-tested lone-parent benefits, as well as unemployment assistance benefits that are not conditional on work or contribution histories (as in Australia, Finland, Germany, Ireland, Malta, New Zealand, UK).

Here, the term 'non-categorical SA' is used to refer to last-resort benefits that are generally available and, thus, not targeted to specific population groups. In addition, other, more targeted, benefit programmes are included in the definition of SA if they serve a similar function (e.g., means-tested lone-parent benefits). Such a broad definition of SA is necessary in order to facilitate comparisons between different designs of SA provision. In the paper, the terms 'social assistance', 'minimum-income benefit', 'minimum safety-net benefits' and 'last-resort benefits' are used interchangeably. In some countries, social assistance benefits play a significant role in providing support to individuals who are unable to work, or whose work capacity is limited, e.g., because of health problems. ${ }^{3}$ To focus the discussion, the summary in this section is limited to benefits targeted at able-bodied working-age individuals and their families.

3. Depending on the structure of support available for individuals with health problems as well as (early) retirees, these groups may fall into the scope of broadly-defined minimum-income programmes. At the same time, very large numbers of recipients of disability or early-retirement benefits in several OECD countries illustrate that these benefits can end up being used for contingencies for which they were not designed (such as long-term unemployment). The particular issues that are pertinent for these two groups are outside the scope of this paper. Issues related specifically to benefit claimants with disabilities or other health-related problems are discussed in the OECD series Sickness, Disability and Work (see www.oecd.org/els/disability). Pension policies, including means-tested, basic and minimum pensions, are discussed in Pensions at a Glance (www.oecd.org/els/social/pag). The latest issue in this series contains a chapter on poverty among old-age individuals (OECD, 2009a). Finally, employment barriers for older workers have been the subject of in-depth country reviews (www.oecd.org/olderworkersforum). 
Table 1. Public social expenditure in OECD countries: levels and composition, $2007^{(1)(2)}$

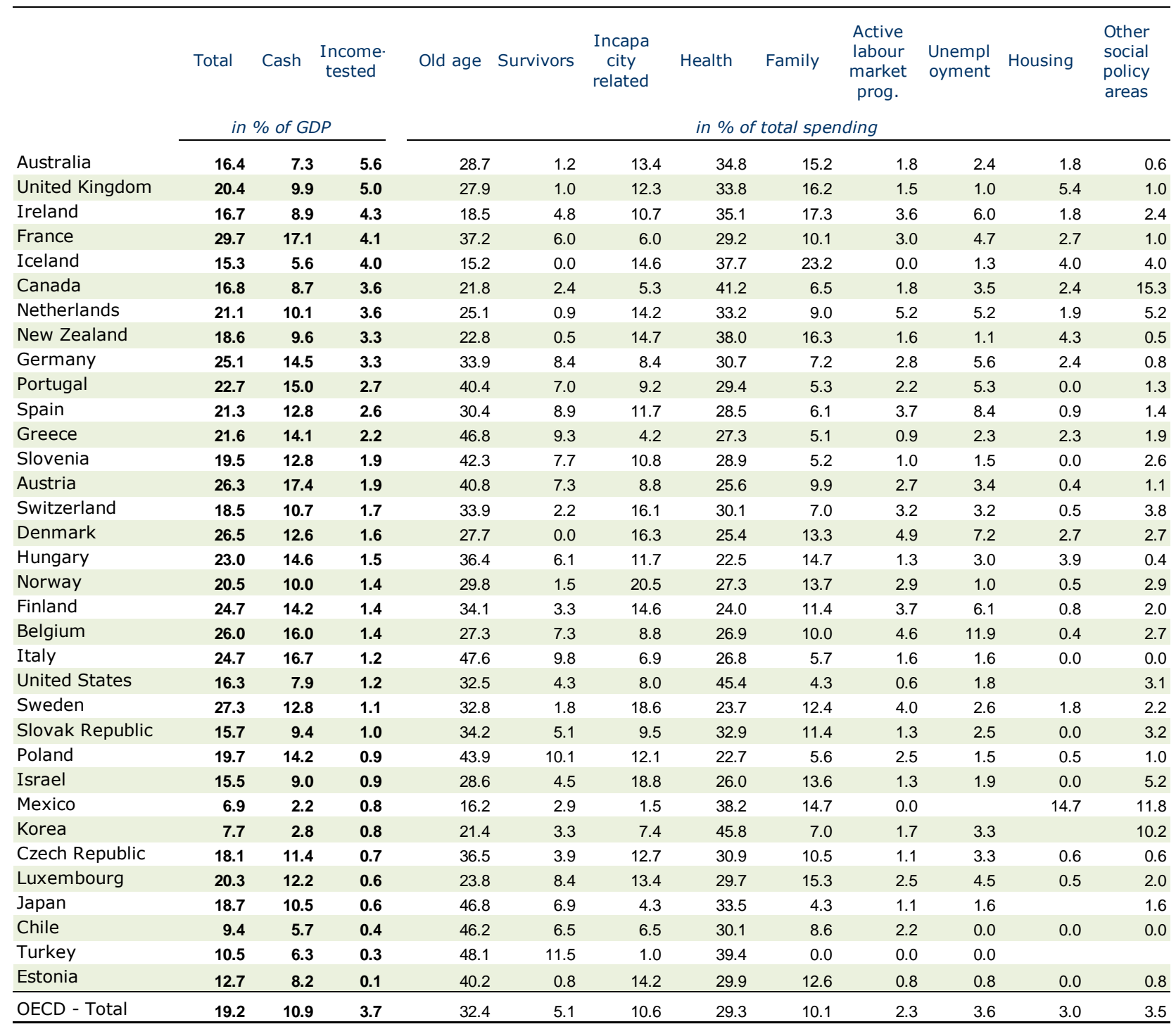

1. Data are in descending order of spending on income-tested cash transfers relative to GDP. They are before tax and account neither for the tax treatment of social benefits nor for tax expenditure (such as tax deductions for children), although tax credits that are paid in cash are included. The OECD also calculates net spending data which address these issues (see link in the sources).

2. Blank entries indicate that data are not available. The following income-tested spending items are included in the 'income-tested' category: spending on 'other contingencies - other social policy areas', income-tested spending on the unemployed (e.g. unemployment assistance), income-tested support payments to elderly and disabled, other income tested payments (family cash transfers). It does not include specific housing subsidies, spending on Active Labour Market Policies, or income-tested medical support.

Source: OECD Social Expenditure Database (www.oecd.org/els/social/expenditure).

In most areas of social spending, overall expenditure data are a good starting point to compare the significance of policies for different contingencies across countries. Spending patterns are illustrated in Table 1 using recent social expenditure data compiled by the OECD. The columns on the right show breakdowns of total public spending across nine social policy domains, while the first three columns report total spending levels as well as spending on cash benefits and on income-tested programmes. It is apparent that targeting low-income groups is a central design feature of cash transfer programmes in the UK, Ireland, New Zealand, Canada and, most notably, Australia. In countries with extensive social insurance benefits, less is spent on means-tested transfers. 
However, these numbers are likely to portray a distorted picture of spending on SA programmes as defined above. First, programme-level spending data is not always available and the decision whether or not to count broader benefit categories as means-tested can therefore be ambiguous. For the same reason, it is not straightforward to exclude programmes that employ means testing but are not in fact SA benefits. Examples are income supplements (rather than replacements) such as employment-conditional 'in-work' benefits, family benefits that are withdrawn only at medium to high income levels, or unemployment assistance that depends on previous work status and/or contribution payments. Second, data quality for the main SA programmes is generally lower than for other spending categories. ${ }^{4}$ Finally, aggregate spending data cannot be broken down by age group and expenditures for the working-age population only are not available.

Because of these limitations, a more detailed look at institutional policy parameters is useful in order to assess the role that SA plays in different countries. Otherwise similar measures can have very different effects depending on the institutional context in which they are used. Table 2 lists the most important cash transfers available to the working-age group using a functional classification. ${ }^{5}$

Unemployment benefits are the main support measures for job losers and other individuals without employment. Unemployment insurance programmes exist in most OECD countries, offering compensation for lost earnings subject to the certain conditions regarding the duration or type of previous employment. Reflecting insurance principles, claimants must have contributed to the insurance fund or have been employed over certain periods in order to be eligible. Claimants must also be actively looking for work and, in most cases, unemployment has to be involuntary, although this may be difficult to observe in practice and the definition varies across countries. Benefit durations are limited in most, but not all countries. Insurance is mandatory for most employees, but voluntary in some Nordic countries.

Job searchers whose entitlement to unemployment insurance benefits has expired, or whose work record is insufficient to make them eligible in the first place, may be entitled to unemployment assistance. In some countries, unemployment assistance is the main unemployment benefit. Eligibility is often, but not always, conditional on previous employment. As unemployment benefits, they are only granted to those who are available and actively looking for work. Benefit durations may or may not be limited. While both insurance and assistance benefit schemes are typically (but, again, not universally) financed by contributions to unemployment insurance funds, the main purpose of assistance benefits is the provision of a minimum level of resources during unemployment rather than the insurance against lost earnings. As a result, benefit levels tend to be lower and less directly dependent on previous earnings. They are reduced if other incomes are available although means-testing tends to be less comprehensive than for SA benefits.

\footnotetext{
4. For instance, the distinction between cash, near-cash and in-kind benefits can be problematic and certain components may not be properly recorded (e.g. special payments in exceptional circumstances or other discretionary payments, such as re-employment support). Also, the decentralised delivery of SA can lead to incomplete reporting, or non-reporting, of spending by local authorities to central government. Importantly, non-categorical SA, which is the main last-resort benefit in most countries, is recorded under the "other social policy areas" heading, which may lead some countries to treat it a residual category.

5. Further details on eligibility and entitlement conditions for each programme are available through http://www.oecd.org/els/benefitsandwagespolicies.htm.
} 
Table 2. Main cash benefits for able-bodied working-age individuals and their families, 2007

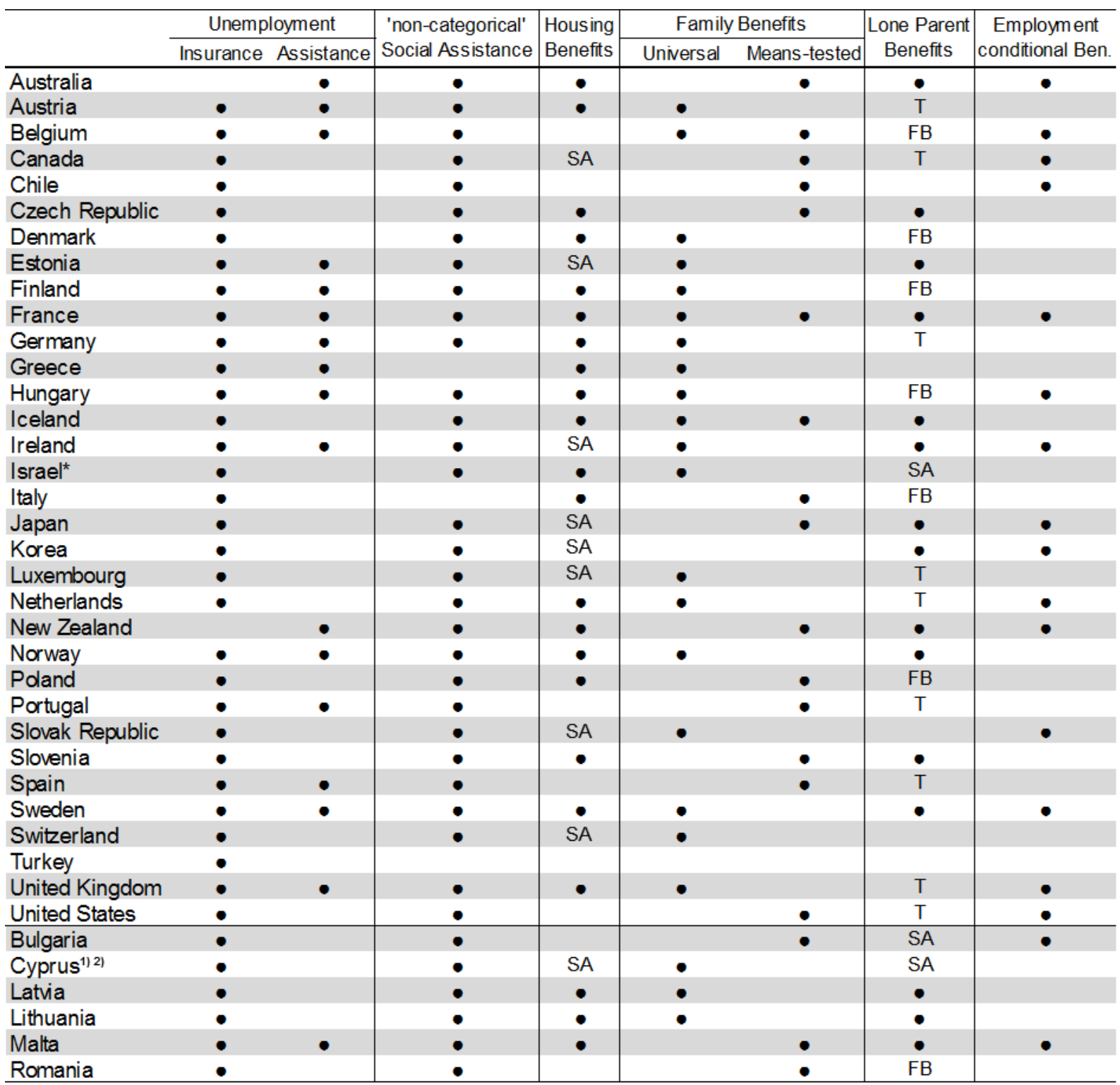

Notes: 2011 for Chile; 2008 for Bulgaria, Romania and Israel. Cash social assistance benefits only. Because of its importance, the US Food Stamps, a 'near-cash' benefit programme, is indicated as well. 'o' indicates that the specific benefit or tax credit exists in this country. Where no specific housing or lone-parent benefit is available, 'SA' (social assistance), or 'FB' (family benefit) indicate that housing or lone-parent specific provisions exist as part of these schemes. ' $T$ ' indicates that the provision takes the form of a tax advantage, such as a tax credit.

* The statistical data for Israel are supplied by and under the responsibility of the relevant Israeli authorities. The use of such data by the OECD is without prejudice to the status of the Golan Heights, East Jerusalem and Israeli settlements in the West Bank under the terms of international law.

1) Note by Turkey:

The information in this document with reference to "Cyprus" relates to the southern part of the Island. There is no single authority representing both Turkish and Greek Cypriot people on the Island. Turkey recognizes the Turkish Republic of Northern Cyprus (TRNC). Until a lasting and equitable solution is found within the context of the United Nations, Turkey shall preserve its position concerning the "Cyprus issue".

2) Note by all the European Union Member States of the OECD and the European Union:

The Republic of Cyprus is recognized by all members of the United Nations with the exception of Turkey. The information in this document relates to the area under the effective control of the Government of the Republic of Cyprus.

Source: OECD Benefits and Wages policy database (www.oecd.org/els/social/workincentives). 
Finally, those who do not qualify for any unemployment benefit may receive non-categorical social assistance benefits, with central or sub-central governments acting as providers of last resort. The main eligibility criteria relate to available incomes and assets, and entitlements do not depend on claimants' work history. Income and asset tests can be very restrictive and always take into account the resources of other persons living with the benefit claimant. Eligibility may also be conditional on the claimant's effort to regain self-sufficiency. Rules and practices vary substantially across countries, but job-search and other activity requirements can be much less demanding than in the case of unemployment benefits. ${ }^{6} \mathrm{SA}$ is typically not subject to explicit time limits but is paid for as long as relevant conditions are met. Activation-related behavioural requirements may, however, differ depending on receipt duration. Formal rules and implementation of such requirements differ both between and within countries. Some of the available information has been summarised in earlier studies, although quantifying the strictness of behavioural requirements precisely can be very challenging (Immervoll, 2010; Marchal and Van Mechelen, 2013). SA can be the main income source or provide 'top-ups' for income from other sources, including in-work earnings and other types of out-of-work benefits. Since SA programmes account for family circumstances and, in particular, the greater resource needs of bigger families, such top-ups are most likely when the benefit claimant has dependent family members.

In addition to non-categorical SA, there are other government transfers that have similar characteristics and can complement or substitute the main SA programmes:

- Low-income households may qualify for cash benefits intended to cover some portion of lowincome families' housing costs. These housing benefits typically employ forms of means-testing that are similar to SA, and benefit amounts are determined in relation to actual housing costs subject to ceilings. Housing benefits (henceforth, HB) may be administered as separate programmes, or they may be payable as part of SA entitlements (entry "SA" in Table 2). Unlike payments of non-categorical SA, dedicated HB programmes are typically not accompanied by work-related requirements or other activation-type interventions that seek to re-establish self-sufficiency.

- Families with children can claim family benefits in most countries (although the definition of what constitutes a 'dependent child' varies considerably). Most countries provide special benefits for lone parents either in the form of additions to regular family or childcare benefits or as separate programmes. Where benefits for children or lone parents are means-tested, they can resemble SA benefits in all but name. ${ }^{7}$ One difference concerns, again, work-related activity requirements. Means-tested family benefits are frequently designed as temporary payments that enable one of the parents to spend time with their children. Apart from time limits (which can be generous and are often implicit, e.g. by specifying a maximum age for a dependent child: see Immervoll, 2012a), work-related behavioural requirements may therefore be minimal or non-existent.

- Targeted income support is increasingly made available to those in work and can, to some extent, substitute for income top-ups provided by SA and other minimum-income benefits. Around half the OECD countries now operate employment-conditional benefits, or in-work benefits of one type or another (a few countries not shown in the table have introduced such programmes since 2007). Like minimum-income benefits, some of these in-work programmes employ a familyor status protection in the form of "suitable-job" criteria. Formally, they would therefore have to accept any available job although the extent to which this is enforced in practice is difficult to establish.

In addition, several countries operate further parental-leave benefits that are not means-tested or are insurance-based (the OECD Family Database gives details: www.oecd.org/els/social/family/database). 
based low-income criterion. But since they are conditional on work, they are not payable to those without any other incomes and therefore are not benefits of last resort. ${ }^{8}$

Table 3. Typology of minimum-income benefits by rank and scope

Main out-of-work safety-net benefits for able-bodied working-age individuals and their families, 2007

Rank

\begin{tabular}{|c|c|c|c|}
\hline \multirow{2}{*}{ Scope } & Broad & $\begin{array}{ll}\text { - } & \text { NZL Unemployment Benefit } \\
\text { - } & \text { AUS Newstart Allowance }\end{array}$ & $\begin{array}{l}\text { 'Non-categorical' SA: } \\
\text { AUS, AUT, BEL, BUL, CAN, CHE, CYP }{ }^{1)} \text { 2), CZE, } \\
\text { DNK, DEU, ESP, EST, FIN, FRA, HUN, IRL, ISL, } \\
\text { ISR, JPN, KOR, LIT, LUX, LVA, MLT, NLD, NOR, } \\
\text { NZL, POL, PRT, ROU, SVK, SVN, SWE, USA } \\
\text { SNAP } \\
\text { Unemployment assistance: } \\
\text { DEU, FIN, IRL, MLT, UK }\end{array}$ \\
\hline & Targeted & $\begin{array}{ll}\text { - } & \text { AUS Parenting Payment } \\
\text { - } & \text { AUS Youth Allowance } \\
\text { - } & \text { IRL One-parent Family Payment } \\
& \text { NZL Domestic Purposes Benefit }\end{array}$ & $\begin{array}{ll}\text { - } & \text { FRA Allocation de Parent Isolé* } \\
\text { - } & \text { FRA Asylum Seeker Waiting Benefit } \\
\text { - } & \text { NOR Transitional Benefit } \\
\text { - } & \text { UK Income Support } \\
\text { - } & \text { USA TANF }\end{array}$ \\
\hline
\end{tabular}

Notes: 'SA': Social Assistance. SNAP: Supplemental Nutrition Assistance Program (formerly Food Stamps), TANF: Temporary Assistance for Needy Families. Incapacity benefits are not shown. The US Supplemental Security Income and the Irish Disability Allowance are lower-tier minimum-income benefits with non-means-tested insurance-based programmes acting as first-tier benefits in both cases. The New Zealand Invalid's Benefit and the Australian Disability Support Pension are examples of means-tested first-tier incapacity-related benefits.

1) Note by Turkey:

The information in this document with reference to "Cyprus" relates to the southern part of the Island. There is no single authority representing both Turkish and Greek Cypriot people on the Island. Turkey recognizes the Turkish Republic of Northern Cyprus (TRNC). Until a lasting and equitable solution is found within the context of the United Nations, Turkey shall preserve its position concerning the "Cyprus issue".

2) Note by all the European Union Member States of the OECD and the European Union:

The Republic of Cyprus is recognized by all members of the United Nations with the exception of Turkey. The information in this document relates to the area under the effective control of the Government of the Republic of Cyprus.

* As of mid-2009, the new French 'non-categorical' SA (Revenue de Solidarité Active, RSA) has been available to all low-income families, including lone parents. The Allocation de Parent Isolé (API) was abolished.

It is clear from this brief overview that SA can be provided under a range of different policy headings. What all programmes have in common is that they are typically received by those with no or very limited other resources of their own, and can provide a fall-back safety-net for low-income families who are not entitled to other income replacement transfers. Table 3 situates countries' programmes along two dimensions:

8. For a summary of countries' experience with these and related "make-work-pay" programmes, see Immervoll and Pearson (2009). In some cases, in-work benefits take the form of temporary payments that are designed to increase the payoff from moving into a new job. A larger group of countries operate programmes that make recurring payments (or tax refunds) to a defined group of low-income workers for as long as other eligibility conditions are met. In order to target in-work payments to relevant groups, eligibility and benefit amounts can depend on a range of characteristics and circumstances. These include having children, working a minimum number of hours, and receiving income from work or entering/changing employment. All employment-conditional measures use at least one of these conditions or they feature gradual phase-ins or phase-outs as a means of targeting individuals at specific earnings levels or working hours. 
Rank: Main income support programme for working-age people or lower-tier benefit.

Scope: Broad safety net or programme targeted at specific groups (notably lone parents).

In most countries, SA takes the form of lower-tier fall-back benefits for those without support from other programmes. Lower-tier programmes with a broad scope are shown in the upper right-hand corner in Table 3. The biggest group in this category are non-categorical SA providing cash and near-cash support (US Food Stamps, since 2008 Supplemental Nutrition Assistance Program, SNAP, are a near-cash benefit). In addition, unemployment assistance benefits in Finland, Germany, Ireland and the UK are available independently of contribution records or previous employment history and, as such, can be counted as broadscope lower-tier benefits. ${ }^{9}$ There are further last-resort benefits targeted at lone parents in France, the UK and the US (lower right-hand corner; although the benefit for Norwegian lone parents of young children is formally an insurance benefit, it is also included here as eligibility is subject to an income test and does not require an employment record).

In a few cases, SA is the main income support programme for the majority of the working-age population (upper left-hand corner of Table 3) or for individual groups (younger individuals in Australia and lone parents in Australia, Ireland and New Zealand ${ }^{10}$ ). In addition to these first-tier programmes, Australia and New Zealand also operate lower-tier emergency benefits, but these are much less common.

\section{Number of benefit recipients}

A new OECD/EU source of administrative data on benefit recipients data shows that, prior to the economic crisis, the shares of working-age individuals receiving non-categorical SA at a given point in time were modest, mostly between 2 to 4 percent but below 2 percent in a few countries.

However, adding other types of minimum-income support results in much higher recipient numbers in some countries. In Australia, Finland, Germany, Ireland and New Zealand, where unemployment assistance is not conditional on prior employment or contribution histories, this type of safety-net benefit represents large or very large proportions of overall SA receipt. Specific safety-net benefits for lone parents are especially sizeable in the Anglo-Saxon countries.

For a number of reasons, SA policies affect a considerably greater number of people higher than Figure 1 would indicate. The recipient statistics in Figure 1 are based on payments and therefore count only one adult per family as a recipient. However, the share of people benefiting from SA is likely to exceed the share of recipients among the working-age population. In addition, over longer periods of time, the proportion of individuals who experience at least one spell during which family incomes fall below minimumincome thresholds will be higher still (see Section 2.2). Finally, non-take-up rates are commonly found to be particularly high for means-tested benefits. Behavioural requirements and other barriers (such as the perceived burden of filing an application) exclude some of those who would otherwise be entitled. Studies on benefit take-up regularly find non-take-up rates in the order of $40 \%$ or more, indicating a significant combined deterrent effect of the various barriers. (Hernanz et al., 2004; Bargain et al., 2012).

\footnotetext{
9. In Ireland, unemployment assistance (Jobseekers' Allowance) is much more important than the general social assistance benefit (Supplementary Allowance).

10. The Domestic Purposes Benefit in New Zealand also provides support for some other groups, such as those caring for family members at home.
} 
Figure 1. Number of social assistance recipients, 2007

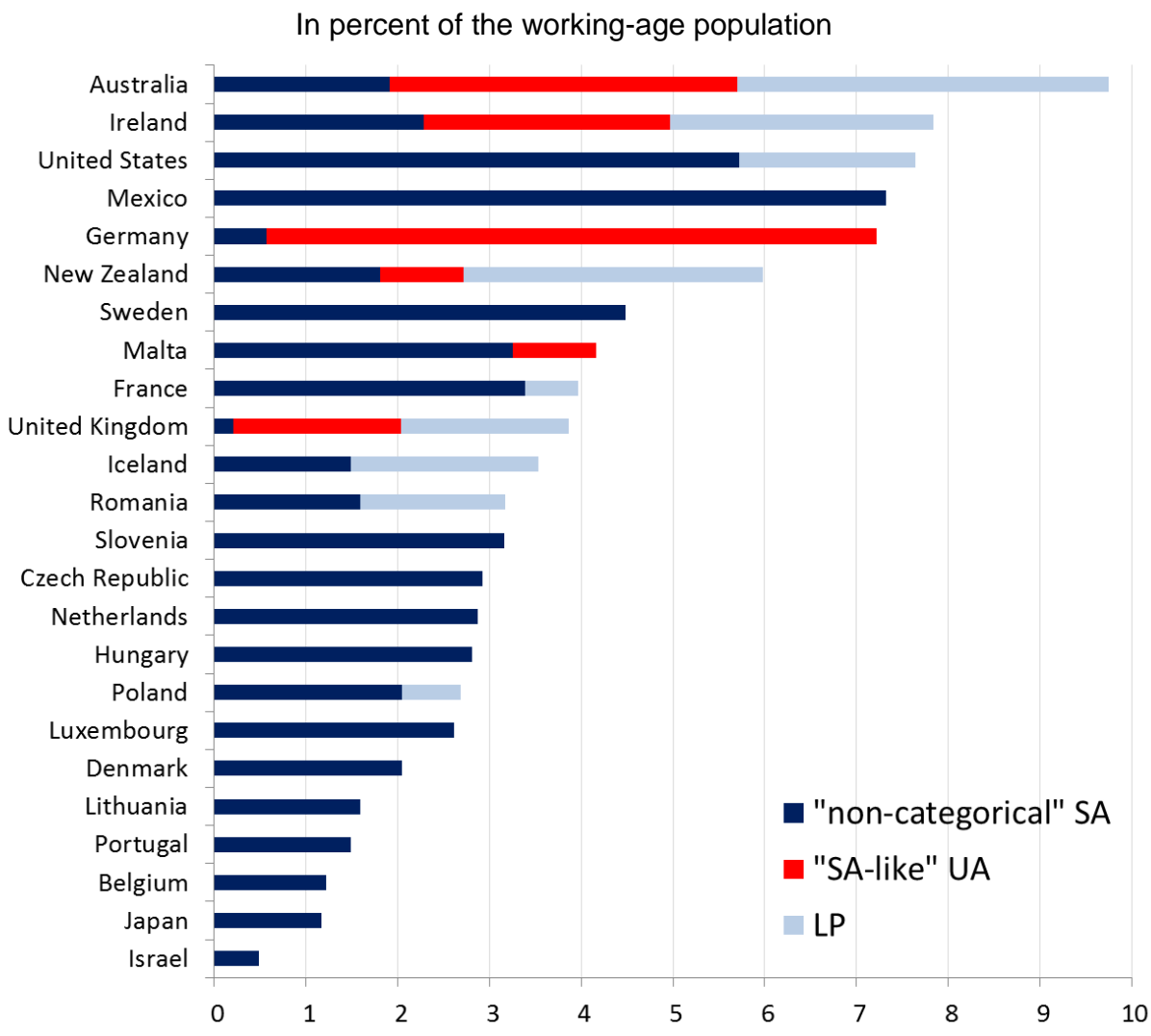

Notes: See Annex 1.B for a full list of programmes by country. Data refer to caseloads, i.e. the number of payments in a specific payment period, or averaged over the year. The working-age population is defined as the number of individuals aged $15-64$ years. 'SA': Social Assistance, 'SA-like UA': Unemployment Assistance that is not subject to previous employment or contribution history; 'LP': Means-tested income-replacement safety-net benefit for lone parents. Data are for income replacement benefits and are based on administrative sources. Means-tested supplements such as housing benefits, family benefits or in-work benefits are not included. Data for the following countries are not available or not comparable: Austria, Canada, Estonia, Finland, Korea, Latvia, Norway, Slovak Republic, Switzerland (national sources report total number of benefit spells of any duration during a given year); Korea and Slovak Republic (national sources do not report numbers of recipient households, but the number of people living in them); Spain (nationally consolidated data on non-categorical SA not available).

The numbers do not correct for any double counting that may result from households receiving different types of benefit concurrently. However, typically, a household cannot receive the different benefits at the same time (i.e., families receive either lone parent or noncategorical SA).

* United Kingdom: Unemployment insurance and assistance benefits are reported as one aggregate since separate recipient numbers are not available from original national sources.

Sources: OECD (2014), Social Benefit Recipient Database (SOCR), forthcoming.

Since SA benefits are meant to alleviate poverty but are often not taken up, it is useful to take a closer look at the fraction of poor people that these benefits reach. To illustrate orders of magnitude, Figure 2 combines administrative data on benefit recipients with survey-based totals of the number of income-poor households. The resulting proportions are 'pseudo coverage rates', in the sense that they express the relative sizes of two groups that overlap only partially (some non-poor households may receive SA benefits). Despite the potential 'leakage' of SA benefits to non-poor higher-income households, the number of recipient households is very much lower than the number of income-poor households - this is true in all countries except Australia. 
In part, this can be explained by benefit levels/ceilings being significantly lower than the chosen poverty cut-off (see Figure 3): where benefit phase-outs are relatively steep, a low benefit ceiling indicates that those with incomes closer to the poverty line are not entitled to SA benefits. But pseudo coverage rates are also very low in some of the countries where benefit levels are higher (e.g. Belgium, Denmark). In these countries, low benefit take-up and/or further eligibility conditions, such as those related to strictly enforced activation measures result in low benefit coverage among the poor. Australia is the only country where the number of SA benefit recipients is approximately the same as the number of income-poor households. Here, SA benefit amounts can be relatively close to the poverty cut-off, at least for families with children. In combination with relatively flat benefit phase-out rates, this implies that families with income around the poverty line can still be entitled to SA support.

Figure 2. Pseudo coverage rates for poor households, 2007

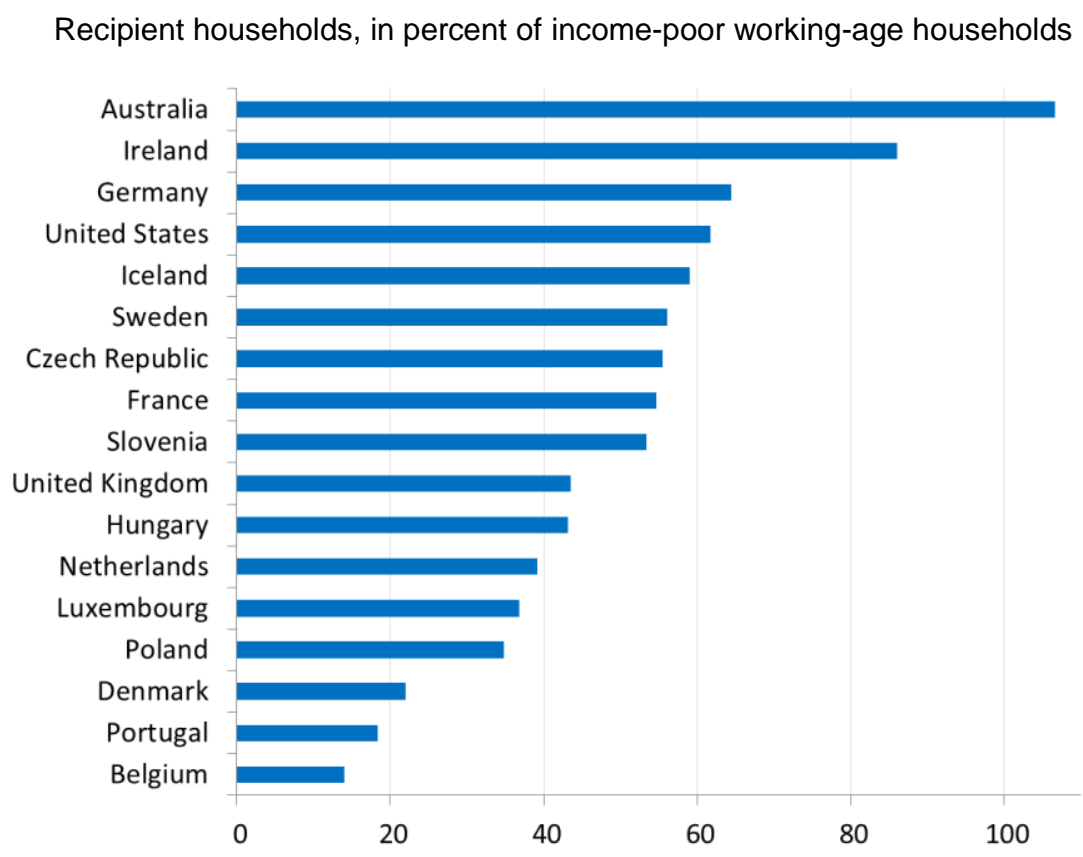

Notes: Based on a poverty threshold of $50 \%$ of median equivalised household income, using the 'square-root of household size' as an equivalence scale. "Working-age households" are those including at least one individual aged 15-64.

Sources: Number of benefit recipients: Figure 1; Number of income-poor households: own calculations based on EU Survey of Income and Living Conditions, Household Income and Labour Dynamics (Australia), Statistics Canada Survey of Labour and Income Dynamics (Canada), Current Population Survey (March supplement, United States).

\section{Social assistance benefit levels}

\section{SA benefit levels in relation to median incomes and relative poverty thresholds}

In view of poverty alleviation objectives associated with SA programmes, a useful starting point for comparing benefit levels across countries is to relate them to commonly used poverty thresholds. Benefit amounts in relation to the income distribution also give a sense of the potential 'reach' of SA as a support programme for lower-income groups: Where SA entitlements are reduced by incomes from other sources, maximum benefit levels in conjunction with benefit withdrawal rates are indicative of the income levels that still qualifies for benefit support (see also footnote 10). 
Figure 3 presents model calculations using the OECD tax-benefit calculator and compares the resulting net income levels to median incomes from income distribution data. In a large majority of OECD countries for which such calculations are available, benefits of last resort are be significantly lower than the three alternative relative poverty lines shown in the figure (40\%, 50\% and $60 \%$ of median income). For the family types shown, the distance to the poverty threshold (the family's poverty gap) is very large in some countries (notably in Greece, Italy and Turkey, where there was no generally/nationally applicable SA benefit). Everywhere, other income sources are needed to avoid substantial poverty risks. ${ }^{11}$

In some countries, however, the possible range of benefit entitlements can be very wide. This is illustrated by the two different benefit levels in Figure 3, which show the difference in benefit entitlements between a situation where the recipient claims no housing costs and one where she lives in privately rented accommodation and obtains partial or full compensation for housing expenditures. HB calculations in this latter case are based on a simple 'high', but not unreasonably high, rent assumption across countries (20\% of the average gross wage of a full-time worker). ${ }^{12}$ For many benefit recipients, payment levels will be somewhere in-between the 'with housing costs' and 'without housing costs' scenarios. In about half of the countries, benefit rates show in fact little or no variation with housing costs as housing support is not available at all, is modest (for instance, there is no separate mechanism to provide cash housing support in the US Food Stamp / SNAP program but housing costs slightly reduce reckonable income in some states) or is provided on a flat-rate basis (for instance, SA entitlements may be designed in a way to cover 'reasonable' housing costs).

Figure 3. Income levels provided by cash minimum-income benefits, 2007

(a) Single, no children, in \% of median household incomes

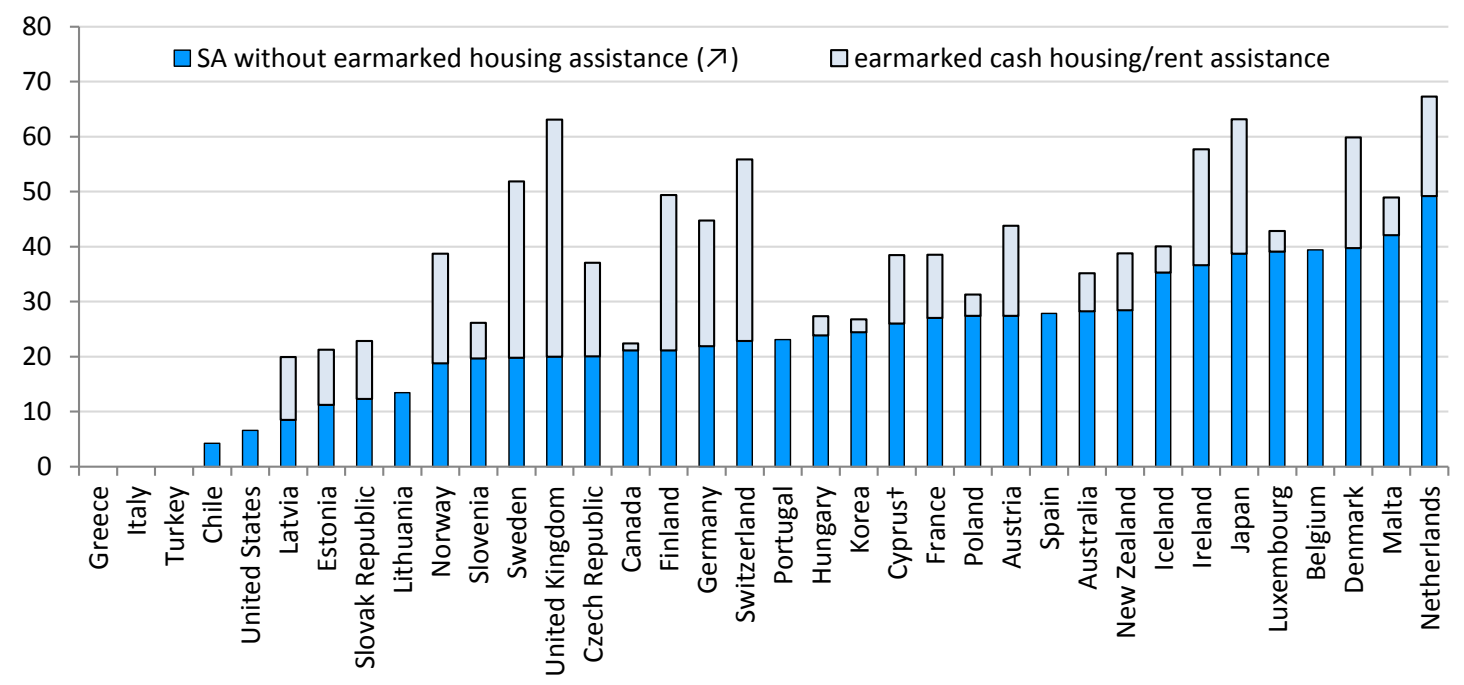

11. The distributional impact of SA is however not limited to recipient families with incomes below the levels indicated in Figure 2. Because concerns about the efficiency costs of work disincentives lead many countries to employ gradual benefit phase-outs, those with non-benefit incomes above the maximum benefit amounts can often still receive income top-ups. Table 9 in Immervoll (2012a) illustrates this by showing the approximate earnings levels, as well as the associated net incomes, where minimum-income benefits are fully phased out.

12. The assumption of $20 \%$ of AW has been motivated by an attempt to capture differences between countries that operate explicit "reasonable rent" ceilings and those that do not (or where there is a large discretionary element involved in making such decisions). In order to show this, it is necessary to choose a rent level that is sufficiently high so that relevant limits become applicable. 
Figure 3 (continued)

(b) Lone parent with two children

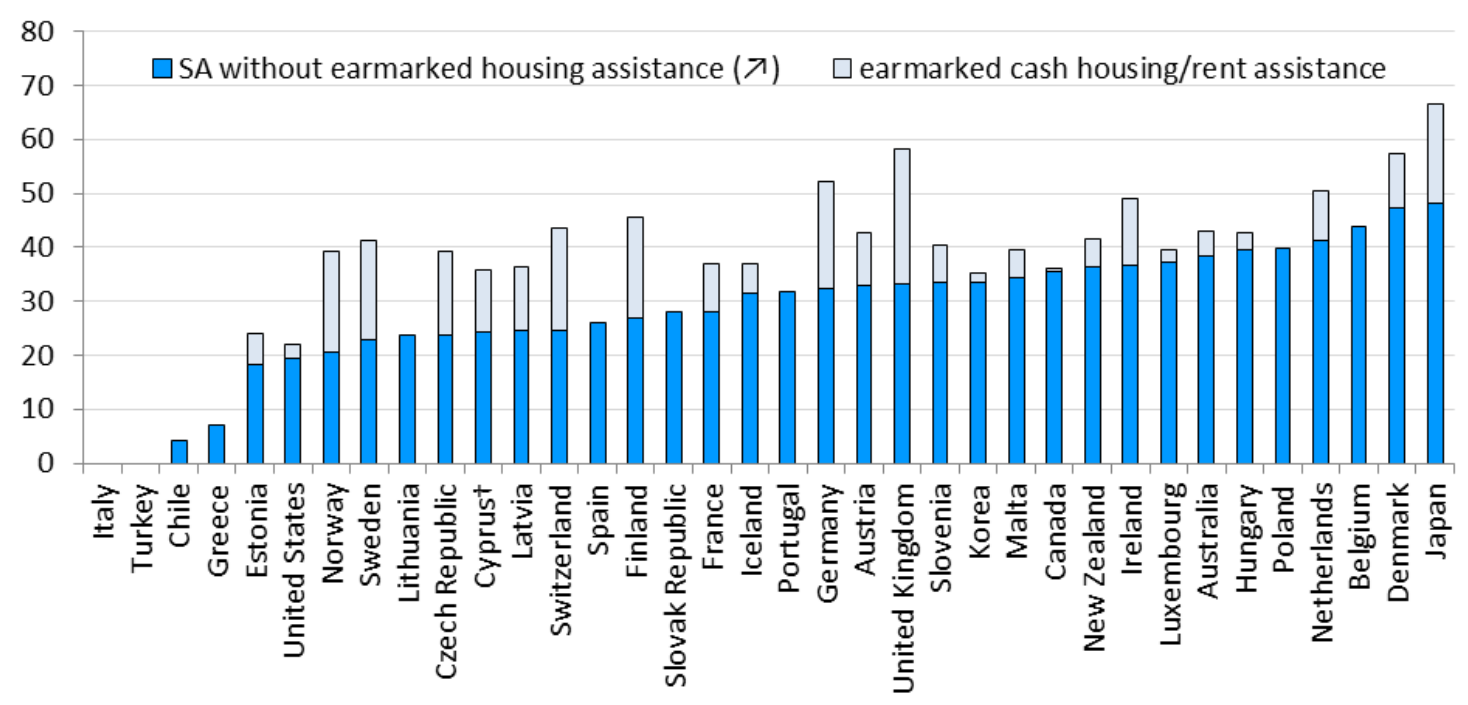

(c) Married couple with two children

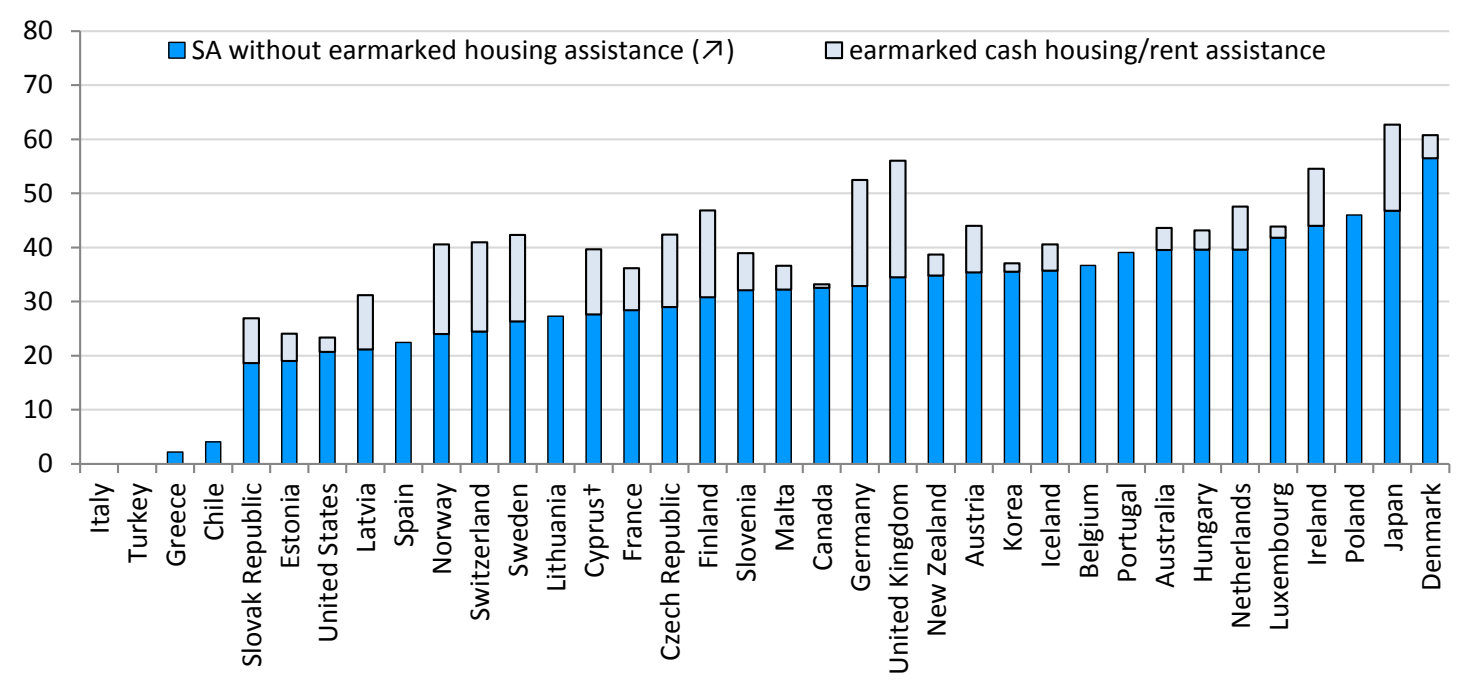

Notes: Median net household incomes are before housing costs (or other forms of 'committed' expenditure). Results are shown on an equivalised basis (equivalence scale is the square root of the household size) and account for all relevant cash benefits (SA, family benefits, housing-related cash support as indicated). US results also include the value of Food Stamps, a near-cash benefit. Income levels account for all cash benefit entitlements of a family with a working-age head, no other income sources and no entitlements to other out-of-work benefits such as unemployment insurance. They are net of any income taxes and social contributions. Where benefit rules are not determined on a national level but vary by region or municipality, results refer to a 'typical' case (e.g. Michigan in the United States, the capital in some other countries). Calculations for families with children assume two children aged 4 and 6 . 'Earmarked cash housing/rent assistance' refers to cash benefits that depend on housing expenditures and are shown for someone in privately rented accommodation with rent plus other charges amounting to $20 \%$ of average gross full-time wages.

${ }^{\dagger}$ Note by Turkey:

The information in this document with reference to "Cyprus" relates to the southern part of the Island. There is no single authority representing both Turkish and Greek Cypriot people on the Island. Turkey recognizes the Turkish Republic of Northern Cyprus (TRNC). Until a lasting and equitable solution is found within the context of the United Nations, Turkey shall preserve its position concerning the "Cyprus issue".

Note by all the European Union Member States of the OECD and the European Union:

The Republic of Cyprus is recognized by all members of the United Nations with the exception of Turkey. The information in this document relates to the area under the effective control of the Government of the Republic of Cyprus.

Sources: OECD tax-benefit models (www.oecd.org/els/social/workincentives) for benefit levels; OECD income distribution database for median household income. 


\section{SA benefit levels relative to in-work incomes}

Out-of-work benefits are a key determinant of whether work 'pays', especially for those with limited earnings potential. Since minimum-income recipients without any earned income mostly have net incomes below commonly-used poverty thresholds, a relevant question is how much someone would need to earn in order to escape income poverty. This amount will depend on two factors. First, higher earnings are required in countries with sizable individual 'poverty gaps' (the amount by which net income falls short of the chosen poverty line). Second, the earnings necessary to reach the poverty line is determined by the part of in-work earnings that effectively adds to household net income and, thus, by the marginal effective tax rate (the part of additional earnings that is 'taxed away' by higher tax burdens or reduced benefit amounts).

One way of showing the situation of low-wage earners is by reference to minimum wages. In around twothirds of OECD countries, wages are subject to statutory minima. Comparisons based on gross minimum wage levels are missing differences in taxes and benefits and can therefore give only a partial indication about the true value of wage floors. Figure 4 shows incomes of full-time employees earning the statutory minimum wage after taxes and benefits and relates these to median household disposable income. ${ }^{13}$ In most countries, a full-time minimum-wage earner in a single-person household makes enough to put her above $50 \%$ of median household income and, with the exception of the United States, full-time minimum-wage earnings are everywhere sufficient to ensure incomes above the $40 \%$ threshold (net incomes can be higher in the considerable number of states with statutory minima exceeding the US federal minimum wage).

Figure 4. Income levels of minimum-wage works and minimum-income benefit recipients, 2007

(a) Single, no children, in \% of median household incomes

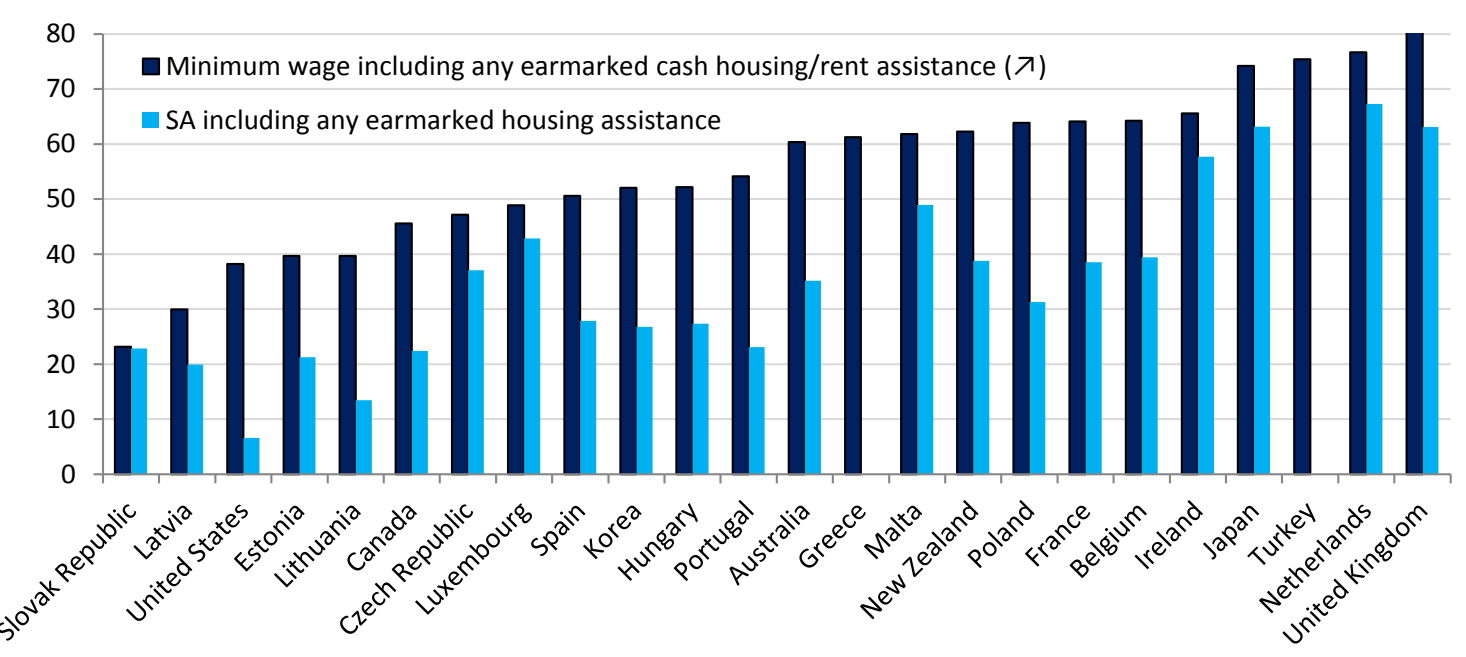


Figure 4 (continued)

(b) Lone parent with two children

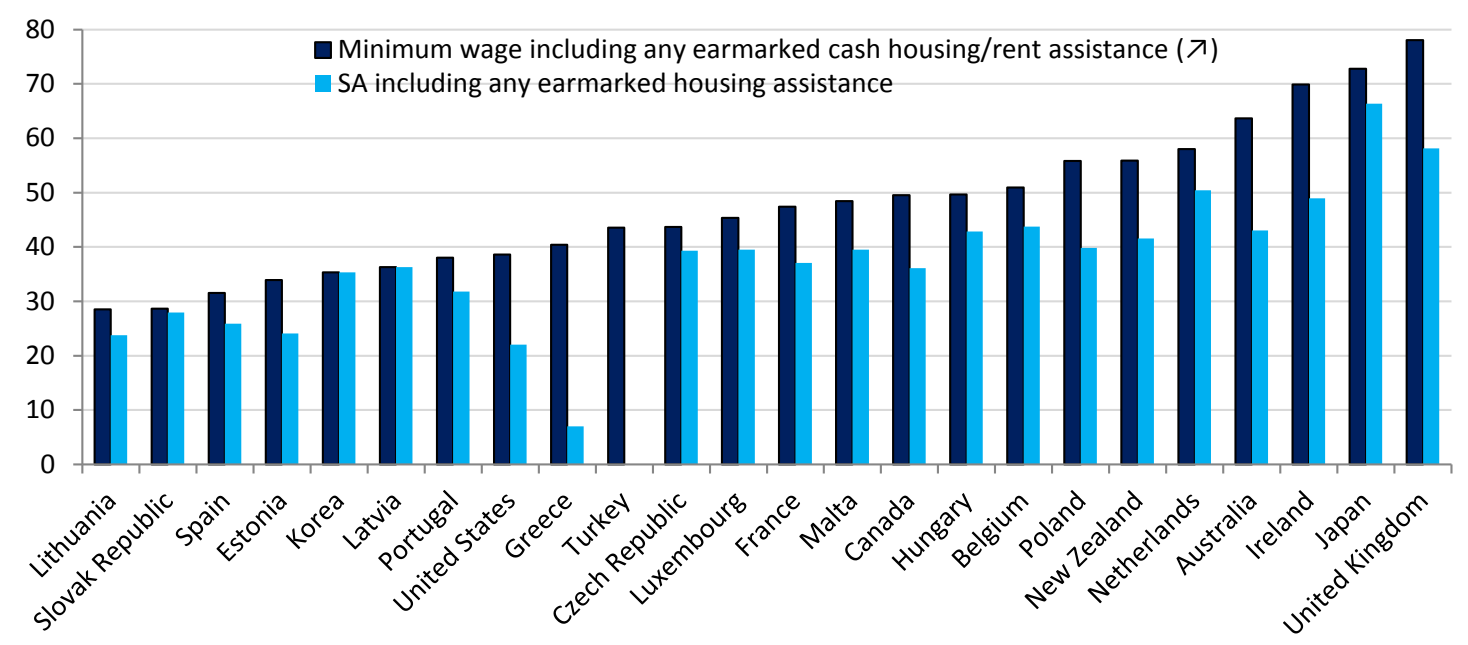

(c) Married couple with two children

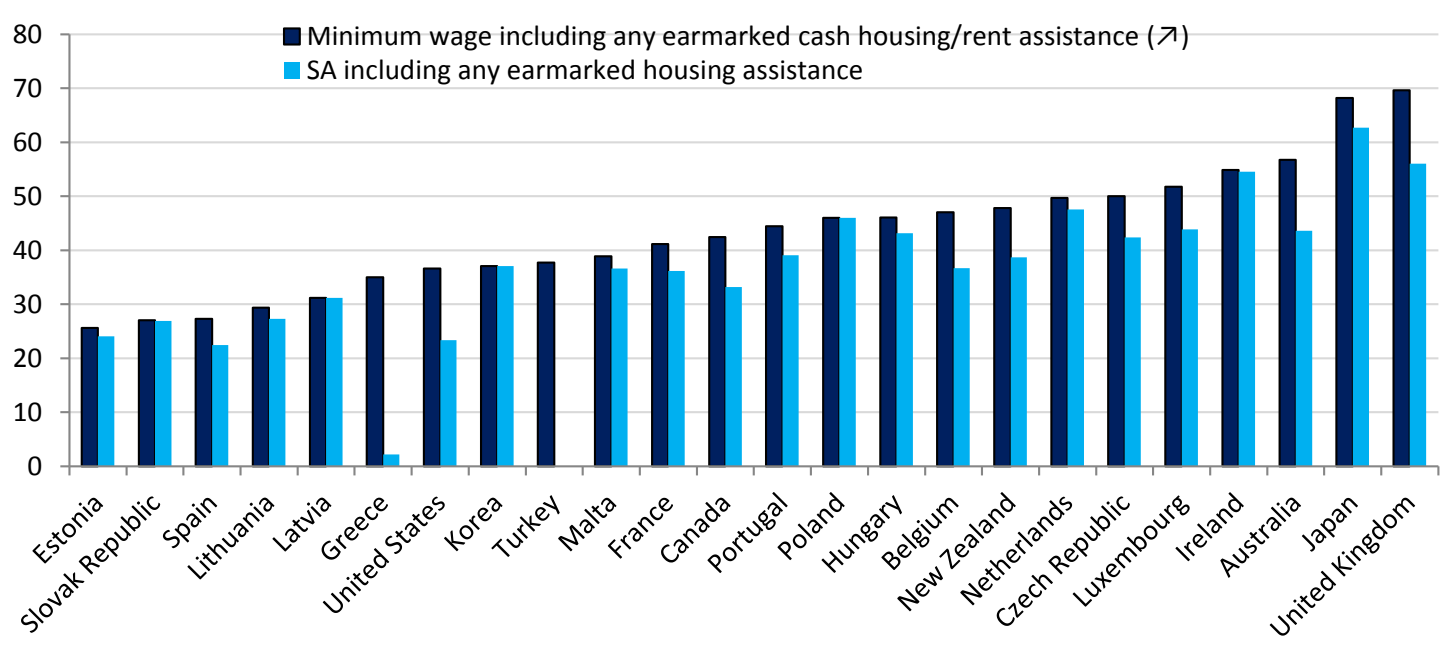

Note: See explanatory notes to Figure 3. Hourly minimum wages are converted to monthly earnings based on 40 working hours per week. Where minimum wages depend on age, profession or sector, figures relate to the adult rate for white-collar workers in the private sector (Belgium, Greece, Portugal). The federal minimum is used for the US. Where there is no country-wide minimum, weighted averages of regional minimum wages are used (Japan). Incomes in the married-couple case relate to a one-earner couple.

Sources: OECD tax-benefit models (www.oecd.org/els/social/workincentives), OECD income distribution database and OECD minimum wage database.

For families, one minimum-wage job is typically not enough to escape relative poverty at the $50 \%$ threshold. However, in-work benefits and/or gradual benefit phase-out rates for families with children, such as in Australia, Ireland and the UK, can provide a significant income boost. Lone-parent full-time minimumwage workers in these countries take home net income at or above $60 \%$ of median incomes. The net in- 
come gain when moving from minimum-income benefits into a full-time minimum-wage job typically exceeds $20 \%$. But in a number of cases, the income gain is in fact quite limited, even if minimum wages are high relative to average wage levels (e.g. Luxembourg and Netherlands, as well as Belgium, France and Hungary in the case of families with children).

\section{SA benefit levels relative to unemployment benefits}

Minimum-income benefits form an integral part of the redistribution system. In setting benefit amounts, policymakers need to consider not only poverty thresholds and the income position of low-wage workers, but also the levels of other, higher-tier benefit payments.

Table 4 shows income levels of SA recipients relative to those provided by unemployment benefits. Where unemployment benefit levels depend on the duration of unemployment, separate lines are shown for each category. Ratios between minimum-income and unemployment benefits can be quite high for longer-term unemployed, notably in countries operating both unemployment insurance and assistance benefits (see Table 2). Likewise, for those with below-average previous earnings, some earnings-related unemployment insurance benefits can be quite close to, or even below, the level of SA or other minimum-income benefits (e.g., one-earner couples in a number of continental and all northern European countries). In these cases, a family may not lose much when unemployment benefit entitlements run out and they start receiving SA instead. In most cases, however, initial unemployment benefits provide incomes that are significantly above minimum-income levels. The gap between the two is greatest in Hungary and Poland, Japan and Korea, Portugal and Spain, as well as Canada and the United States - especially for unemployed individuals living alone.

In countries where minimum-income benefits are at the same time the main out-of-work benefit, the ratios are 100\% (Australia, New Zealand). The same is true for Ireland and the UK, where eligible jobseekers are entitled to a flat-rate insurance benefit during an initial period of unemployment and the follow-up assistance benefit is paid at the same level as long as the family has no other incomes.

A ratio of minimum-income to unemployment benefit levels above $100 \%$ provides an indication of the potential importance of minimum-income payments as top-up benefits for those with low unemployment benefit entitlements.14 This can provide useful contextual information for understanding the characteristics of benefit recipients. For instance, for most family types, the net incomes provided by the Finnish Basic Allowance and Labour Market Support benefits (paid to jobseekers who are not - or no longer - entitled to earnings-related unemployment insurance payments) tend to be below SA levels. As a result, about $40 \%$ of SA recipients are receiving these unemployment assistance benefits at the same time (STAKES, 2008).

14. In combination with the income levels of minimum-income recipients relative to the poverty line in Figure 2, it also indicates the extent to which unemployment benefit claimants are likely to be affected by income poverty. 
Table 4. Minimum-income benefit levels relative to unemployment benefits ${ }^{(1)}$

By previous earnings and unemployment duration, in percent, 2007

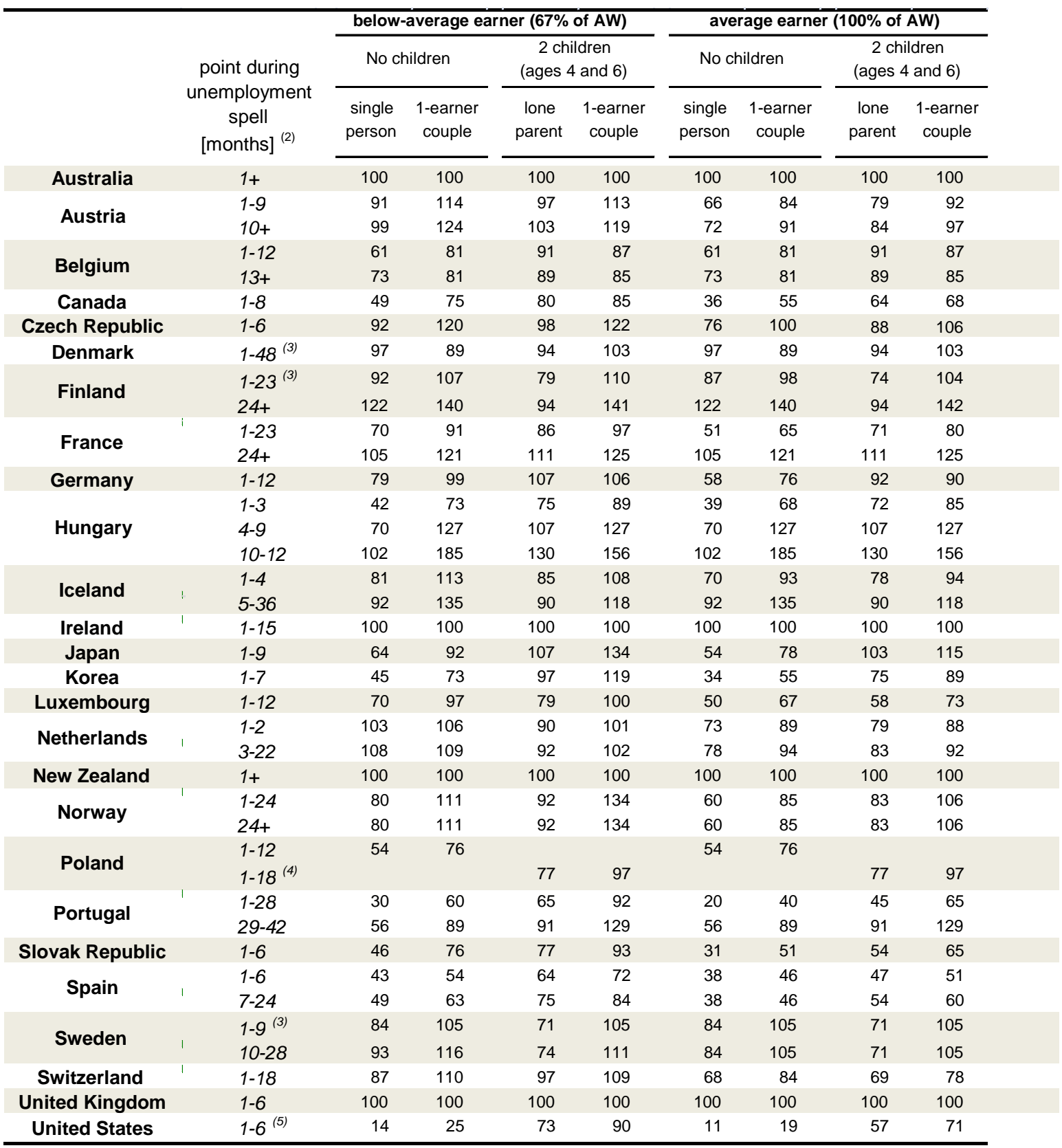

Notes: (1) Housing-related support is included in the net incomes of both the unemployment and minimum-income recipients (using housing-cost assumptions as explained in the notes to Figure 3). Greece, Italy, Mexico and Turkey are not shown as they do not operate broad minimum-income cash-benefit programmes (nor, in the case of Mexico, a generally available unemployment benefit system). (2) The period indicates the maximum duration of unemployment benefits for a 40-year old worker with a 'long' employment and contribution record. Separate periods are shown for each successive benefit programme (e.g. insurance and assistance benefits) or if benefit levels in a given programme decline during the entitlement period. (3) Membership in the unemployment insurance fund is voluntary. (4) Unemployment benefit durations are longer for families with children. (5) Unemployment benefit durations are longer in states where the unemployment rate exceeds a specified level.

AW denotes the average wage of a full-time worker in industry sectors C-K (ISIC Revision 3.1).

Source: OECD tax-benefit models (www.oecd.org/els/social/workincentives). 
Detailed information on the dynamics of SA benefit receipt is crucial for the design of effective social safety nets. Recipient numbers provide insights on the coverage of last-resort benefits and their role in reducing poverty or as automatic stabilizers in times of economic crisis. Benefit transition rates indicate whether variations in receipt rates over time are driven primarily by changes in inflows or outflows, and thus possibly whether policies to reduce benefit receipt work better when they focus on reducing entries or promoting exits. Other central policy parameters, such as benefit levels and the design of activation measures, should depend on who receives benefits and for how long.

This section - as the remainder of the document - focuses on the dynamics of SA benefit receipt taking a longitudinal perspective. It complements the analysis of contemporary SA systems in OECD countries, which took a cross-sectional perspective and looked at a snapshot of countries' benefit systems at given points in time. The section provides an analysis of aggregate trends of benefit receipt rates and transition rates into and out of benefit receipt. It also provides an overview of the most important recipient groups, to the extent that this is possible given data limitations.

When studying the dynamics of benefit receipt, data requirements are much greater than for a crosssectional analysis. First, information needs to be at the micro level to allow identification of benefit receipt for specific individuals or households. Second, data need to have a panel dimension that permits following individuals' paths onto and off benefits over time. Micro-level panel data of this type can be taken from national household panel surveys, yet the information on benefit receipt in these surveys is typically available only at the annual level. ${ }^{15}$ An alternative source of data are administrative records, which however are rarely directly accessible for research purposes. To present results for the largest possible number of countries, the analysis presented in this section is based primarily on annual data. Section 3 then provides results on the micro-dynamics of SA benefit receipt at the monthly level for a smaller selection of countries where such data are available.

Even when working with annual data, the number of countries for which suitable data are available is relatively small. As outlined in Table 5, this section reports results for eight countries, six of which are EU member countries. For Canada, Latvia, Luxemburg, the Netherlands, Norway, and Sweden, the original data come from administrative records. For Germany and the United Kingdom, data from large household surveys are used. For countries where only monthly data are available, annualized versions of these data are used in those parts of the analysis that are based on annual data. Observation periods vary by country and mostly extend from the early- or mid-1990s to the late 2000s, in some cases covering part of the crisis years. An exception is Latvia, for which the original data are more recent but cover a much shorter observation period.

The analysis below focuses on the programmes listed under 'principal social assistance variable' for ablebodied, working-age individuals. In Germany and the United Kingdom, this includes programmes that are formally labelled as unemployment benefits but, following the typology in Section 1, share key characteristics of SA programmes. For Germany, Latvia, the Netherlands, Norway, and the United Kingdom, results are also provided for HB. Since receipt of both benefit types is conditional on passing a means test at the family level, individuals are categorised as SA recipients if benefit payments are recorded for any household member in that period. In this sense, the approach differs from the one used in Figure 1, where only the number of claimants is presented. Section 4 discusses the advantages and limitations of this approach.

15. An additional complication is that large sample sizes are required for studying SA benefit transitions because only a small share of the population enters or leaves benefits in any given period. Typically, crossnational household surveys, such as EU-SILC, are therefore not suitable for such an analysis. 
Table 5. Data sources used in the empirical analysis

\begin{tabular}{|c|c|c|c|c|c|}
\hline Country & $\begin{array}{l}\text { Observation } \\
\text { period }\end{array}$ & Data type & Sources of data or results & Principal social assistance variable & $\begin{array}{l}\text { Housing } \\
\text { benefits }\end{array}$ \\
\hline \multicolumn{6}{|l|}{ Annual data: } \\
\hline Canada & $1993-2010$ & administrative & $\begin{array}{l}1 \% \text { sample from the Longitudinal Administrative Data- } \\
\text { base (LAD) that covers } 20 \% \text { of Canadian tax records }\end{array}$ & Social Assistance & no \\
\hline Germany & $1995-2011$ & survey & German Socio-Economic Panel (SOEP) & $\begin{array}{l}\text { Social Assistance, Unemployment } \\
\text { Assistance (1995 - 2004) \& Unem- } \\
\text { ployment Benefit II (2005 - 2011) }\end{array}$ & yes \\
\hline Netherlands & $1995-2009$ & administrative & $\begin{array}{l}\text { Income Panel Study (IPO), which provides information } \\
\text { on a } 0.6 \% \text { sample from the Dutch resident population }\end{array}$ & Social Assistance (bijstand) & yes \\
\hline Sweden & $1990-2009$ & administrative & $\begin{array}{l}\text { Data provided by the National Board of Health and } \\
\text { Welfare that cover the entire recipient population }\end{array}$ & Social Welfare Allowance & no \\
\hline $\begin{array}{l}\text { United } \\
\text { Kingdom }\end{array}$ & $1991-2008$ & survey & British Household Panel Survey (BHPS) & $\begin{array}{l}\text { Income Support, Unemployment Ben- } \\
\text { efits (1991 - 1995) \& Jobseeker's } \\
\text { Allowance }(1996-2008)\end{array}$ & yes \\
\hline \multicolumn{6}{|l|}{ Monthly data: } \\
\hline Latvia (Riga) & $2006-2011$ & administrative & $\begin{array}{l}\text { Results from a World Bank report on social assis- } \\
\text { tance receipt (World Bank, 2013) based on records } \\
\text { for social assistance benefit recipients across Latvia. } \\
\text { Only results for the city of Riga are reported. }\end{array}$ & Guaranteed Minimum Income (GMI) & yes \\
\hline Luxembourg & $1988-2010$ & administrative & $\begin{array}{l}\text { Records from the Fonds National de Solidarité (FNS) } \\
\text { that cover the entire recipient population }\end{array}$ & Guaranteed Minimum Income (RMG) & no \\
\hline Netherlands & $1999-2010$ & administrative & $\begin{array}{c}\text { Sociaal Statistisch Bestand (SSB), which covers the } \\
\text { entire recipient population }\end{array}$ & Social Assistance (bijstand) & yes \\
\hline Norway & $1993-2008$ & administrative & $\begin{array}{l}10 \% \text { sample from the FD-Trygd database that covers } \\
\text { the entire population }\end{array}$ & Social Economic Assistance & yes \\
\hline Sweden & $2001-2009$ & administrative & $\begin{array}{l}\text { Data provided by the National Board of Health and } \\
\text { Welfare that cover the entire recipient population }\end{array}$ & Social Welfare Allowance & no \\
\hline
\end{tabular}

Note: For Latvia, Luxembourg, and Norway, part of the analysis is based on annualized data constructed from monthly data sets to provide results that are comparable across countries. For Norway, results are based on a 10\% sample from the population. For Sweden, the NBHW data set provides monthly data only from 2001 (and annual data before). For the Netherlands, the analysis is based on two datasets: annual data come from the IPO; monthly data come from the SSB from which a $0.5 \%$ random sample is drawn. For the United Kingdom, the data on benefit receipt do not permit a distinction between income-based and means-tested Jobseeker's Allowance (JSA), which is why both types are included in the analysis. Cappellari \& Jenkins (2008a, p. 14) however report that the large majority of recipients were paid income-based JSA. 
The chosen sample includes individuals of working age (25-59 years). ${ }^{16}$ This is usual practice in work on SA benefit dynamics and ensures that the presented transition rates are not affected too heavily by individuals who enter the labour market or retire. It implies of course that in cases where absolute recipient numbers are presented, these are lower than the corresponding numbers for the entire population.

An individual's health status is not considered for sample selection, also because, in most cases, it cannot be observed in the data. Individuals with health issues thus remain in the sample and will be included among recipients in countries where SA benefits can be paid to those temporarily or permanently unfit for work.

The analysis draws on results provided in earlier country studies on SA benefit receipt initiated as part of this project. They include Britain (Cappellari \& Jenkins, 2008a, 2014), Norway (Bhuller \& Königs, 2011, Bhuller, Brinch \& Königs, 2014), Luxembourg (Königs, 2012), Germany (Königs, 2013a, 2014a), the Netherlands (Königs, 2013b), and Canada (Finnie \& Pavlic, 2013). For Latvia, results are taken from material prepared by the World Bank (World Bank, 2013).

\section{Composition of the recipient population}

As last-resort safety nets, SA benefits tend to support a highly heterogeneous population. Important recipient groups are usually young adults with little work experience, those with low education, single parents with young children, immigrants, individuals with health problems, and other groups with limited incomes and no or little support through other benefit programmes. To the extent that these groups find it more difficult to become self-sufficient than less disadvantaged individuals, the composition of the recipient population will be reflected in the dynamics of SA benefit receipt, e.g. through long benefit durations. While the two survey-based data sets provide detailed information on individual and household characteristics, such information is much more limited in most of the administrative sources used. This paper only presents breakdowns of characteristics that can be compared across countries; more detailed national results are provided in the country studies referenced above.

In all countries except for the UK, singles without children are the largest group of benefit-receiving households accounting for about $27 \%$ (UK) to $51 \%$ (Sweden) of recipient households (Table 6). Single parents and couples with children account for about one-quarter of the households each, while benefit receipt among couples without children is much less frequent. In most countries, women make up the majority of working-age benefit recipients. This holds true for both SA benefits (except of Norway and Sweden, panel A) and HB (panel B). One factor explaining this gender pattern is that most single parents are women.

16 For Latvia, results cover individuals aged 15-64 years, which is the age range used in the Eurostat (2012) population statistics for Riga used to calculate entry rates. 
Table 6. Composition of the benefit recipient population

\begin{tabular}{|c|c|c|c|c|c|c|c|c|}
\hline \multicolumn{9}{|c|}{ Panel A - Recipients of social assistance benefits } \\
\hline & Canada & Germany & Latvia & Luxembourg & Netherlands & Norway & Sweden & United Kingdom \\
\hline \multicolumn{9}{|l|}{ Share of individuals in \%: } \\
\hline Women & 56.7 & 56.0 & 60.4 & 50.7 & 55.3 & 44.9 & 48.8 & 58.7 \\
\hline Foreign nationals* & .. & 17.0 &.. & 35.6 & 41.7 & $22.6^{*}$ & 34.5 & .. \\
\hline \multicolumn{9}{|l|}{ Share of households in \%: } \\
\hline Singles, with children & 22.0 & 27.6 & .. & .. & 18.5 & 24.5 & 22.8 & 28.5 \\
\hline Singles, without children & 39.3 & 37.4 & .. & .. & 21.2 & 45.9 & 50.8 & 27.4 \\
\hline Couples, with children & 26.3 & 19.7 & .. & .. & 30.8 & 26.5 & 20.0 & 27.8 \\
\hline Couples, without children & 12.3 & 15.2 & .. & - & 8.5 & 3.0 & 6.4 & 15.1 \\
\hline HB recipients & $\mathrm{x}$ & 30.4 & 79.5 & $x$ & 47.8 & 24.3 & $x$ & 69.9 \\
\hline \multicolumn{9}{|c|}{ Panel B - Recipients of housing benefits } \\
\hline & Canada & Germany & Latvia & Luxembourg & Netherlands & Norway & Sweden & United Kingdom \\
\hline \multicolumn{9}{|l|}{ Share of individuals in \%: } \\
\hline Women & $x$ & 58.8 & 63.5 & $x$ & 60.7 & 58.8 & $x$ & 61.6 \\
\hline Foreign nationals* & $x$ & 16.3 &.. & $x$ & 33.5 & 24.1 & $x$ &.. \\
\hline \multicolumn{9}{|l|}{ Share of households in \%: } \\
\hline Singles, with children & $x$ & 33.2 & .. & $x$ & 19.4 & 33.6 & $x$ & 27.9 \\
\hline Singles, without children & $x$ & 34.2 & .. & $x$ & 26.8 & 43.5 & $x$ & 31.0 \\
\hline Couples, with children & $x$ & 26.3 & .. & $x$ & 24.6 & 21.1 & $x$ & 25.1 \\
\hline Couples, without children & $\mathrm{x}$ & 6.3 & .. & $\mathrm{x}$ & 14.6 & 1.8 & $\mathrm{x}$ & 14.5 \\
\hline SA recipients & $x$ & 50.0 & 51.4 & $x$ & 39.2 & 35.4 & $x$ & 56.8 \\
\hline
\end{tabular}

Note: Results for the United Kingdom are unweighted; For Norway, results refer to the proportion of immigrants rather than the proportion of foreign nationals, and for Sweden, they show the proportion of recipients living in households in which one of the adults was born abroad. For the Netherlands, the recipient shares across different household types do not add up to 100 due to an omitted category 'other' '.' indicates that no results are available; ' $x$ ' indicates not applicable.

Sources: see Table 5 
Information on nationality or immigrant status is not available for all countries. Where it is, relatively large shares of SA recipients have been born abroad or do not have the national citizenship (between $17 \%$ in Germany and $42 \%$ in the Netherlands). The corresponding figures for HB are only slightly lower. Overrepresentation of non-natives among benefit recipients is a standard finding in the literature on SA benefit receipt dynamics and has motivated a series of studies examining the reasons of this so-called 'immigrant-native gap' in benefit receipt. Evidence from Sweden suggests that differences in observable characteristics only account for a small part of the differences in the frequency of benefit receipt between migrants and natives, but that state dependence in benefit receipt, i.e. a possible 'scarring effect' of past benefit receipt, may be higher for migrants (Hansen \& Lofstrom, 2003, 2008; see discussion in Section 4). By contrast, Riphahn \& Wunder (2012) find that for Germany the gap disappears once socio-economic characteristics are accounted for. Differences in findings across countries are however to be expected given large heterogeneity in the immigrant populations and cross-country differences in the extent to which different migrant groups have access to standard social safety nets.

Receipt of SA and HB is complementary in many countries: a substantial share of SA benefit recipients also receive $\mathrm{HB}$, and vice versa. ${ }^{17}$

\section{Rates and trends of benefit receipt}

The two top panels of Figure 5 summarize trends in SA benefit receipt by plotting annual receipt rates for working-age individuals in the eight countries. The presentation is split by data source, because the method used for defining the benefit variable depends on the type of data. Specifically, rates of benefit receipt calculated for administrative data reflect benefit receipt at any time during the given calendar year, while benefit receipt in survey data sets is measured at the time of the interview only. The reference group in both cases is the total working-age population. All else equal, rates of benefit receipt calculated from administrative data will therefore be higher than those from survey data.

Calculations based on these annual / annualised data suggest a remarkable degree of convergence in rates of benefit receipt over time. In the early- to mid-1990s, rates of receipt differ quite substantially between countries varying from around $2 \%$ in Luxembourg to close to $12 \%$ in Canada and the UK. Towards the end of the observation period in the late 2000s, the frequency of SA benefit receipt is around 4-6\% for all countries with the exception of Germany. Rates of benefit receipt in Latvia are much lower than for the remaining countries but rise substantially from the start of the recession. Three out of the eight countries in the sample - Germany, Latvia, and Luxembourg - show increasing rates of benefit receipt during the observation period.

Declining rates of benefit receipt likely reflect at least in part an improvement in the general economic environment after the economic downturn in the early 1990s with negative GDP growth rates in Canada, Norway, Sweden, and the United Kingdom. Policy reforms are another possible driver of these trends, notably stricter eligibility requirements and a greater focus on the activation of employable benefit recipients. Cappellari and Jenkins (2014) relate part of the decline in receipt rates in the United Kingdom to the introduction of the Jobseeker's Allowance in 1996 and the Working-Families Tax Credit in 1999. Hansen et al. (2014) point to the decrease in unemployment rates as the main factor for falling receipt rates. They however suggest also that a 1996 reform to the financing of social assistance expenditures may have

17 Since administrative data report benefits received at any point during the year, this does not necessarily mean that payments from both benefit programmes are received simultaneously - although this is likely but rather that households receive benefits from both programmes during the same calendar year. 
played a role that resulted in reduced transfers from the federal government to the provinces and stronger incentives for the provinces to move recipients from benefits into work.

The rising receipt rates in Germany may result from a gradual move of benefit recipients from insurancebased unemployment benefits into social assistance. Receipt rates peak at around 11\% in 2006, the year after the 'Hartz reforms' and then decline to $8 \%$ along with falling unemployment rates (Königs, 2013a). In Luxembourg, the positive secular trend in receipt rates can be understood in the context of a gradual expansion of the minimum-income benefit system after the introduction of the Guaranteed Minimum Income (Revenu Minimum Garanti, RMG) in 1986, likely reflecting a combination of increased take-up rates, a relaxation of eligibility conditions and larger benefit generosity (Königs, 2012).

Figure 5. Rates of social assistance benefit receipt in selected OECD and EU countries
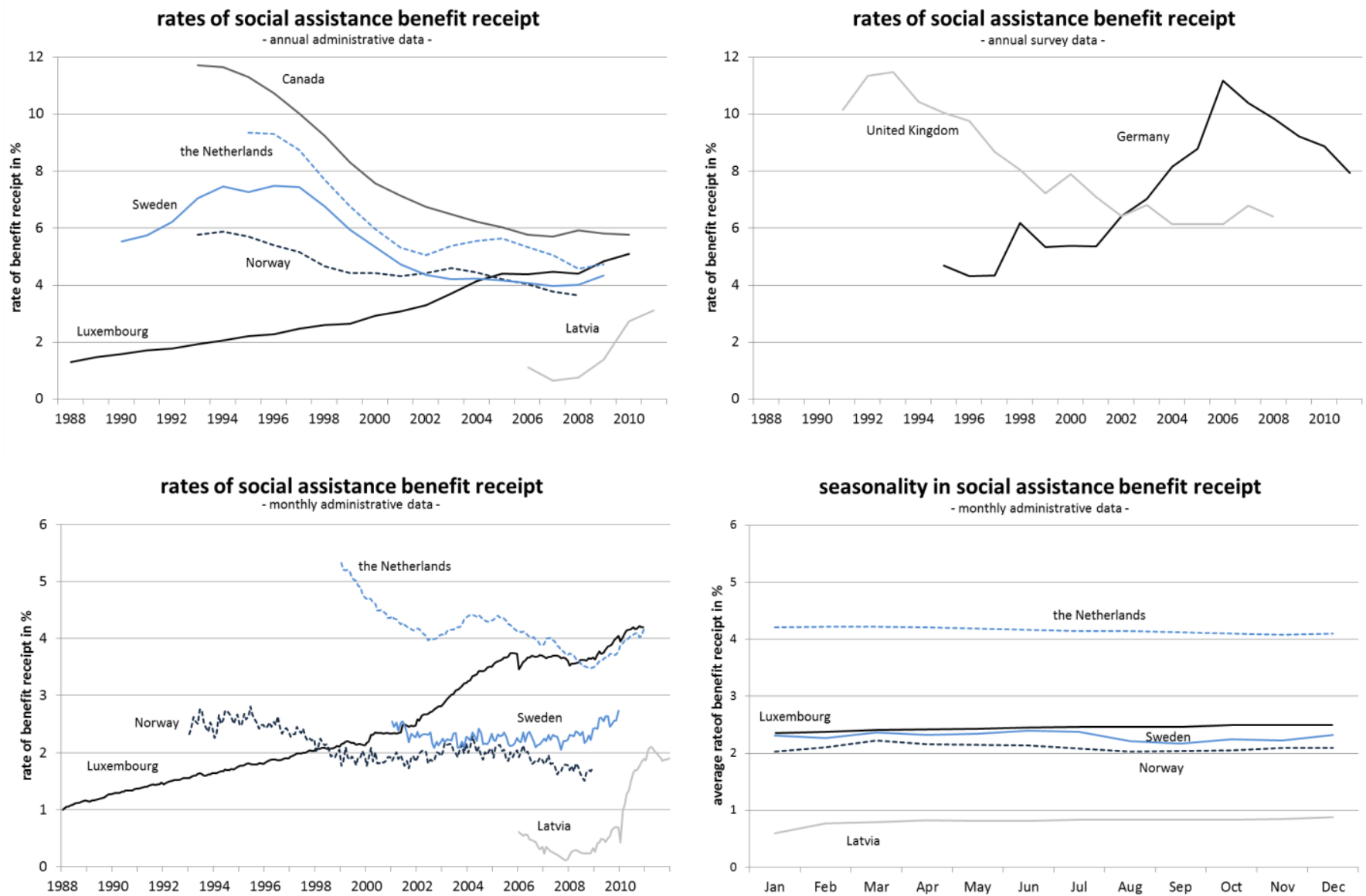

Note: Annual rates of benefit receipt based on administrative data measure an individual's benefit receipt at any time during the year. For survey data, benefit receipt is measured at the time of the interview only. Rates of benefit receipt for Germany and the United Kingdom have been calculated using individual sampling weights. Seasonality measures the frequency of benefit receipt for a given calendar month averaged over all years of the respective observation periods. For information on the type of benefit programmes included in the definition of 'social assistance', see Table 5.

Sources: see Table 5

Calculations based on monthly data show however that the annual rate of benefit receipt is not a very precise measure of the proportion of individuals who receive payments at a given point in time. The bottomleft panel reveals that rates of benefit receipt calculated based on monthly data are considerably lower than those based on equivalent annual data (top-left panel). This is true especially for Norway and Sweden, where receipt rates of around $2 \%$ are only about half as high as those calculated based on annual data. This result reflects the fact that the rate of benefit receipt in any given month is necessarily lower than the share 
of individuals who receive payments at any time of the year. Overall trends in benefit receipt by contrast match relatively well with those calculated from annual data.

There is no sign of seasonal fluctuations in benefit receipt in any of the five countries. ${ }^{18}$ The bottom-right panel of Figure 5 plots the average rate of benefit receipt in each calendar month across all years of the observation period. The lines for all five countries are essentially flat, which implies that there is very little systematic variation in rates of benefit receipt between calendar months. Any month-to-month fluctuations in benefit receipt observed in the monthly rates of benefit receipt for Sweden and Norway in the bottomleft panel represent 'noise', i.e. random variations, rather than seasonal effects.

Receipt rates of $\mathrm{HB}$ also display substantial cross-country differences, but much weaker time trends than rates of the 'core' SA benefit. Figure 6 shows that 2-4\% of working-age individuals in Latvia and Norway receive $\mathrm{HB}$ while the corresponding share is 3-6\% in Germany and 8-10\% in the Netherlands and the United Kingdom. HB receipt rates are thus higher than for SA in the Netherlands and the United Kingdom, at similar levels for Latvia, and lower in Germany and Norway. The limited changes of HB receipt rates over time could be explained by different, and often higher, income thresholds than are used for 'core' SA. Low-income families may therefore receive $\mathrm{HB}$ regardless of employment status, which could explain a lower responsiveness to cyclical changes in employment levels.

Figure 6. Rates of housing benefit receipt in selected OECD and EU countries
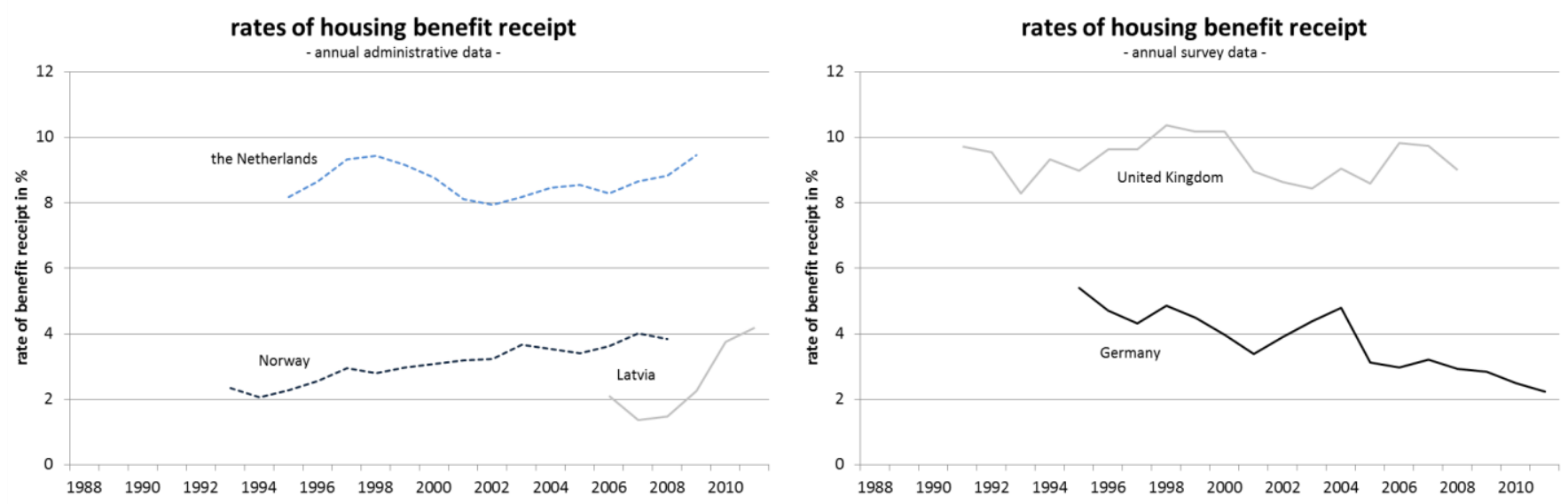

Note: Annual rates of benefit receipt based on administrative data measure an individual's benefit receipt at any time during the year; for survey data, benefit receipt is measured at the time of the interview only; rates of benefit receipt for Germany and the United Kingdom have been calculated using individual sampling weights.

Sources: see Table 5

Rates of benefit receipt at one point in time, and even the changes in these rates over time, say very little about how often people move on or off benefits. In particular, from looking at the rates of benefit receipt alone, it is not possible to tell whether the recipient population changed completely from one period to the next or whether the same group of individuals remained on benefits.

Some of these underlying benefit dynamics can be uncovered, however, by comparing monthly and annual rates of benefit receipt. As illustrated in Figure 5, there is generally a gap between annual rates of benefit

18 For Norway and Sweden, this result changes if individuals below the age of 25 are included. This is the case, because rates of benefit receipt are considerably higher over the summer months as young adults flow into social assistance to bridge gaps in their educational programmes. 
receipt, as presented in the top-left panel, and the underlying monthly rates of benefit receipt presented in the bottom-left panel. Averages of these annual and monthly rates of SA benefit receipt are presented in Table 7. The gap between the two provides a measure of the 'turnover' in benefit receipt during the calendar year. While the monthly rate gives an (approximate) measure of the instantaneous frequency of benefit receipt, the annual rate gives the share of individuals who receive benefits at any time during that calendar year. ${ }^{19}$ The ratio of the two (column 4 of Table 7) measures the extent to which the recipient population changes from month to month. ${ }^{20}$

Table 7. Annual and monthly rates of social assistance benefit receipt

\begin{tabular}{cccc}
\hline country & average monthly rate in \% & average annual rate in \% & ratio of columns III and II \\
\hline Latvia & 0.8 & 1.6 & 2.02 \\
Luxembourg & 2.4 & 3.0 & 1.22 \\
Netherlands & 4.2 & 5.4 & 1.29 \\
Norway & 2.1 & 4.7 & 2.23 \\
Sweden & 2.3 & 4.2 & 1.84 \\
\hline
\end{tabular}

Note: The average annual rate of benefit receipt is the share of individuals who receive benefits at any time in a given year averaged across all years of the respective observation period. The average monthly rate of benefit receipt is the average of the monthly rates of benefit receipt over the entire observation period. The ratio of the two is a measure of turnover. Observation periods are shown in Table 5. For the Netherlands and Sweden, where annual and monthly data do not come from the same data source, average receipt rates have been calculated over the period where data from both sources are available (2001-2009 for Sweden, 1999-2009 for the Netherlands).

Sources: see Table 5

The underlying turnover in benefit receipt is much higher in Latvia, Norway and Sweden than it is in Luxembourg and the Netherlands. For the two latter countries, the annual rate of benefit receipt is less than $30 \%$ higher than the average monthly rate of benefit receipt. In other words, over the course of a year, and for a stable annual rate of benefit receipt, less than $30 \%$ of all Luxembourg and Dutch recipients at the beginning of a year leave benefits and are 'replaced' by new benefit entrants. The corresponding figures are substantially higher for the two Nordic countries: In Sweden, the share of individuals who receive benefits at any time during the year is $84 \%$ higher than the average monthly rate of benefit receipt. In Latvia and Norway, the recipient population completely changes on average at least once during a calendar year. ${ }^{21}$

The results demonstrate that relatively similar average monthly rates of benefit receipt in Luxembourg, Norway, and Sweden can go hand in hand with very different degrees of turnover and, hence, benefit durations. This aspect is studied in more detail in Section 3.

The monthly rate is a true measure of "instantaneous" benefit receipt if the shortest period of benefit receipt is a month. If shorter durations are possible and common then the monthly rate is higher than the true instantaneous rate.

One way of making this more obvious is to think about the "static' case in which all recipients stay on benefits for the entire year. In this situation, the average monthly rate will be the same as the annual rate. If, instead, benefit receipt is "fully dynamic' in the sense that from each month to the next all benefit recipients stop receiving social assistance payments and an entirely new group of non-recipients start receiving benefits, then the annual rate will be exactly twelve times the average monthly rate. A higher value of the ratio of monthly to annual rates therefore implies stronger turnover.

This does not imply however that individual recipients may not remain on benefits for longer than a year, as others will enter and leave social assistance multiple times per year. Further evidence on spell durations is provided in Table 9 . 
These numbers can also be used to illustrate that where turnover is high, a greater share of the population may be in SA for at least a short period at some point during their lives. For instance, among working-age individuals in Norway who were in the sample for a full eight-year period (2001-2008), 10.2\% received SA at least once (not shown). This share is more than five times the average monthly rate of benefit receipt of $1.9 \%$ among the same individuals. In the Netherlands, the average monthly receipt rate among individuals observed for the same eight years is $3.9 \%$, but $9.8 \%$ of individuals receive benefits at some point during the period. In both countries, the number of individuals who draw on SA at some point is much higher than the low monthly rate of benefit receipt may suggest. Benefit receipt thus tends to be a transitory phenomenon, and 'recipients' and 'non-recipients' should therefore not necessarily be considered as two very distinct groups.

\section{Benefit transition rates and the relative importance of entries vs. exits}

Trends in SA receipt are closely linked to transition rates into and out of benefits. Let the entry rate be defined as the number of individuals who receive benefits in the current period and who did not receive benefits in the previous period as a percentage of all non-recipients in the previous period. ${ }^{22}$ Analogously, the exit rate is the number of benefit leavers as a share of all benefit recipients in the previous period. Figure 7 plots year-to-year entry and exit rates for the eight countries, again using different panels to distinguish between types of data source.

The decline in SA benefit receipt observed for many countries in Figure 5 has been driven primarily by falling entry rates into benefit receipt. The two top panels of Figure 7 show that the patterns observed for entry rates are remarkably similar to those reported earlier for the rates of benefit receipt. There is a clear downward trend in year-to-year entry rates into benefit receipt for five countries, for which entry rates into SA benefits appear to converge to around 1-1.5\% towards the end of the observation periods. Exceptions are again the entry rate for Germany, which fluctuates heavily between $2 \%$ and $4.5 \%$ possibly in response to the 2005 'Hartz reforms', and the one for Latvia, where no clear trend can be identified due to the shorter observation period. Exit rates by contrast are relatively stable over time for most countries, with the exceptions of Germany, Latvia and the UK where the rates decline (lower panels of Figure 7).

To the extent that the fall in benefit receipt rates observed in Figure 5 is due to lower unemployment rates and policy reforms that make claiming SA less attractive, such effects appear to have worked primarily by keeping individuals off benefits rather than by promoting departures. This is true in particular because, at falling receipt rates, the stable exit rates observed in Figure 7 imply a reduction in the absolute number of exits from benefits.

A conceptual point worth noting is further that entry and exit rates are expressed in relation to different subpopulations. The magnitude of entry and exit rates therefore cannot be compared directly: An entry rate that appears very low may correspond to a large number of individuals because it refers to a share of the entire non-recipient population. Exit rates by contrast are expressed as a fraction of the number of benefit recipients only, who typically already represent a small share of the population. social assistance. Entry rates are therefore calculated using population numbers for working-age individuals from Eurostat (2012) for Latvia and from OECD.Stat (http://stats.oecd.org/) for Luxembourg and Sweden. Robustness checks for Norway suggest that using OECD population statistics rather than the monthly population numbers constructed from the FD-Trygd sample leaves the results virtually unaffected. 
Figure 7. Social assistance transition rates in selected OECD and EU countries - annual data
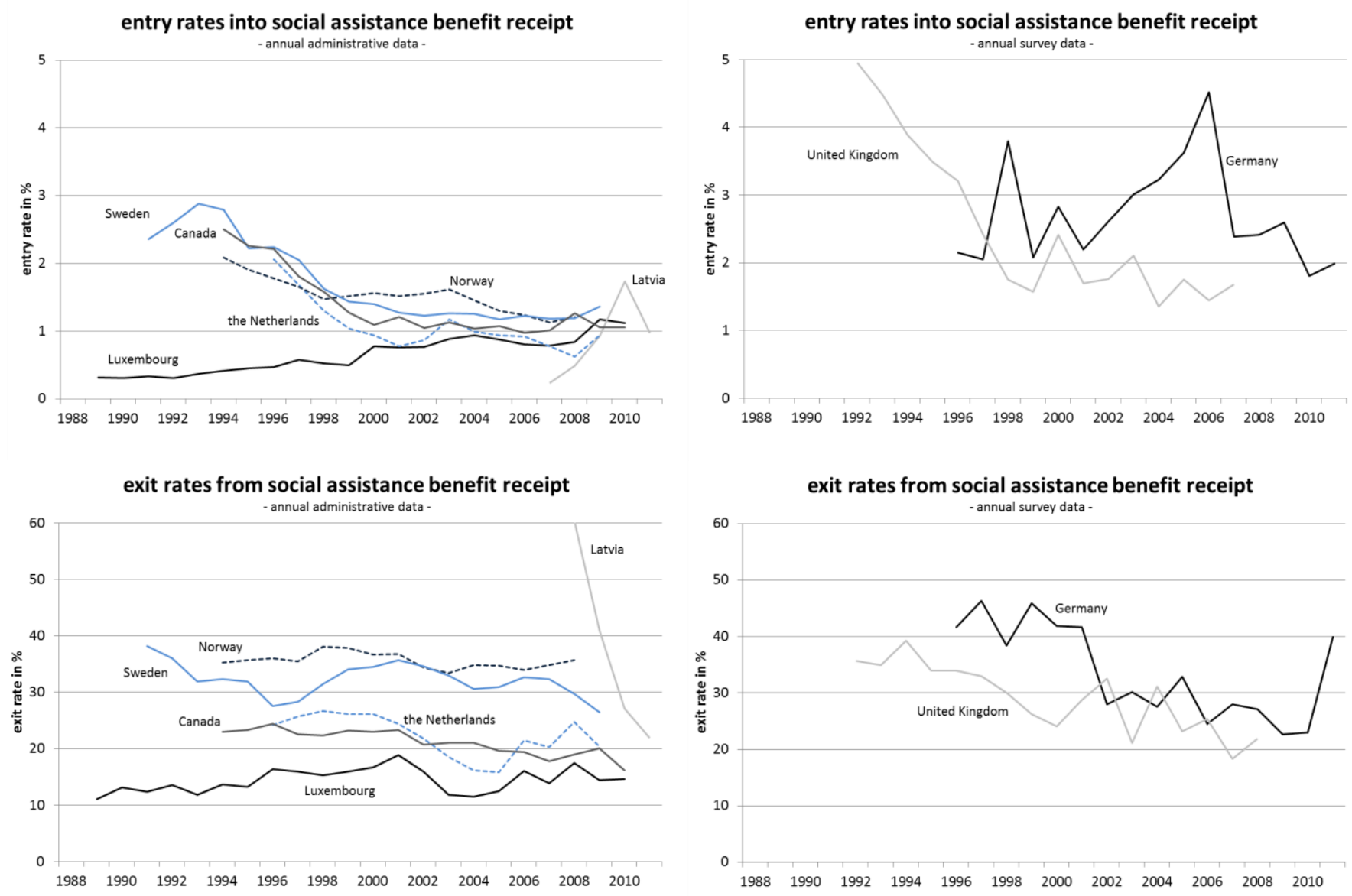

Note: An entry rate is defined as the number of individuals who receive benefits in year $t$ and who did not receive benefits in $t-1$ divided by the total number of non-recipients in $t-1$; An exit rate is defined accordingly as the number of individuals who do not receive benefits in year $t$ but who received benefits in $t-1$ as a fraction of all benefit recipients in $t-1$. Benefit transition rates for administrative data have been constructed based on an individual's benefit receipt at any time during the year; for survey data, transition rates measure the change in benefit receipt status from one annual interview to the next. Unlike for the monthly transition rates presented in Figure 8, possible transitions during the year are not reflected. Transition rates for Germany and the United Kingdom have been calculated using individual sampling weights.

Sources: see Table 5

The importance of this is illustrated in Table 8, which presents average transition rates along with the number of exits and entries per year in absolute terms. For Luxembourg, for instance, a very low average entry rate of $0.6 \%$ translates into 1,400 new benefit recipients from one year to the next. The average exit rate of $14.4 \%$ by contrast corresponds to less than 1,000 individuals that leave benefits from one year to the next. In spite of the very low entry rate, the absolute number of entries is thus nearly $50 \%$ higher than the number of benefit leavers, which explains the steady rise in the rate of SA receipt in Luxembourg observed in Figure 5.

An implication of these average transition rates is that 'raw' state dependence in benefit receipt is very strong. As summarized in Table 8, the shares of individuals who enter benefits from one year to the next is generally low varying from $0.6 \%$ on average in Luxembourg to $2.7 \%$ in Germany. This compares to very high persistence rates: Even for Latvia, where individuals leave benefit receipt the quickest, an exit rate of $42.7 \%$ implies that over $57 \%$ of recipients remain in benefits from one year to the next. 
Table 8. Average annual transition rates and number of entries and exits

\begin{tabular}{|c|c|c|c|c|c|}
\hline Country & $\begin{array}{l}\text { Average entry } \\
\text { rate in } \%\end{array}$ & $\begin{array}{l}\text { Average exit } \\
\text { rate in } \%\end{array}$ & $\begin{array}{l}\text { Average number of } \\
\text { entries per year }\end{array}$ & $\begin{array}{l}\text { Average number } \\
\text { of exits per year }\end{array}$ & $\begin{array}{l}\text { Ratio of number } \\
\text { of entries to exits }\end{array}$ \\
\hline Canada & 1.4 & 21.2 & 160,000 & 215,000 & 0.74 \\
\hline Germany & 2.7 & 33.6 & 785,000 & 691,000 & 1.14 \\
\hline Latvia & 0.9 & 42.7 & 6,500 & 3,600 & 1.81 \\
\hline Luxembourg & 0.6 & 14.4 & 1,400 & 960 & 1.46 \\
\hline Netherlands & 1.1 & 22.9 & 69,800 & 100,780 & 0.69 \\
\hline Norway & 1.5 & 35.6 & 31,800 & 37,500 & 0.85 \\
\hline Sweden & 1.7 & 32.2 & 67,000 & 74,400 & 0.90 \\
\hline $\begin{array}{l}\text { United } \\
\text { Kingdom }\end{array}$ & 2.4 & 29.0 & .. & .. &.. \\
\hline
\end{tabular}

Note: absolute numbers are sample estimates; no absolute numbers could be calculated for the UK.

Sources: see Table 5

The theoretical literature identifies two factors as the main drivers of the large differences in observed persistence and entry rates (Heckman, 1981a). First, personal and socio-economic characteristics (such as educational attainment or health status) influence the likelihood of benefit receipt. Since recipients and non-recipients differ in terms of these characteristics entry and persistence rates are also expected to be different. For instance, recipients with low education are likely to remain on benefits for longer because their low education status may be associated with low incomes. Second, and irrespective of any differences in characteristics, the experience of benefit receipt per se might make future receipt more likely. This could for instance be the case if a history of benefit receipt is interpreted as a sign of low productivity by a potential future employer, which might make finding a suitable job more difficult for SA recipients. The causal effect of past or present benefit receipt on the likelihood of future receipt is typically referred to as a 'structural' effect or as 'scarring'. One focus of the recent empirical literature on the dynamics of SA benefit receipt is to distinguish between those two factors, i.e., to study whether observed state dependence is mainly driven by individual characteristics (and thus 'spurious'), or whether there exists a strong causal (and thus 'genuine' or 'structural') effect. Key results from this literature for five countries are summarised in Section 4 and point towards significant structural state dependence.

A downside to studying annual transition rates is that it can be difficult to give them a meaningful interpretation because they reveal little about the underlying benefit dynamics at the monthly level. An individual who is classified as a benefit recipient in two subsequent years based on annual data might in reality have remained off benefits for most of the time during these two years, or have repeatedly 'cycled' into and out of benefits. Annual data therefore tend to give overestimates of the degree of persistence in benefit receipt, and this effect is sizable when benefit spells are short and repeat benefit receipt is common.

SA transitions calculated at the monthly level indeed reveal much more striking differences in entry rates between countries, a reflection of the large differences in 'turnover' observed earlier. Month-to-month entry rates into benefit of around $0.4 \%$ to $0.6 \%$ in Norway and Sweden are substantially higher than those for Latvia, Luxembourg and the Netherlands, which fluctuate around or below $0.1 \%$ (top-left panel of Figure 8). This is in contrast to results in Figure 7, which showed that annual transition rates did not vary much across countries towards the end of the observation period. Again, some of the strong turnover in benefit receipt in the two Nordic countries thus got lost once data were aggregated to the annual level. Exit rates at the monthly and annual level by contrast match relatively well. 
A result from the monthly transition rates is that the magnitude of observed state dependence is much larger at the monthly level. Only up to around $0.5 \%$ of non-recipients enter SA benefits from one month to the next. The proportion of benefit recipients who continue to receive benefits also in the next month by contrast varies between $75 \%$ in Norway and over $95 \%$ in Luxembourg and the Netherlands. State dependence in benefit from one month to the next is very high, and current benefit receipt is a very good predictor of benefit receipt in the next period. Again, this in itself however does not imply that current benefit receipt causes receipt in the next period.

Figure 8. Social assistance transition rates in selected OECD and EU countries - monthly data
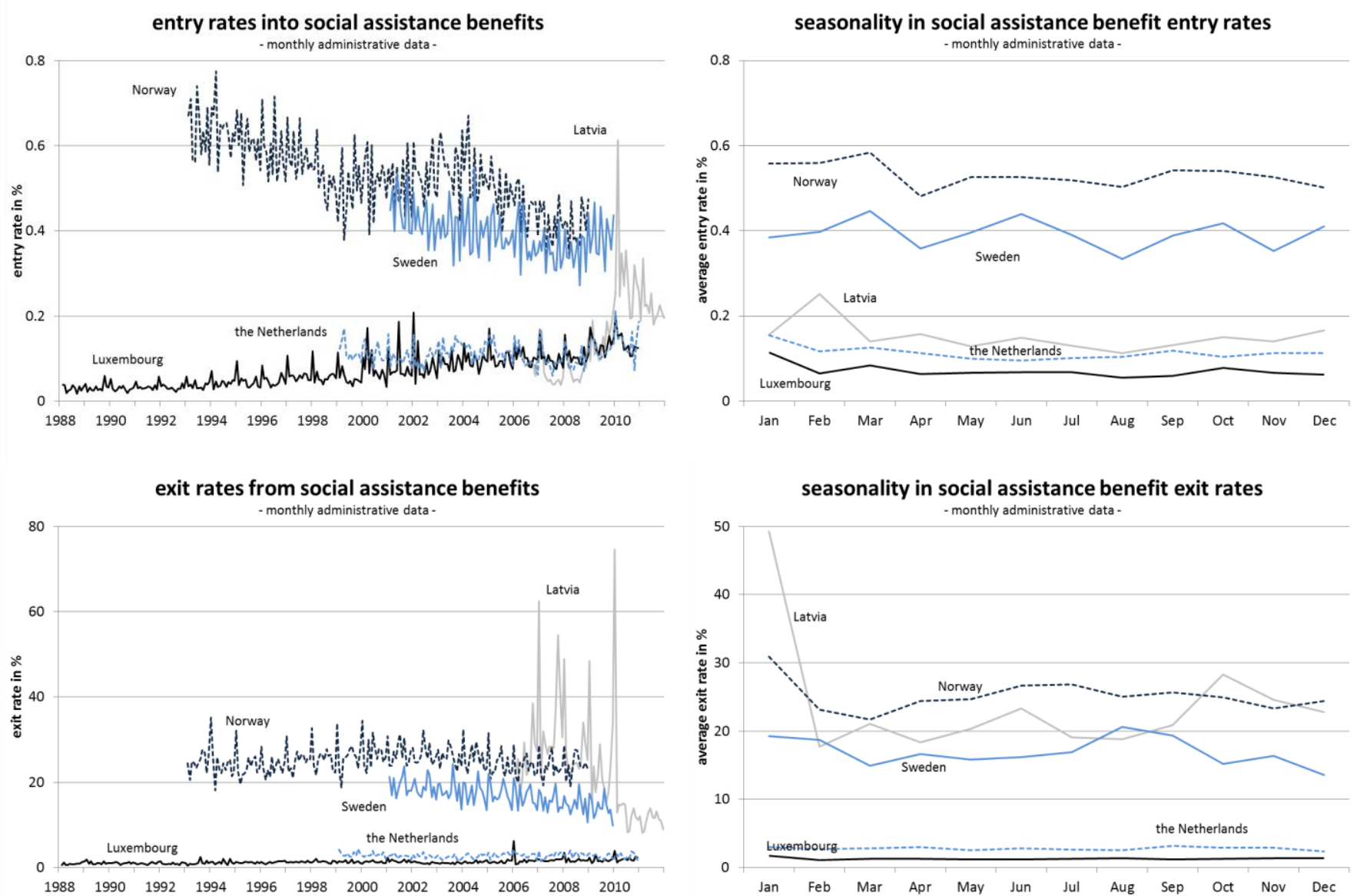

Note: Entry rates are defined as the number of individuals who receive benefits in period $t$ and who did not receive benefits in $t-1$ divided by the total number of non-recipients in $t-1$; Exit rates are defined accordingly as the number of individuals who do not receive benefits in period $t$ but who received benefits in $t-1$ as a fraction of all benefit recipients in $t-1$. Seasonality is analysed by looking at the benefit transition rate in a given month averaged over all years of the observation period.

Sources: see Table 5

Finally, it can be seen that, like rates of benefit receipt, benefit transition rates display a perhaps unexpected lack of seasonality. While some fluctuations across calendar months are observed, the only systematic patterns appear to be the somewhat higher exit rates from benefits in the summer months, and in January and December for the two Nordic countries. For Luxembourg and the Netherlands, the low observed exit rates and the lack of seasonality in entries and exits hint at long benefit spell durations for these countries. In Latvia, the very large spikes in exits from SA benefits must probably be attributed to data entry errors in the administrative information. Overall, the large fluctuations in month-to month benefit transition 
rates seen for all five countries thus do not reflect seasonality in benefit receipt. ${ }^{23}$ Of course, results might look different in countries where there exist stronger seasonal fluctuations in economic activity.

For HB, the transition patterns in Figure 9 indicate that the much higher rates of housing benefit receipt in the Netherlands and the UK compared to Norway and Germany (see Figure 6 above) are due to a combination of higher entry rates and lower exit rates. Similar as for SA benefits, the time trends in rates of housing benefit receipt appear to be driven primarily by changes in exit rates. An exception is again the large change in HB transition rates for Latvia during the recession years. For the United Kingdom, both entry and exit rates decline strongly over the observation period, leaving the overall rate of HB receipt more or less stable.

Figure 9. Housing benefit transition rates in selected OECD and EU countries - annual data
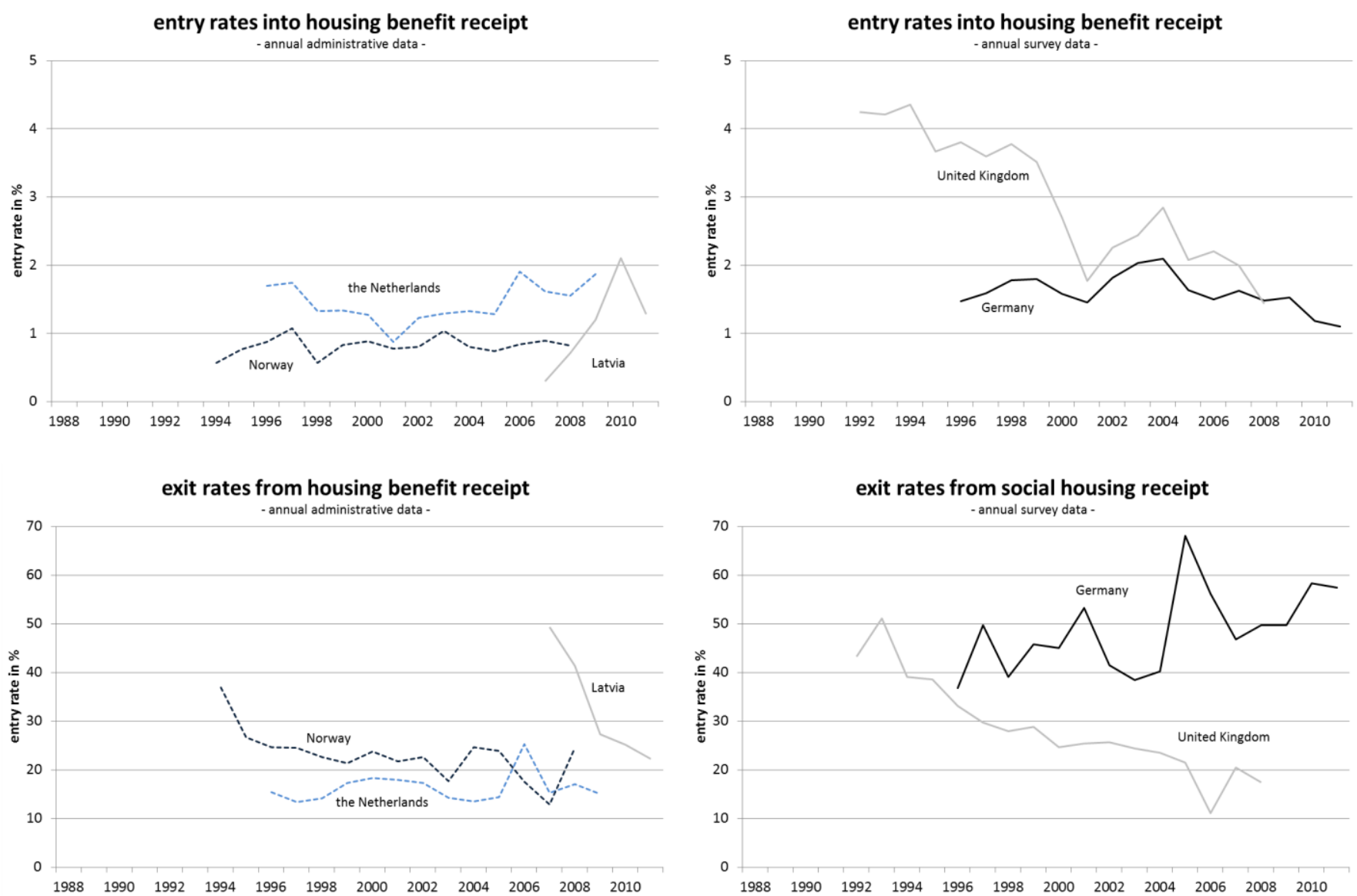

Note: Entry rates are defined as the number of individuals who receive benefits in period $t$ and who did not receive benefits in $t-1$ divided by the total number of non-recipients in $\mathrm{t}-1$; Exit rates are defined accordingly as the number of individuals who do not receive benefits in period $\mathrm{t}$ but who received benefits in $\mathrm{t}-1$ as a fraction of all benefit recipients in $\mathrm{t}-1$. Benefit transition rates based on administrative data use an individual's benefit receipt at any time during the year; for survey data, transition rates measure the change in benefit receipt status from one annual interview to the next; transition rates for Germany and the United Kingdom have been calculated using individual sampling weights.

Sources: see Table 5

Note that these fluctuations do not necessarily result from inadequate sample sizes. For Luxembourg and Sweden, the analysis is based on data for the entire population such that any fluctuations in transition rates reflect actual month-to-month variations. For Norway and the Netherlands, respectively a $10 \%$ and a $0.5 \%$ sample from the population are used, which means that the number of observations is considerable. In the case of Latvia, the large fluctuations likely reflect at least in part problems of bad coding in the original data. 


\section{Main findings from Section 2}

Understanding the dynamics of SA benefit receipt is important for designing well-functioning social safety nets. This section examined the dynamics of benefit receipt for eight EU and OECD economies (Canada, Germany, Latvia, Luxembourg, the Netherlands, Norway, Sweden, the United Kingdom) using aggregated data for the 1990s and 2000s.

- Annual rates of SA benefit receipt converge to around 4-6\% in the mid-2000s, a trend that implies falling rates of benefit receipt in most of the countries since the 1990s. Exceptions are Luxembourg, where the incidence of SA benefit receipt has increased by 4 percentage points, and Germany, where receipt rates rose by 6 percentage points until 2006 but have declined again since. The rate of SA benefit receipt also rises strongly for Latvia, albeit during a much shorter time period (recipient data for Latvia cover the period since 2006).

- An analysis of monthly data from administrative records shows that, on average, only around 2$4 \%$ of working-age individuals receive SA benefits in the late 2000s in any given calendar month. Annual rates of SA benefit receipt - the standard measure of benefit receipt in most empirical work - are therefore not generally a good measure of benefit receipt at a point in time. The result also implies that a significant number of people receive benefits for relatively short periods (less than a year). The ratio of annual to average monthly rates of benefit receipt can be interpreted as a measure of turnover in benefit receipt: among the five countries looked at, turnover is highest in Norway and lowest in Luxembourg and the Netherlands.

- $\quad$ SA and HB programmes resemble each other in their recipient composition: The largest recipient group are typically singles without children; approximately $1 / 4$ of recipient households are lone parents and another $1 / 4$ couples with children. Couples without children are typically the smallest recipient group. Non-natives tend to be strongly over-represented among benefit recipients, perhaps in part because they find it more difficult to qualify for other types of income support, and benefit recipients are more often women than men.

- Changes in the annual rate of benefit receipt tend to be primarily driven by changes in entry rates: In particular, the observed decline in the rate of benefit receipt since the 1990s coincides with a drop in annual entry rates from around $2 \%$ to $1 \%$ in many countries. By contrast, annual exit rates from benefit receipt are remarkably stable over the observation period, although they differ strongly across countries, ranging from $14 \%$ in Luxembourg to $43 \%$ in Latvia. In a comparison of entry and exit rates, it is important to keep in mind that the former are expressed relative to the (much larger) number of non-recipients while the latter give a proportion of recipients. A comparison of absolute numbers of benefit entries illustrates that rates of benefit receipt can rise despite very low entry rates of below $1 \%$ from one year to the next (e.g. in Latvia and Luxembourg).

- None of the countries for which monthly data were available appears to display significant seasonality in SA benefit receipt. More specifically, neither rates of benefit receipt nor transition rates into or out of benefit receipt change systematically across calendar months over the years of the observation period. 


\section{The micro-dynamics of benefit receipt}

The benefit receipt rates and transition rates presented in Section 2 raise important questions about the underlying behaviour of individual benefit recipients. Policy debates in many OECD countries evolve around a widespread perception that a sizeable group of SA benefit recipients relies on income-support payments for prolonged periods of time. If this perception were true, such long-term benefit dependence would raise doubts as to whether minimum-income benefit systems are successful at delivering the intended short-term protection against economic hardship while giving recipients support and incentives to quickly regain self-sufficiency. A related question is whether individuals who leave SA remain selfsufficient, or whether they tend to repeatedly 'cycle' into and out of benefits over longer periods of time. Such questions on the micro-dynamics of benefit receipt cannot be answered by looking at aggregate data. This section therefore extends the analysis of the dynamics of SA benefit receipt by taking a spell-based perspective.

While there has been a long interest in studying the duration of SA benefit spells, the required high-quality panel data with short observation intervals have not been readily available. Early studies on benefit spell durations are based on annual data on benefit receipt focusing primarily on the receipt of Aid to Families with Dependent Children (AFDC) in the United States (Bane \& Ellwood, 1983, 1994; O’Neill, Bassi, \& Wolf, 1987; Hoynes \& MaCurdy, 1994).$^{24}$ One common conclusion of these studies is that while there is clear evidence of long-term benefit receipt, the large majority of spells are relatively short. An obvious limitation is however that the measurement of spell durations in these studies is quite imprecise. For individuals who remain on benefits for prolonged periods, benefit spell lengths will be overestimated as no distinction can be made between single long spells and a series of recurrent shorter spells. Later studies of U.S. welfare benefit dynamics use information at the monthly level taken from survey data. A number of articles use the Survey of Income and Programme Participation, SIPP (Fitzgerald 1991, 1995; Harris, 1993, 1996; Blank \& Ruggles 1994). Pavetti (1993) calculates AFDC spell lengths from the National Longitudinal Survey of Youth (NLSY) and compares results obtained from monthly and annualized data. ${ }^{25} \mathrm{~A}$ drawback of using such household-survey data is that interviews typically only take place on a quarterly or even annual basis and that information on benefit receipt in-between interviews is likely to be unreliable. ${ }^{26}$

From the late 1990s, increased availability of data from administrative records for research purposes primarily outside the U.S. has allowed researchers to produce what are arguably more reliable results on the length of benefit spells. For Canada, Barrett \& Cragg (1998) study welfare use in the province of British Columbia using administrative data for the 1980s and early 1990s. They find benefit duration to be typically short, with $75 \%$ of spells ending within six months. Repeat benefit receipt however is frequent, with $25 \%$ of benefit leavers returning within three months and half of all benefit leavers returning within a year. Wilson (1999) uses administrative data from New Zealand to study benefit receipt for a cohort of welfare

24 AFDC was the precursor of Temporary Assistance for Needy Families (TANF), which was introduced in 1996.

A rare example of an early study of welfare benefit dynamics based on monthly data from administrative sources comes from Blank (1989), who, using six years of data from Denver and Seattle for the early 1970s, finds weak evidence for duration dependence in AFDC receipt. Hoynes (2000) presents evidence on receipt of AFDC in California based on administrative data for the period from 1987 to 1992. The spell lengths she finds are relatively similar to those calculated in previous studies that use survey data, with $28 \%$ of spells lasting at most six months and 38\% lasting over two years. Among benefit leavers, $41 \%$ reenter within two years of leaving.

For instance, Pavetti (1993) reports that $22 \%$ of all welfare spells last exactly from January to December and that December endings account of $47 \%$ of all spell endings. This 'seam bias problem' is attributed to difficulties that respondents may have when answering questions that relate to early parts of the survey period. For a more extensive discussion, see Annex 4.B. 
receivers from 1993 over a period of five years. While only 5\% of benefit recipients remained on benefits for the entire period, more than one-third were still receiving benefits at the end of the observation period. A challenge therefore appears to be not so much to quickly move recipients off benefits, but rather to ensure that they remain self-sufficient after having left.

A series of articles based on fortnightly administrative data from the Australian Longitudinal Data Set (LDS) illustrate again the high frequency of repeated spells and emphasize the importance of considering transfers across different income-support programmes. For the 1995 inflow sample of recipients of meanstested single parent benefits, Gregory \& Klug (2003) show that spell lengths tend to be short with $45 \%$ of all spells lasting shorter than one year. However, nearly half of all recipients had spells of other types of income-support benefits during the $5 \frac{1}{2}$-year observation period (though this includes receipt of Newstart Allowance, Australia's unemployment benefit). Tseng \& Wilkins (2003) show that up to one-third of the Australian working-age population touches on at least one of various income-support benefits in a given year; one-sixth of all recipients continuously receive support over the same $51 / 2$-year period. Tseng, Vu, \& Wilkins (2008) find that 'churning' is a typical feature of income-support receipt with over half of all recipients leaving and re-entering benefits at least once over a five-year period. Repeated cycling into and out of benefits by contrast is not the norm, and less than one-quarter of 'churners' have four or more spells. Transfers between different programme types during a single benefit spell do not occur very often.

Relatively little evidence exists to date on benefit spell lengths in Europe. A series of studies look at benefit receipt duration at the city level using monthly data from Bremen (Buhr \& Weber, 1998; Leisering \& Leibfried, 1999), Bremen and Gothenburg (Gustafsson \& Voges, 1998), and a set of eight different European cities (Gustafsson, Müller, Negri, \& Voges, 2002). The first three studies conclude that SA receipt is mostly a temporary phenomenon, whereas Gustafsson et al. find large differences in benefit spell lengths across cities as discussed further below. With observation periods of five years or less, the authors are however limited in their ability to account for repeat spells in benefit receipt. In a recent study on benefit receipt in the Dutch city of Rotterdam, Snel, Reelick, \& Groenenboom (2013) challenge Leisering \& Leibfried's conclusion (drawn for a different city) that episodes of SA receipt are typically short. Based on seven years of administrative data starting in 1999, they calculate that nearly two-thirds of benefit spells last longer than a year. One in four recipients have a total (or 'net') benefit duration of five years or more over the seven-year period. Repeat spells by contrast are found to be the exception, with four out of five benefit recipients in 1999 having had only one single spell. Dahl \& Lorentzen (2003) look at the duration of benefit receipt in Norway for the 1995 cohort of SA recipients over an eight-year period from 1992 to 1999. Using the same source of administrative data as in the present paper, they illustrate the point raised by Bane \& Ellwood (1994) that sample selection (above all the distinction between samples of starting vs. on-going spells) and spell censoring have a strong influence on measured spell lengths.

This section presents and compares the micro-dynamics of benefits for the countries for which monthly data are available: Latvia, Luxembourg, the Netherlands, Norway, and Sweden. The analysis adds to the existing research in two main respects: First, it provides comparable evidence on receipt dynamics in five different European countries. Results for the Netherlands and Sweden complement existing studies at the city level by Snel et al. (2013) for Rotterdam and by Gustafsson et al. (1998) for Gothenburg and Helsingborg. The analysis for Norway updates and extends results presented by Dahl \& Lorentzen (2003) for an earlier time period. The study of benefit dynamics for Luxembourg is the first of its kind. Second, it adds more specifically to the scarce existing evidence on repeat benefit receipt. This is possible because of the exceptionally long observation periods of the panels in four out of the five countries.

The data sources used are a subset of those described in the previous section. Time periods covered in the analysis differ by country, varying from a minimum of six years or 72 months for Latvia $(2006$ - 2011) to a maximum of 23 years or 276 months for Luxembourg (1988 - 2010). For all countries but Latvia, the observation periods overlap for 8 years from 2001 to 2008. All five data sets contain data for the entire 
(recipient) population in the country over the respective observation period. ${ }^{27}$ For Latvia, Luxembourg, and Sweden, results are produced based on data for the universe of benefit recipients, while results for the Netherlands and Norway are again based on a $0.5 \%$ and a $10 \%$ sample, respectively.

The analysis summarises and extends recent country studies on the dynamics of SA receipt for Norway (Bhuller \& Königs, 2011; Bhuller, Brinch \& Königs, 2014), Luxembourg (Königs, 2012), and the Netherlands (Königs, 2013). In addition, it presents previously unpublished results for Sweden. The results for Latvia are taken from findings of a World Bank study (World Bank, 2013) in which two of the authors were involved. Where possible, results are compared with findings from earlier studies on SA benefit dynamics that are based on similar data.

\section{Duration of benefit spells (1) - evidence from long panels}

Monthly data on benefit receipt allow for a very precise measurement of the length of recipients' benefit spells - sometimes arguably more so than it would be required. A contentious issue in the existing literature has indeed been how short interruptions in benefit receipt should be dealt with when defining benefit spells. Typically, it is not always clear from the data whether short periods without benefit receipt represent actual exits from benefits, or whether they result from 'administrative churning' (for instance due to delays in benefit pay-outs, errors in data entry, etc.) and should thus be corrected for. Information on the amount of benefits paid is typically only available at the annual level and therefore does not provide much guidance on this issue.

Even under the assumption that data have been recorded correctly a case can be made for ignoring very short exits from benefit receipt because they may not represent genuine departures of the recipient from a situation of dependency. Kazepov (1999) for instance introduces the concept of dependence episodes to describe periods of benefit receipt that might span multiple cash episodes, (i.e. benefit spells) interrupted by only short times without benefit receipt. Blank (1989) ignores interruptions in benefit receipt of up to three months in cases where she cannot link them to changes in employment status or income, and a similar approach is taken in most of the later work on the topic.

This analysis takes a different approach by defining a benefit spell as a period during which a positive amount of benefits is observed for every single month. A spell is thus coded as having ended as soon as no further monthly benefit payment is recorded. The main motivation for this approach is that a large share of the observed benefit spells are of only short duration, and that it is not obvious why short spells on and off benefits should be treated asymmetrically. To check the robustness of the findings, this paper also reports results obtained when ignoring interruptions in benefit receipt of two months or less. Unlike it is done by previous authors, these interruptions are however not counted as contributing towards the length of the benefit spell. ${ }^{28}$

A first way of summarizing differences in spell durations is by plotting the average exit rate from benefits at various stages of a spell, i.e. the hazard rate of exits from benefits (Figure 10). In all four countries, hazard rates show a declining pattern indicating that the probability of leaving benefits in a given period (conditional on not yet having left in any of the previous periods) falls with increased spell duration. Exit

$27 \quad$ For Latvia, only information for the city of Riga is used.

For instance, an individual might be observed as receiving benefits for two times four months interrupted by a period without payments of two months. In this analysis, such an episode would be classified as either two separate four-month spells or as a single spell of eight months; Gustafsson et al. (2002) for instance would record a single spell of ten months instead. 
probabilities however differ substantially across the five countries: In Norway and Sweden, the periodspecific exit rate from benefits is above $30 \%$ per month in the beginning of a benefit spell but strongly declines to around 10\% after 12 months and further to around 5\% after 36 months. In Latvia, exit probabilities are slightly lower during the first few months of a spell. In Luxembourg and the Netherlands, exit probabilities are much lower and consequently decline less strongly.

The hazard rates' declining patterns cannot be interpreted as evidence for duration dependence. Instead, the fall in exit rates with increased spell duration is likely to primarily reflect compositional effects. Individuals with more favourable labour market characteristics leave benefits quickly; those who remain are more disadvantaged and their exit rates lower.

\section{Figure 10. Hazard rates of exits from benefits}

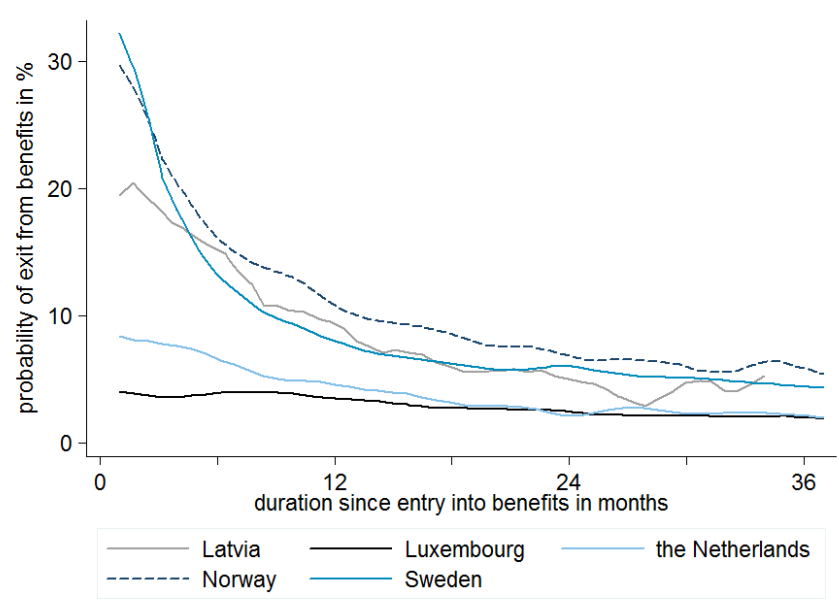

Source: Note: The hazard rate gives the probability of leaving benefits at a given spell duration conditional on not having left in any of the earlier periods. For instance, in Norway, the monthly exit rate for individuals who reach the 4th month on benefits is about $20 \%$.

Sources: see Table 5

The implied observed spell durations differ substantially across countries. Table 9 presents an overview of the duration of all benefit spells that start during the observation period. Spell durations are generally relatively short in Latvia, Norway and Sweden but much longer in Luxembourg and the Netherlands (Table 9, panel A). The average duration of a benefit spell in the sample varies from below 4 months in Norway to over 30 months, i.e., $2^{1 / 2}$ years, in Luxembourg. Median durations indicate that short-term benefit receipt is the norm in Latvia, Norway, and Sweden, where 50\% of all spells are of duration 2-3 months or shorter. By contrast, for the Netherlands and Luxembourg, half of all benefit spells last at least 9 or 15 months, respectively.

The duration of benefit receipt is also heterogeneous across spells within countries. In all five countries, at least a small proportion of recorded spells are very long. In Luxembourg, $60 \%$ of all spells are longer than 12 months and close to $40 \%$ last two years or longer. In Norway, where mean and median spell lengths are shortest, about $2 \%$ of all spells last for at least 24 months. 
Table 9. The duration of benefit spells - all starting spells

\begin{tabular}{|c|c|c|c|c|c|c|c|c|c|}
\hline \multicolumn{10}{|c|}{ Panel A - Standard sample } \\
\hline \multirow{2}{*}{ Country } & \multirow{2}{*}{$\begin{array}{l}\text { Observation } \\
\text { period }\end{array}$} & \multirow{2}{*}{$\begin{array}{l}\text { \# of } \\
\text { spells }\end{array}$} & \multicolumn{2}{|c|}{$\begin{array}{l}\text { Spell duration in } \\
\text { months }\end{array}$} & \multicolumn{4}{|c|}{ Share of spells in $\%$ with a duration of at least } & \multirow{2}{*}{$\begin{array}{c}\text { Censored spells in } \\
\%\end{array}$} \\
\hline & & & Median & Mean & 3 months & 6 months & 12 months & 24 months & \\
\hline Latvia & $2006-2011$ & 58,656 & 3 & 5.2 & 61.6 & 31.9 & 11.1 & 0.8 & 18.5 \\
\hline Luxembourg & $1988-2010$ & 43,862 & 15 & 30.6 & 90.8 & 79.6 & 59.4 & 37.7 & 25.1 \\
\hline Netherlands & $1999-2010$ & 6,929 & 9 & 19.2 & 82.3 & 63.1 & 42.3 & 24.6 & 20.9 \\
\hline Norway & $1993-2008$ & 361,728 & 2 & 3.7 & 35.3 & 15.7 & 5.9 & 1.8 & 1.7 \\
\hline Sweden & $2001-2009$ & $1,742,738$ & 2 & 5.2 & 43.5 & 23.1 & 10.9 & 4.1 & 6.6 \\
\hline \multicolumn{10}{|c|}{ Panel B - Ignoring short-term exits } \\
\hline \multirow{2}{*}{ Country } & \multirow{2}{*}{$\begin{array}{l}\text { Observation } \\
\text { period }\end{array}$} & \multirow{2}{*}{$\begin{array}{l}\text { \# of } \\
\text { spells }\end{array}$} & \multicolumn{2}{|c|}{$\begin{array}{l}\text { Spell duration in } \\
\text { months }\end{array}$} & \multicolumn{4}{|c|}{ Share of spells in $\%$ with a duration of at least } & \multirow{2}{*}{$\begin{array}{c}\text { Censored spells in } \\
\%\end{array}$} \\
\hline & & & Median & Mean & 3 months & 6 months & 12 months & 24 months & \\
\hline Latvia & $2006-2011$ & 37,227 & 5 & 8.2 & 77.5 & 49.2 & 24.7 & 5.4 & 29.1 \\
\hline Luxembourg & $1988-2010$ & 40,238 & 17 & 33.4 & 92.0 & 81.9 & 62.7 & 40.9 & 27.4 \\
\hline Netherlands & $1999-2010$ & 6,482 & 9 & 20.6 & 83.1 & 64.6 & 44.1 & 26.4 & 22.4 \\
\hline Norway & $1993-2008$ & 208,320 & 2 & 6.4 & 46.4 & 26.1 & 13.1 & 5.8 & 2.9 \\
\hline Sweden & $2001-2009$ & 972,329 & 3 & 9.2 & 53.3 & 35.3 & 22.0 & 11.4 & 11.7 \\
\hline
\end{tabular}

Note: Calculations are based on monthly administrative data from Luxembourg (FNS database), the Netherlands (SSB), Norway (FD-Trygd), and Sweden (NBHW database). Results for Latvia were produced by the World Bank (2013) based on GMI records for Riga. Panel A uses the standard sample while Panel B ignores exits from SA benefit receipt of up to two mons. Mre spelically, months. More specilcally, spels that are interupted by a period of non-receipt of $1-2$ months are coun as cof counted towards the duration of the benefit spell. Spells are counted as c at start during the respective observation periods.

Sources: see Table 5 
A methodological point worth noting is that for spells that are ongoing in the last month of the observation period, no end date can be observed. The observed spell duration until the end of the observation period will therefore generally be an underestimate of the true spell length. This is referred to as a problem of right-censoring. In samples with long observation periods like the ones used in this analysis, rightcensoring is typically not very severe because only a low share of all spells in the sample will be ongoing in the final period. Table 9 however indicates that a substantial fraction of spells in Luxembourg and the Netherlands are censored. Since these censored spells are included in the calculations, the already long average spell durations calculated for those countries still underestimate true spell lengths.

Ignoring short exits from benefits in the calculation of spell lengths does not strongly affect results. Median spell durations change little, remaining stable in Norway and the Netherlands, increasing by one month in Sweden and by two months for Luxembourg. In Latvia, ignoring short exits from benefits has a larger effect increasing medium spell durations from 3 to 5 months. By contrast, measured mean spell durations rise by about three-quarters for the two Nordic countries from 3.7 to 6.4 months in Norway and from 5.2 to 9.2 months in Sweden. This increase is driven primarily by an increase in the durations of already long benefit spells. The proportion of spells that last 24 months or longer rises from $4.1 \%$ to $11.4 \%$ in Sweden, more than triples from $1.8 \%$ to $5.8 \%$ in Norway, and increases by a factor of 7 for Latvia. In the Netherlands and Luxembourg, ignoring short-term exits from benefit receipt does not have a major effect on mean spell durations.

The results are not driven by differences in observation periods across countries. In the presence of time trends in benefit spell durations, cross-country comparisons would be problematic since observation periods differ. A robustness check however indicates that the distributions of spell durations vary little over the observation periods. In particular, the shares of spells with durations of at least six, twelve, and 24 months among spells starting in a given month are surprisingly stable over time (not shown). The only exception to this is Latvia, where the proportion of spells with longer durations surges along with the rise in benefit receipt rates in 2009.

It is interesting to compare the presented spell durations with those found in earlier studies, keeping in mind of course that some of the relevant studies relate to different countries or specific cities. Blank (1989) reports in her analysis of AFDC-receipt in Denver and Seattle that $62 \%$ of the completed spells for a household ended within a year, with an average duration of benefit payments of 13 months. She however does not include the $36 \%$ of right-censored spells in these calculations, which generally have a longer duration until censoring. Fitzgerald (1991) calculates a much longer median AFDC benefit spell length of 20 months over a shorter observation period (32 months), but calculates a median spell duration of 11-12 months for receipt of AFDC and Food Stamps in a follow-up study (Fitzgerald, 1995). ${ }^{29}$ Also Hoynes (2000) reports longer AFDC spell lengths for California, where $46 \%$ of spells end within 12 months and $62 \%$ end within 24 months. The finding of relatively long AFDC spell lengths, at least compared to spell lengths in Norway and Sweden, is maybe not so surprising since the U.S. AFDC primarily targeted highly disadvantaged single mothers, who would generally be expected to remain on welfare for longer.

More recent and comparable results are presented by Gustafsson et al. (2002) in their study of SA dynamics in eight European cities. For a 42-month period starting in the late 1980s or early 1990s, they report median spell durations of around 4 months for an individual's first observed spell in Gothenburg and Helsingborg and of 5-6 months for Bremen, Milan and Turin. By contrast, median benefit spell durations are one year for Vitoria, over two years for Barcelona and nearly 3 years for Lisbon. The results for Helsingborg and Gothenburg are relatively close to the ones reported in Table 9 for Sweden. The median durations for Barcelona and Lisbon are much longer than the ones reported in this paper, which as Gustafsson et al.

$29 \quad$ Fitzgerald explains the differences by generally lower benefit spell durations for Food Stamps as opposed to AFDC and by a different treatment of short breaks between spells. 
(2002) suggest might reflect stricter means-tests in these cities that might lead to a more disadvantaged recipient population.

The results for Norway are remarkably similar also to those reported by Dahl \& Lorentzen (2003) who study benefit spell durations in Norway using the same data set for an earlier period. For their sample of spells that start in 1995, they calculate median and mean spell durations of 2 and 4 months, respectively, and a 94\%-share of spells that last 12 months or shorter (p. 295, Table 6). These numbers are nearly identical to those presented in Table 9 for a later and longer time period.

The presented findings for the Netherlands by contrast differ from those reported by Snel et al. (2013) for bijstand receivers in the city of Rotterdam. For the 1999 inflow cohort, they calculate a median spell duration of 23 months (p.184, Table 6), which is more than double the 9 months reported in Table 9 of this document for the country as a whole. Similarly, they calculate that only $35 \%$ of benefits spells last one year or less, compared to around 58\% of spells with a duration below 12 months reported in Table 9 .

Even though the benefit receipt rate in urban Rotterdam is two to three times as high as the one for the country as a whole, heterogeneity in spell durations within the country does not appear to be responsible for the differences in findings. The postcode information in the SSB data can be used to restrict the sample to recipients who live in city of Rotterdam at the beginning of their spell. Over the eight-year period, the median and mean spell lengths for this restricted sample are 10 months and 21 months, respectively. 53\% of all spells last longer than 12 months. These numbers are only a little higher than those reported in Table 9 for the entire country and thus still much lower than those reported by Snel et al. Since there are no apparent differences in methodology or sample selection between the two studies, the much higher spell durations calculated by Snel et al. might simply be due to the different observation period. More specifically, the 1999 inflows sample used by Snel et al. was drawn before the start of the observation period of the present analysis and at a time when benefit receipt rates were still much higher. ${ }^{30}$ The differences in spell durations in the two studies might thus hint at a positive relation between spell durations and the receipt rate at the start of a spell. Unfortunately, it was until now beyond the scope of this project to study this aspect in more detail.

\section{Duration of benefit spells (2) - a cross-sectional perspective}

This far, the analysis of benefit spell lengths has considered all spells that start during an extended observation period. However, since data of the type used in this analysis are rarely available, policy debates about the length of benefit spells commonly refer to the duration of on-going spells measured at a single point in time. In particular, discussions are often concerned with the proportion long-term recipients among those currently in receipt of SA benefits. Conclusions based on such 'cross-sectional' samples however are often highly misleading.

In a seminal study on the duration of welfare benefit spell in the U.S., Bane \& Ellwood (1994) emphasise that in a cross-sectional sample, a snapshot of all on-going spells (a sample of 'stocks') will yield very different spell durations than a sample of all spells that start or end in that period (a sample of 'flows'). To illustrate the importance of this point, this paper re-produces part of the analysis done by Bane \& Ellwood to provide evidence on the gap in measured SA spell durations when comparing stock and flow samples in countries for which monthly data are available. 
Table 10 shows the duration of benefit spells for each country at one single point in time calculated for (i) a sample of on-going spells, (ii) a sample of starting spells, and (iii) a sample of ending spells. To minimize the impact of censoring, calculations have been made for the cross-sectional wave that lies in the middle of the respective observation period: June 1999 (wave 136) for Luxembourg, December 2004 (wave 72) for the Netherlands, December 2000 (wave 96) for Norway, and June 2005 (wave 54) for Sweden. All samples include short exits from benefits (as the 'standard sample' used for panel A of Table 9). The results are however robust to choosing different sampling waves and to ignoring short interruptions in benefit receipt.

Table 10. The length of benefit spells - stock vs. flow samples

\begin{tabular}{|c|c|c|c|c|c|}
\hline \multirow{2}{*}{ Country } & \multirow{2}{*}{ Sample type } & \multirow{2}{*}{ \# of spells } & \multicolumn{2}{|c|}{ Spell duration in months } & \multirow{2}{*}{ Censored spells in \% } \\
\hline & & & Median & Mean & \\
\hline \multirow{3}{*}{ Latvia } & stock & 1,398 & 6 & 8.1 & 1.4 \\
\hline & inflows & 487 & 5 & 6.3 & 1.4 \\
\hline & outflows & 214 & 2 & 2.3 & 0.0 \\
\hline \multirow{3}{*}{ Luxembourg } & stock & 4,573 & 102 & 112.0 & 31.3 \\
\hline & inflows & 105 & 17 & 41.1 & 9.5 \\
\hline & outflows & 143 & 19 & 28.7 & 4.2 \\
\hline \multirow{3}{*}{ Netherlands } & stock & 1,869 & 85 & 83.5 & 56.2 \\
\hline & inflows & 67 & 12 & 25.6 & 17.9 \\
\hline & outflows & 39 & 9 & 24.4 & 23.1 \\
\hline \multirow{3}{*}{ Norway } & stock & 6,534 & 8 & 17.1 & 1.2 \\
\hline & inflows & 1,953 & 2 & 4.4 & 0.2 \\
\hline & outflows & 1,572 & 1 & 3.1 & 0.1 \\
\hline \multirow{3}{*}{ Sweden } & stock & 96,133 & 15 & 26.1 & 12.4 \\
\hline & inflows & 14,821 & 2 & 4.5 & 0.8 \\
\hline & outflows & 19,770 & 2 & 5.4 & 1.0 \\
\hline
\end{tabular}

Note: Calculations are based on monthly administrative data from Luxembourg (FNS database, 1988-2010), the Netherlands (SSB, 1999-2010), Norway (FD-Trygd, 1993-2008), and Sweden (NBHW database, 2001-2009). Results for Latvia were produced by the World Bank (2013) based on GMI records for the years 2006-2011. Stock samples are samples of spells that are on-going in a given period $t$. Inflow and outflow samples are the samples of spells starting and ending in period $t$, respectively. All samples are for the wave in the middle of the observation period for the respective country to minimize the impact of censoring. This corresponds to June 2008 (wave 42) for Latvia, June 1999 (wave 136) for Luxembourg, December 2004 (wave 72) for the Netherlands, December 2000 (wave 96) for Norway, and June 2005 (wave 54) for Sweden. No correction has been made for short exits from benefit receipt.

Sources: see Table 5

Both median and mean spell durations in the stock samples of on-going spells are much longer than for samples of either inflows or outflows. The magnitude of this effect varies but is considerable for each of the five countries. The gap between mean durations is largest in Sweden, where the mean durations of ongoing spells in June 2005 was 26 months, while the average duration of spells starting in that month is less than one fifth of this (4.5 months). The gap between median durations is larger still: for the Netherlands, $50 \%$ of all on-going spells in December 2004 have lasted 85 months or longer, while median durations of spells that start and end in that same month are only 12 and 9 months, respectively. These numbers still underestimate the true size of the gap because a larger share of spells in the 'stock sample' are again censored. ${ }^{31}$

31 The stock sample suffers from both a right- and left-censoring problem, while the spells in the inflow or outflow sample can only be either right- or left-censored. 
The explanation for this striking result is that samples of on-going spells strongly oversample longer spells. ${ }^{32}$ Any inference on spell durations that is based on a sample of on-going spells will therefore produce estimates of the degree of long-term benefit dependence that are strongly upwards-biased. Claims like " $X \%$ of benefit recipients have been receiving benefits for more than one year" or " $Y \%$ of current recipients are long-term recipients" are therefore misleading, because they are based on the spell durations of people who are receiving benefits at a given point in time. The large share of long benefit spells among all ongoing spells by contrast correctly indicates that long-term recipients are responsible for the most significant part of benefit caseloads and thus of the expenditures for benefit payments in a given period (Bane and Ellwood, 1994).

\section{Repeat spells and time until re-entry}

An important question related to the length of benefit spells is whether individuals remain self-sufficient once they have stopped receiving benefits, or how long it takes until they return to benefit receipt. As seen, individual benefit spells in Latvia and the Nordic countries tend to be much shorter than in Luxembourg and in the Netherlands. However, benefit leavers might return to benefit receipt more quickly if they do not find a stable source of adequate income after leaving the benefit rolls. This subsection therefore studies the number of benefit spells per individual, and the time until re-entry.

In such an analysis, two difficulties arise in terms of sample selection: First, the number of observed benefit spells per individual and the time until a re-entry is observed depend on the length of the observation period. Calculations are therefore presented for both the entire observation period in each of the five countries as well as for the years 2001 to 2008 only, which can be done for four of the five countries. The second difficulty is that since the analysis is based on a sample from the working-age population, individuals enter the sample late (by turning 25 years old) or leave early (by turning 60). ${ }^{33}$ As a result, the number of spells per individual counted in the data will be an underestimate of what would be observed if the panel were 'balanced', i.e. if all individuals were observed in all periods. This second problem is addressed by restricting the sample to individuals who are at least 25 years old at the beginning of the observation period and younger than 60 years at its end. In other words, individuals who join the sample late or drop out early for age-related reasons are excluded. The resulting panel is balanced except for individuals who leave the data set due to migration or death. ${ }^{34}$

The hazard rates for re-entries into benefits among those non-recipients who previously ended a spell of SA receipt show a very similar pattern as the one observed for exit rates in Figure 10. In the two Nordic countries, exit rates are much higher in the early periods of a spell off benefits declining from around $25 \%$ in the initial months to $2-3 \%$ at 12 months and $1 \%$ at 24 months and thereafter. In Luxembourg and the

32 To see this, it helps to recall that the inflow, outflow, and stock samples used for the calculations in Table 10 represent only one possible set from a range of samples that could have been selected (there is one sample for each of wave of the observation period). Any non-censored spell is represented in only one inflow and one outflow sample, but is included in several separate stock samples depending on the spell's duration. A long spell will be included in many more stock samples than a shorter spell, which is equivalent to saying that each stock sample includes a disproportionately large number of long spells.

For Norway, even over the restricted observation period from 2001 to 2008, less than two-thirds of individuals in the sample are observed for the full 96 monthly waves; the average observation period is 76 waves or a bit above six out of the eight years.

Construction of a truly balanced panel is not possible because the data sets for Luxembourg and Sweden only provide information on individuals while they are on benefits. No information is available on whether an individual who does not receive benefits remains in the panel. 
Netherlands, re-entry rates of benefit leavers are only $6 \%$ per month already at the beginning of a spell off benefits and decline less strongly. 18 months after the end of a benefit spell, the re-entry hazard rates in all four countries have practically converged.

Figure 11. Hazard rates of re-entries into benefits

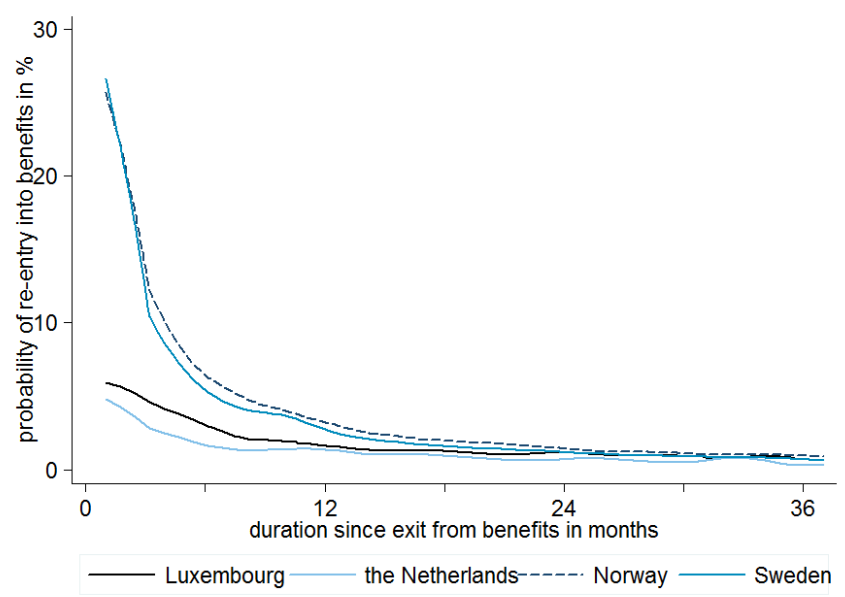

Source: Note: The hazard rate gives the probability of re-entering among benefit leavers after a given duration off benefits conditional on not having re-entered in an earlier period. For instance, in Norway, the monthly re-entry rate for individuals who reach the 4th month off benefits is just below $10 \%$.

Sources: see Table 5

Rapidly falling hazard rates from self-sufficiency back into benefits indicate that a large share of departures from SA only represent short interruptions, potentially as individuals seize short-term employment opportunities, or indeed as a result of administrative churning.

The differences in hazard rates shown in Figure 11 imply that the number of benefit spells per individual is inversely related to the duration of spells (Table 11). For Luxembourg and the Netherlands, countries with a significant fraction of long benefit spells, repeat spells are infrequent. Less than half of all individuals in Luxembourg who are observed for the entire observation period from 1988 to 2010 have more than a single spell. The corresponding share drops to $29 \%$ of all recipients for the restricted observation period from 2001 to 2008. In the Netherlands, $26 \%$ of recipients are observed as having multiple spells of the eightyear period from 2001 to 2008. This is comparable to the number presented by Snel et al. (2013), who report that $80 \%$ of recipients in Rotterdam only have one single spell over the seven-year observation period. In the two Nordic countries, by contrast, re-entries into SA are relatively frequent. Even over the restricted observation period from 2001 to 2008, more than two-thirds of benefit recipients have multiple spells and about one-third have five spells or more. The results for Latvia do not quite fit this pattern, because short spell durations coincide with a relatively low frequency of repeat spells.

Especially for the Nordic countries, the number of repeat spells drops considerably if short exits from benefit receipt are ignored. Even then, however, about half of all benefit recipients have at least two spells over the eight-year period, and a sizable minority of $11.4 \%$ of recipients in Norway and $6.9 \%$ in Sweden have five spells or more. 
Table 11. Number of benefit spells per individual

\begin{tabular}{|c|c|c|c|c|c|c|c|c|c|c|}
\hline \multicolumn{11}{|c|}{ Panel A - standard samples } \\
\hline \multirow{3}{*}{ Country } & \multicolumn{5}{|c|}{ Full observation period } & \multicolumn{5}{|c|}{ January 2001 - December 2008} \\
\hline & \multirow{2}{*}{$\begin{array}{c}\text { \# of } \\
\text { recipients }\end{array}$} & \multicolumn{2}{|c|}{ \# of spells } & \multicolumn{2}{|c|}{ Share of individuals with } & \multirow{2}{*}{$\begin{array}{c}\text { \# of } \\
\text { recipients }\end{array}$} & \multicolumn{2}{|c|}{ \# of spells } & \multicolumn{2}{|c|}{ Share of individuals with } \\
\hline & & Median & Mean & 2 spells & 5 spells & & Median & Mean & 2 spells & 5 spells \\
\hline Latvia & 22,451 & 2 & 2.2 & 55.3 & 9.2 & & & & & \\
\hline Luxembourg & 8,472 & 1 & 1.8 & 42.1 & 3.6 & 12,056 & 1 & 1.4 & 29.0 & 0.5 \\
\hline Netherlands & 3,116 & 1 & 1.5 & 32.2 & 1.5 & 2,572 & 1 & 1.4 & 25.9 & 0.5 \\
\hline Norway & 23,116 & 3 & 5.6 & 74.1 & 40.2 & 19,900 & 3 & 4.2 & 70.6 & 33.8 \\
\hline Sweden & 360,960 & 3 & 3.8 & 68.4 & 28.6 & 348,806 & 2 & 3.6 & 67.1 & 27.1 \\
\hline \multicolumn{11}{|c|}{ Panel B - ignoring short-term exits } \\
\hline \multirow{3}{*}{ Country } & \multicolumn{5}{|c|}{ Full observation period } & \multicolumn{5}{|c|}{ January 2001 - December 2008} \\
\hline & \multirow{2}{*}{$\begin{array}{c}\text { \# of } \\
\text { recipients }\end{array}$} & \multicolumn{2}{|c|}{ \# of spells } & \multicolumn{2}{|c|}{ Share of individuals with } & \multirow{2}{*}{$\begin{array}{c}\text { \# of } \\
\text { recipients }\end{array}$} & \multicolumn{2}{|c|}{ \# of spells } & \multicolumn{2}{|c|}{ Share of individuals with } \\
\hline & & Median & Mean & 2 spells & 5 spells & & Median & Mean & 2 spells & 5 spells \\
\hline Latvia & 22,451 & 1 & 1.4 & 29.0 & 0.5 & & & & & \\
\hline Luxembourg & 8,472 & 1 & 1.6 & 37.5 & 2.2 & 12,056 & $\ddot{1}$ & $\ddot{1.3}$ & 23.1 & 0.1 \\
\hline Netherlands & 3,116 & 1 & 1.4 & 28.0 & 0.6 & 2,572 & 1 & 1.3 & 21.2 & 0.1 \\
\hline Norway & 23,116 & 2 & 3.1 & 63.1 & 22.0 & 19,900 & 2 & 2.3 & 56.3 & 11.4 \\
\hline Sweden & 360,960 & 1 & 2.1 & 48.7 & 8.0 & 348,806 & 1 & 2.0 & 47.1 & 6.9 \\
\hline
\end{tabular}

Note: Calculations are based on monthly administrative data from Luxembourg (FNS database, 1988-2010), the Netherlands (SSB, 1999-2010), Norway (FD-Trygd, 1993-2008), and Sweden (NBHW database, 2001-2009). Results for Latvia were produced by the World Bank (2013) based on GMI records for the years 2006-2011. The sample is restricted to individuals aged at least 25 years at the beginning of the observation period (complete or restricted) and below 60 years at the end of the observation period (complete or restricted). '..' indicates that no results are available.

Panel A uses the standard sample while Panel B ignores exits from SA benefit receipt that last a maximum of two month. More specifically, spells that are interrupted by a period of non-receipt of 1-2 months are counted as continuous, but the interjacent period of 1-2 months off benefits is not counted towards the duration of the benefit spell. For example, two benefit spells of 4 months each that are interrupted by 2 months of non-receipt are thus counted as a single spell of 8 months. Spells are counted as censored if they extend to the last period of the respective observation period for the country.

Sources: see Table 5 
The negative cross-country relation between benefit spell lengths and the number of spells per individual could be purely mechanical. As individuals in the Netherlands and Luxembourg remain on benefits for longer, they will have less opportunity to return to benefit receipt over a limited observation period. Gustafsson et al. (2002), who obtain a similar result, are hesitant to attribute much relevance to it due to since their observation period of 48 months is very short. The greater spell numbers for recipients in Norway and Sweden reported in Table 11 are however consistent with the higher re-entry hazards for these countries presented in Figure 11. These hazard rates account for the right-censoring of spells and thus for the fact that individuals with very long spells may have less time remaining to re-enter before the end of the observation period.

To quantify differences in re-entry rates across countries, information on the share of benefit leavers who return to benefits is presented in Table 12. More specifically, these numbers give the proportion of SA leavers (with or without a repeat spell) who re-enter benefits within a certain interval after leaving conditional on not yet having reached the end of the observation period. ${ }^{35}$ The observation period is restricted to the years 2001 to 2008 to guarantee comparability across countries, which is why Latvia is not included in the table.

In Norway and Sweden, returns to benefits tend to happen relatively quickly, with over half of all benefit leavers returning into benefits within three months. This explains the earlier finding that ignoring short interruptions in benefit receipt has a much stronger impact on both measured spell durations and numbers in the Nordic countries. Only about $25 \%$ of benefit 'leavers' in these countries remain self-sufficient for at least the next two years. By contrast, only $10 \%$ of benefit leavers in the Netherlands return to benefits within three months and two-thirds of those who are observed for at least two years after leaving remain off benefits during that time. For Luxembourg, the numbers turn out to be very similar to those calculated by Hoynes (2000) for California, who reports re-entry rates into AFDC receipt of 23\% within the first 6 months, of $33 \%$ within 12 months, and of $41 \%$ within 24 months of leaving (page 355, Table 1).

Table 12. Time until re-entry

\begin{tabular}{ccccc}
\hline \multirow{2}{*}{ Country } & \multicolumn{4}{c}{ Share of social assistance leavers in \% who have re-entered... } \\
\cline { 2 - 5 } & within $\mathbf{3}$ months & within $\mathbf{6}$ months & within $\mathbf{1 2}$ months & within $\mathbf{2 4}$ months \\
\hline Luxembourg & 12.0 & 22.3 & 32.0 & 42.0 \\
Netherlands & 9.6 & 16.1 & 23.1 & 32.6 \\
Norway & 46.7 & 60.8 & 70.9 & 77.8 \\
Sweden & 48.6 & 60.3 & 69.2 & 75.2 \\
\hline
\end{tabular}

Note: Calculations are based on monthly administrative data from Luxembourg (FNS database, 1988-2010), the Netherlands (SSB, 1999-2010), Norway (FD-Trygd, 1993-2008), and Sweden (NBHW database, 2001-2009); The table gives the share of benefit leavers who return to benefit receipt within a certain time among those who have not yet reached the end of the panel at that time. Calculations refer to the period 2001-2008 where the observation periods for the four countries overlap.

Sources: see Table 5

In summary, the shorter benefit spell durations in Norway and Sweden coincide with a higher propensity to return into benefits. Moreover, a substantial share of re-entries into benefits in Sweden and Norway happen relatively quickly. Without full monthly income data, it is difficult to tell however whether these short interruptions in benefit receipt in the Nordic countries are the result of 'administrative churning', or whether individuals indeed gain self-sufficiency for short periods for instance by finding temporary work. Irrespec-

35 An individual who for instance leaves social assistance 10 months before the end of the observation period or before reaching the upper age threshold was only included in the calculations for columns II and III of Table 12, but not for columns IV and V. 
tive of this, the number of spells per individual is higher in the Nordic countries, even if short-term benefit interruptions of one or two months are ignored.

\section{Total duration of social assistance benefit receipt}

The results above suggest that turnover in benefit receipt is much higher in Norway and Sweden than in the Netherlands and Luxembourg, with benefit spells being substantially shorter and repeat spells more frequent. These results can be combined to give what is referred to as the 'total time on welfare' (Gottschalk \& Moffitt, 1994) or the 'net duration' of benefit receipt (Leisering \& Leibfried, 1999), i.e. the total time individuals spend on benefits across spells during the observation period. For better comparability across countries, the analysis is again restricted to the years 2001 to 2008 and based on a balanced panel. Results are presented in Table 13.

Table 13. Total duration of individuals' benefit receipt

\begin{tabular}{ccccccc}
\hline \multirow{2}{*}{ Country } & \multicolumn{5}{c}{ Average total duration of individual benefit receipt - years 2001 - 2008 } \\
\cline { 2 - 7 } & Median & Mean & $\mathbf{2}$ 3 months & $\mathbf{2}$ 6 months & $\mathbf{2 1 2}$ months & $\mathbf{2}$ 24 months \\
\hline Luxembourg & 32 & 39.8 & 95.3 & 88.7 & 76.3 & 59.5 \\
Netherlands & 23 & 36.3 & 89.9 & 79.9 & 65.6 & 49.6 \\
Norway & 7 & 16.5 & 73.6 & 56.0 & 39.2 & 23.6 \\
Sweden & 10 & 20.7 & 76.6 & 62.3 & 47.5 & 30.8 \\
\hline
\end{tabular}

Note: Calculations are based on monthly administrative data from Luxembourg (FNS database), the Netherlands (SSB), Norway (FDTrygd), and Sweden (NBHW database). The total period of benefit receipt corresponds to the cumulative time spent in SA across all spells that are observed to start during the years $2001-2008$. The sample is restricted to individuals aged at least 25 years at the beginning of the observation period and below 60 years at its end.

Sources: see Table 5.

For the majority of SA recipients in the two Nordic countries, total time spent on SA falls well short of one year over the eight-year observation period. Median net duration on benefits is seven months in Norway and ten months in Sweden. The proportion of benefit recipients who receive benefits for more than two years out of the eight-year period is $24 \%$ in Norway and $31 \%$ in Sweden.

In Luxembourg and the Netherlands, recipients generally depend on benefit payments for much longer: the median time spent on benefits is 32 months and 23 months, respectively. $60 \%$ of recipients in Luxembourg and half of recipients in the Netherlands remain on benefits for at least two years. The number for the Netherlands is again slightly lower than the one calculated by Snel et al. (2013), who report a median net benefit duration of 30 months over a period of seven years for Rotterdam. In spite of the fact that recipients in Norway and Sweden are more likely to have multiple benefit spells, the total time spent on benefits is hence considerably shorter in these countries.

\section{Characteristics of short- and long-term recipients}

To be able to specifically tailor policies at long-term recipients early in their benefit spells, benefit administrations and employment services need to identify the risk factors for long-term benefit receipt. As mentioned earlier, a shortcoming of the monthly data used in this section is unfortunately that the available information on the characteristics of benefit recipients is not very rich. This subsection breaks down groups of recipients with the longest and shortest benefit spells by individual characteristics in an attempt to char- 
acterize groups that are at greater risk of long-term benefit receipt. Specifically, the analysis considers recipients with spells in the bottom and top decile of the distribution in the respective country, and describes them in terms of available information on personal characteristics. The results of this analysis are presented in Table 14.

In the Netherlands and to a lesser degree in Luxembourg, women are more strongly represented among recipients who start spells with long durations. This result might be driven in part by a large share of single parents among long-term recipients. Interestingly, the gender pattern is reversed in Norway and Sweden, where, perhaps surprisingly, single parents are over-represented in the 'short spells' group. In Norway, this finding may again be linked to the fact that low-income single parents will typically receive Transitional Allowance rather than Social Economic Assistance. For Sweden, it is difficult to come up with a policyrelated explanation for this finding.

In Luxembourg, more senior individuals tend to remain on benefits for longer, with the share of over-55 year-olds being nearly twice as high among recipients in the top decile of spell durations compared to those in the bottom decile. In the other four countries, this pattern is however much weaker (in Latvia and the Netherlands) or even reversed (in Norway and Sweden).

Table 14. Characteristics of short- and long-term recipients

\begin{tabular}{|c|c|c|c|c|c|}
\hline & Latvia & Luxembourg & Netherlands & Norway & Sweden \\
\hline \multicolumn{6}{|l|}{ Proportion of females in $\%$} \\
\hline among recipients with short spells & 59.7 & 45.4 & 31.7 & 50.3 & 51.8 \\
\hline among recipients with long spells & 61.7 & 54.4 & 61.0 & 43.0 & 47.4 \\
\hline \multicolumn{6}{|l|}{ Proportion of single parents in $\%$} \\
\hline among recipients with short spells & .. & .. & 8.4 & 32.2 & 25.5 \\
\hline among recipients with long spells & .. & .. & 28.4 & 25.9 & 17.6 \\
\hline \multicolumn{6}{|l|}{ Proportion of over- 55 year-olds in \% } \\
\hline among recipients with short spells & 13.8 & 5.5 & 8.1 & 11.0 & 7.1 \\
\hline among recipients with long spells & 14.8 & 10.8 & 8.8 & 9.1 & 6.8 \\
\hline \multicolumn{6}{|l|}{ Proportion of immigrants in \% } \\
\hline among recipients with short spells & .. & $55.0^{*}$ & 36.6 & 15.4 & $23.0=$ \\
\hline among recipients with long spells & .. & $42.6^{*}$ & 54.9 & 33.2 & $52.8^{* x}$ \\
\hline
\end{tabular}

Note: Calculations are based on monthly administrative data from Luxembourg (FNS database, 1988-2010), the Netherlands (SSB, 1999-2010), Norway (FD-Trygd, 1993-2008), and Sweden (NBHW database, 2001-2009); short spells are defined are defined as those spells with a spell length in the lowest decile; long spells are those with a spell duration in the top decile; recipient characteristics are measured in the first period of the spell. * share of recipients without Luxembourg nationality; ${ }^{* \star}$ proportion of recipients living in households in which one of the adults was born abroad. '..' indicates that no results are available.

Sources: see Table 5

Immigrants or individuals with a foreign nationality are represented more strongly among recipients with long benefit spells. In Norway, the share of immigrants among recipients with spell lengths in the top decile is about twice as high than among those with spell lengths in the bottom decile. Similarly the share of recipients living in the household with an immigrant in Sweden is more than twice as high among recipients with long spells than among those with short spells. The gap for the Netherlands is smaller but still sizeable. The fact that the opposite is observed for Luxembourg may again be driven by strong residence requirements for the Luxembourg RMG. While these restrictions were relaxed at the beginning of the observation period in 2001, the share of non-Luxembourg benefit recipients has strongly risen over the observation period. This implies that most non-Luxembourg recipients have been on benefits for a shorter (and more recent) time period. 


\section{Implications and Limitations}

The drivers of cross-country differences in SA benefit dynamics are difficult to determine based alone on the administrative data used in this subsection. Some of the observed patterns are likely due to institutional features of the benefit systems, for instance the strictness of eligibility criteria or the availability of active labour-market programmes. Unfortunately, recent cross-country evidence on the design of social assistance policies is relatively rare (for an exception, see Immervoll (2012a)). Where SA is administered at the local level - as for instance in the Netherlands, Norway and Sweden - within-country policy variation can moreover be large.

One possible explanation for the longer duration of benefit receipt in Luxembourg and the Netherlands is the greater generosity of social assistance benefits. Figure 4 in Section 1 provides information on the level of minimum-income benefits compared to median household income. Benefit levels in Luxembourg and the Netherlands are among the highest in OECD countries, reaching up to around $40 \%$ of national median household income. In Norway and Sweden, where spell durations are much shorter, the income provided by SA is lower corresponding to only about $20 \%$ of median household income. While one should be careful when drawing conclusions based on such descriptive statistics, the positive relation between benefit generosity and the length of benefit spells may indicate that benefit recipients in Luxembourg and the Netherlands face weaker incentives to take up work.

The dynamics of social assistance benefit receipt may also be influenced by the design of the social safetynet more broadly. As a last resort-benefit, social assistance targets individuals who do not qualify (anymore) for higher-tier unemployment insurance or assistance benefits. Institutional features for instance of the unemployment benefit system, e.g. the maximum duration of unemployment insurance benefit receipt or the availability of unemployment assistance programmes, will therefore have a direct effect on transitions into social assistance.

Also the availability of alternative income-support programmes targeted at low-income individuals will affect the composition of the social assistance recipient population and thus spell durations. In Norway, low receipt rates and short spell durations for Social Economic Assistance certainly reflect the fact that low-income single parents typically qualify for the more attractive Transitional Allowance. Similarly, the Netherlands, Norway and Sweden all operate comprehensive disability benefit programmes. The share of social assistance recipients who suffer from problems of physical or mental health may therefore be lower than in Luxembourg, where no such benefits exist.

A more comprehensive interpretation of the results would require extending the analysis to other sources of data. The administrative data used in the present analysis are suited exceptionally well for studying spell durations. For more detailed insights on the composition of the recipient population, the analysis could be complemented with results from household survey data that usually provide much richer information on individual and household characteristics (see for instance the above-mentioned county studies by Cappellari \& Jenkins (2008a) for the United Kingdom or by Königs (2013a) for Germany). To be able to study interaction effects of SA with other benefit programmes, more extensive administrative data would be needed. Tseng, Vu, \& Wilkins (2008) illustrate the importance of taking into account recipients' transitions between different programmes using administrative data on various income-support programmes from the Australian Longitudinal Data Set (LDS). A similar analysis could be implemented with data from the Norwegian FD-Trygd (which for instance also cover Transitional Allowance, Housing Benefits and Unemployment Benefits) but not for the other four countries where comparable data are lacking. 


\section{Main findings from Section 3}

Some of the most interesting questions about the dynamics of SA receipt relate to the paths individuals take into and out of benefit receipt. Due to the limited availability of suitable individual-level panel data with frequent observations on benefit receipt, and despite considerable policy interest in benefit duration and 'dependence', relatively little is known about the length of SA benefit spells, the frequency of repeat spells, or how these patterns differ across recipient groups. Such information is however relevant for successful policy design (for instance for targeting activation measures). This section presents new empirical results on these issues.

- Durations of individuals' SA spells are frequently short, but they differ substantially both across countries and across recipients within a country:

- Typical benefit spells are short in Latvia, Norway and Sweden, where more than half of all spells last no-longer than two to three months.

- In the Netherlands and Luxembourg, by contrast, long-term benefit receipt is much more common, with half of the spells longer than 9 or 15 months, respectively.

- The incidence of very long benefit spell durations also differs strongly across countries. In Luxembourg, $38 \%$ of all benefit spells last longer than two years.

One-size-fits-all policies are unlikely to be effective for such a heterogeneous population. Instead, targeting and customising activation and employment support policies is likely to be key.

- As pointed out earlier by Bane and Ellwood (1994), measuring spell durations based on a sample of on-going spells at a specific point in time, as is often done, greatly overestimates the length of time spent on benefits, and produces a highly misleading picture of true spell durations. The reason is that the sample of on-going spells includes a disproportionately high number of very long spells. The data illustrate that for instance in the Netherlands, $50 \%$ of all on-going spells in December 2004 last 85 months or longer. By contrast, a more appropriate measure of spell durations shows a much smaller median of 12 months for all those starting a spell around this time.

- Multiple benefit spells are common, meaning that many of those leaving the benefit rolls do not remain self-sufficient in the longer term. The number of benefit spells per individual is inversely related to spell duration in that country. For Luxembourg and the Netherlands, where spell durations are longest, over two-thirds of recipients have only one single benefit spell over an eightyear period and less than $1 \%$ have five or more spells. In Latvia, Norway and Sweden, most recipients have multiple spells, with one-third of all recipients in Norway having 5 spells or more.

- Times in-between benefit spells tend to be short and benefit 'leavers' returning to benefit receipt tend to do so quickly: in Norway and Sweden, more than 50\% of benefit recipients who leave SA re-enter within the first three months. Even in Luxembourg, where repeat benefit receipt is much less common, $30 \%$ of benefit leavers return to benefits within the first year of leaving.

- When adding individuals' time spent on benefit across all spells, the median 'net' duration in Norway and Sweden is 7 and 10 months over an eight-year period, which is significantly longer than the duration of individual spells (median of 2 months). Despite a much greater incidence of multiple spells, the total time spent on benefits in Norway and Sweden is still substantially shorter than in Luxembourg (median 'net' duration of 32 months) and the Netherlands (median of 23 months) where repeat spells are infrequent. Over an eight-year period from 2001-2008, close to $60 \%$ of all benefit recipients in Luxembourg and nearly $50 \%$ of recipients in the Netherlands remain on benefits for 2 years or longer. In Norway and Sweden, the corresponding shares are $24 \%$ and $31 \%$ of all benefit recipients. 
- Based alone on data on social assistance receipt it is difficult to evaluate the drivers of observed cross-country heterogeneity in benefit dynamics. Disparities in spell lengths and re-entry rates may be due to differences in benefit generosity or the availability of in-work benefits; social assistance dynamics are likely impacted also, however, by features of the social security system more broadly such as unemployment benefit eligibility criteria or the availability of disability benefits for individuals with long-term health issues. A comprehensive analysis of social assistance dynamics requires data also on the receipt of other types of income-support that allow studying the interactions between different programmes. 


\section{State dependence in benefit receipt: Do past benefit spells make continued receipt more likely?}

It is commonly observed that rates of SA benefit receipt are greater for individuals who have received SA benefit in the past than individuals who have not, i.e. that receipt history matters. This is illustrated by the experience of Britain: The proportion of working-age individuals receiving SA in an average year during the 1992-2008 period was $71 \%$ among those who were receiving SA one year earlier, but only $2.4 \%$ among those who were not, a difference of 68 percentage points, or - put differently - a probability ratio of about 30 to $1 .^{36}$ Why does an individual's benefit receipt history have such a strong association with current receipt, and how should statistics such as these be interpreted? In particular, to what extent is the $o b$ served (or 'raw') state dependence in benefit receipt just described an indication that past SA receipt 'causes' future receipt? What are the policy implications? These are the questions addressed in this last section.

\section{Heterogeneity, genuine, and spurious state dependence}

Two sets of drivers can explain a strong association between benefit receipt in different periods. For a number of different reasons, receipt of SA benefits in the past may cause greater chances of receiving SA benefits in the future. Time out of work may lead to a deterioration in an individual's skills or provide an adverse signal to potential employers about the person's employability. A spell of receipt may change people's attitudes to work and the lack of money or deteriorating physical or mental health may reduce their ability to search effectively for a job. Reports in the media also refer to a possibility of attitudinal changes in the form of a 'benefit culture' which might develop through social multiplier effects in communities where benefit receipt is common. These drivers of genuine state dependence in benefit receipt are discussed at length in Section 4.3.

Observed differences in benefit receipt rates for past recipients and non-recipients are however misleading about genuine state dependence. Certain types of individuals are more likely to have a history of previous benefit receipt than others, and these characteristics tend to persist over time. The association between past and present benefit receipt just described therefore at least in part reflects a cross-time correlation of characteristics rather than the effects of benefit receipt. For example, previous studies show that individuals with few educational qualifications are more likely to receive SA than more qualified individuals, and education levels do not change over time for most working-age people. Unobserved characteristics - i.e. traits that are not measured in micro-data or that are intrinsically unobservable (for example 'ability') - can have a similar effect. In technical terms, the share of observed state dependence that can be attributed to persistent observed and unobserved heterogeneity is referred to as spurious.

The aim of econometric modelling is to provide a quantitative estimate of the extent to which observed state dependence is genuine rather than spurious. The model that is most commonly used in recent studies of benefit receipt is the dynamic random-effects probit (DREP) model. This model can be explained as follows.

Let the latent (i.e., unobserved) propensity of SA receipt by each individual $i=1, \ldots, N$ in each year $t$ of the sequence of $T_{i}$ years for which each $i$ is observed, excluding the first year $(t=1)$, be described by:

$$
p^{*}{ }_{i t}=\gamma^{\prime} Z_{i t-1}+\lambda y_{i t-1}+\tau_{i}+\zeta_{i t} ; \quad t=2, \ldots, T_{i .}
$$

36 The transition rates cited refer to the entry rate and one minus the exit rate as presented for the UK in Table 8 . 
If $p^{*}>0$, individual $i$ receives SA in year $t$, i.e. $y_{i t}=1$. If $p^{*}{ }_{i t} \leq 0$, individual $i$ does not receive SA: $y_{i t}=0$.

Equation (1) states that the likelihood that an individual is observed to be receiving SA in a given year depends on three main factors:

- observable characteristics included in $Z_{i t-1}$, some of which may vary across time, with the effect size of the different characteristics captured by the elements of the coefficient vector $\gamma$; covariates typically consist of a selection of individual characteristics (sex, age, migrant status, educational attainment, health status), household characteristics (household size, family type, a control for small children in the household), spouse characteristics, and possibly a control for variations in the economic conditions across regions and over time, e.g. the regional unemployment rate;

- unobserved individual factors characterised by an individual-specific component that is fixed over time $\left(\tau_{i}\right)$ plus a random idiosyncratic error component $\left(\zeta_{i t}\right)$. These two (error) terms are assumed to be uncorrelated with each other and with the explanatory variables included in $Z_{i t-1}$, and each component is assumed to have a mean of zero and be normally distributed (which makes the DREP a probit model), with the variance of $\zeta_{i t}$ normalised to equal one. The variance of $\tau_{i}$ is estimated from the data;

- past benefit receipt, specifically whether SA was received in the previous year or not, with the effect size related to the size of the parameter $\lambda$ (more on this shortly). The specification given in Equation (1) implicitly assumes that only receipt in the previous period matters and not receipt in earlier years. This 'first-order Markov' assumption is commonly used in the empirical work to date (see Annex 4.A).

A complication is that individuals whose unobserved characteristics make them more prone to receive SA, other things being equal, are more likely to receive SA also in the first year in which they are observed: $y_{i 1}$ is likely to be correlated with the unobserved factor $\tau_{i}$. This 'initial conditions' issue will lead to biased estimates of the relative roles played by heterogeneity and genuine state dependence unless it is appropriately controlled for. Three main methods have been devised for taking account of the initial conditions problem by Heckman (1981b), Orme (2001), and Wooldridge (1995). Which method is used appears to make little difference as long as individual histories of SA receipt are reasonably long. For further details, see Akay (2012), Arulampalam and Stewart (2009), and Cappellari and Jenkins (2008a).

Assuming that Equation (1) and the accompanying specification of the initial conditions are appropriate characterisations of benefit receipt histories, there is a clear distinction between the effects of heterogeneity on the one hand, summarised by parameters $\gamma$ and the variance of $\tau_{i}$, and genuine state dependence on the other hand, summarised by the parameter $\lambda$. A statistical test of whether past SA receipt affects current receipt is based on whether the sample estimate of $\lambda$ differs significantly from zero. In practice, such tests are not particularly informative, since researchers invariably find that estimates of $\lambda$ are positive and differ significantly from zero. Of greater interest is the magnitude of the state dependence effect, which however is difficult to evaluate directly due to the non-linear form of the model.

The aim is therefore to produce a measure with a metric that is more interpretable than the coefficient estimate itself, and that can be compared with 'raw' estimates of state dependence that do not take account of heterogeneity. Recall that the magnitude of the 'raw' state dependence (RSD) effect is the difference between the SA receipt rate for individuals who received SA one year earlier and the receipt rate for nonrecipients one year ago (68 percentage points in the British example cited earlier). Put differently, this is the difference between the SA persistence rate (for past recipients) and the SA entry rate (for past nonrecipients). These 'raw' rates are averages across recipients and non-recipients, respectively, and do not take account of differences in characteristics between these groups. 
The magnitude of genuine state dependence in contrast is defined to be the difference between $(i)$ the SA persistence rate were all individuals to have received SA last year, and (ii) the SA entry rate were all individuals not to have received SA last year. To arrive at this difference, persistence and entry probabilities are predicted for each individual using the estimated model and then averaged across all individuals. Using the model estimates ensures that individual heterogeneity is accounted for in the predictions; averaging predictions across individuals ensures that the aggregate transition rates take account of the distribution of characteristics in the sample.

More formally, for the model described by Equation (1), the SA entry probability for a non-recipient at $t-$ $1, e_{i t}$, can be shown to be equal to

$$
e_{i t} \equiv \operatorname{Pr}\left(y_{i t}=1 \mid y_{i t-1}=0, Z_{i t-1}\right)=\Phi\left[\left(\gamma^{\prime} Z_{i t-1}\right)(1-\rho)^{0.5}\right] \text {. }
$$

Similarly, the SA persistence probability for a non-recipient at $t-1, s_{i t}$, is

$$
s_{i t} \equiv \operatorname{Pr}\left(y_{i t}=1 \mid y_{i t-1}=1, Z_{i t-1}\right)=\Phi\left[\left(\lambda+\gamma^{\prime} Z_{i t-1}\right)(1-\rho)^{0.5}\right],
$$

where $\Phi(\cdot)$ is the standard normal cumulative distribution function and $\rho=\sigma_{\tau}^{2} /\left(1+\sigma_{\tau}^{2}\right)$ is the fraction of the variance of unobservable factors that is attributable to variation in the time-invariant individual effects.

The estimated degree of genuine state dependence is measured by the average partial effect (APE)

$$
A P E=(1 / N) \Sigma_{i}\left(s_{i t}-e_{i t}\right),
$$

where model parameters are replaced by their sample estimates and it is then averaged over the $N$ sample members. In econometric terms, the expression for genuine state dependence is the average partial effect (APE) of parameter $\lambda$. An alternative measure summarizes state dependence in relative rather than absolute terms. The predicted probability ratio (PPR) is defined as

$$
P P R=(1 / N) \sum_{i} s_{i t} /(1 / N) \sum_{i} e_{i t}
$$

Since APE and PPR are calculated from the estimated model parameters and averaged over all individuals in the (sub-) sample, they are largely unaffected by observed and observed heterogeneity across the individuals in the sample. For this reason, they are useful measures to evaluate the degree of genuine state dependence and to make comparisons across subsamples within countries, across countries and over time. ${ }^{37}$

\section{Estimates of the degree of state dependence, spurious and genuine}

This subsection illustrates the concepts discussed so far, focusing on estimates from studies for six countries (Britain, Canada, Germany, the Netherlands, Norway, and Sweden) while briefly referring to some related studies as well. (For an additional study of Sweden estimates of state dependence could have been included if they had been provided in the form required.) The reason for discussing only six studies is that the number of studies of state dependence in SA receipt is quite small. The coverage of the field pro-

37 The APE (and PPR) are sometimes evaluated by plugging the sample mean values of the $Z_{i t-1}$ into (2) and (3) rather than each individual's values: see Stewart (2007: 522). In the working-paper version of a study on state dependence in social assistance receipt in Canada cited below, Hansen, Lofstrom, and Zhang (2006) evaluate the APE using the characteristics of one "representative household'. 
vided in this analysis is thus relatively good. The studies discussed are comparable in the sense that all of them use a DREP model or a close relative to examine receipt dynamics and state dependence, all of them control for initial conditions appropriately, and all of them use broadly similar definitions of SA. For a more detailed discussion of comparability issues between studies, see the Annex 4.A. All six studies focus on adults of 'working age', albeit defined slightly differently in each study. To be included in the overview, each study also had to provide estimates of spurious and genuine state dependence as defined in the previous section, or report statistics that made it possible to derive such figures. In every study discussed, the estimate of the coefficient on lagged SA receipt $(\lambda)$ is precisely estimated relative to conventional benchmarks of statistical significance.

The six studies and their estimates of state dependence are summarised in Table 15 below. The notes to the table provide some additional details about each study, including about model specification and definitions of the SA variable. Again, these aspects are discussed in more detail in Annex 4.A. All studies cover the 1990s, and also some of the 2000s, though to a varying extent. For Britain and Canada, estimates are available only for all working-age adults; for Germany, there are also estimates derived for men and women and for natives and migrants separately. The study for the Netherlands provides estimates for natives, other EU-born and non-EU-born individuals as well as for all individuals. For Norway, there are estimates based on three definitions of SA that include different benefit types. For Sweden, estimates are available for six groups of recipients defined by sex, migrant / refugee status, and country of birth. Since native-born men and women form the vast majority of the Swedish population, and since APE and PPR are calculated for the entire sample and not just the sample of benefit recipients, the state dependence estimates for all adults can be expected to be close to the estimates for these two groups. For Canada and Germany, the cited studies also provide regional breakdowns of the level of state dependence, but these numbers are not included in Table 15.

The British statistics for raw state dependence in the first row of the table correspond to those cited earlier for a slightly shorter observation period (Cappellari and Jenkins, 2008a). The degree of genuine state dependence is substantially smaller than of raw state dependence. The APE is around 14 percentage points (rather than 63 percentage points) and the PPR is 4 (rather than 27). Put another way, genuine state dependence is only around one fifth of raw state dependence $(22.8 \%=14.4 / 63.1)$. At the same time, not all of observed dependence is spurious: APE $>0$ and PPR $>1$.

Similar patterns are apparent for the other countries, that is, the degree of state dependence is substantially smaller than the degree of raw dependence, but still clearly positive. The results for Germany, presented by Königs (2013a), are strikingly close to those for Britain, with estimated levels of raw and genuine state dependence of 65 and 14 percentage points, respectively. By contrast, levels of state dependence reported for Canada by Hansen, Lofstrom, Liu, and Zhang (2014) are substantially higher: The difference between observed year-to-year persistence and entry rates is around 80 percentage points, which corresponds to a factor of 43. Once observed and unobserved heterogeneity is controlled for, benefit receipt in the previous period is associated with an increase in the probability of benefit receipt in the current period by 35 percentage points. Similarly, Königs' (2013b) study for the Netherlands reports an estimated degree of genuine state dependence that is markedly larger (the APE for all working-age individuals is around 28 and the PPR around 7).

One potential explanation for the much higher levels of state dependence, both raw and genuine, in the studies for Canada and the Netherlands is the different method used for defining the SA variable: Rather than to measure benefit receipt at one point in time each year, Hansen et al. (2014) and Königs (2013b) model benefit receipt at any time during the year (i.e., a person is counted as a benefit recipient in year $t$ if they have received SA at any point during the year). As discussed in Section 2, this approach may be necessary due to the limitations of the available data, and generally leads to higher rates of benefit receipt and a stronger degree of measured persistence in benefit receipt over time. For Norway, Bhuller, Brinch and 
Königs (2014) illustrate that using a 'benefit year' approach to defining the SA variable also leads to higher levels of estimated state dependence than when benefit receipt is measured at one single time each year.

The estimates reported in Table 15 also highlight that the magnitude of state dependence is itself heterogeneous, varying across groups within a country. (For a more detailed discussion of this issue, see the notes on the different approaches to modelling heterogeneity in the Annex 4.A.) For Germany, Königs (2013a) finds that the magnitude of genuine state dependence is slightly larger for women than for men (an APE of 15 compared to 13). Interestingly, the reverse is the case in in the Netherlands and Sweden, where genuine state dependence is lower for women than for men: For example, Hansen and Lofstrom (2011) calculate that the APE for native-born Swedish men is just over 6; for native-born Swedish women, the APE is 4.6. The lower state dependence among women compared to men in Sweden may be one explanation for their shorter spell durations reported in Table 14 of Section 3.

The German and Swedish estimates also reveal substantial differences in state dependence related to nativity and refugee status. In Germany, state dependence among migrants is nearly twice as high among migrants than among natives (APEs of 23 vs. 12 ppts). In Sweden, for both men and women, the APE for native-born individuals is substantially lower than the APE for refugee foreign-born individuals, with that for non-refugee foreign-born people in between. ${ }^{38}$

By contrast, Königs' (2013b) finds a much smaller difference in state dependence between native-born individuals and others in his study for the Netherlands. The APE for non-EU-born and for natives is 28, while that for other-EU-born individuals is 35 . The smaller cross-group gradient may be a reflection of the composition of the immigrant population in the Netherlands compared to Sweden. A recurrent finding for instance is that state dependence is stronger for more disadvantaged groups; a higher immigrant-native gap in state dependence for Sweden compared to the Netherlands might therefore result from a large share of more disadvantaged migrants (e.g. asylum seekers) in the population, or greater access of such groups to SA benefits.

There is moreover evidence of geographical variation in state dependence within countries (not shown). Hansen et al. (2014) demonstrate that genuine state dependence differs considerably across Canadian provinces, with the APE varying between 22 percentage points in British Columbia and 47 percentage points in Quebec. The authors suggest that state dependence may be higher in provinces where the benefit system is more generous. Königs (2013a) finds that state dependence is about twice as high in Eastern Germany compared to Western Germany (when measured in absolute terms) even once differences in the regional unemployment rate are controlled for.

There is also a gradient across groups in terms of the fraction of raw state dependence that is accounted for by genuine state dependence (APE). For native-born Swedish men, the proportion is $10 \%$ (and thus around half the corresponding German statistic), for non-refugee foreign-born men it is $21 \%$, and a massive $45 \%$ for refugee foreign-born men. Among Swedish women, there is a similar gradient but the fractions are smaller.

Confirmation of the differences in state dependence for native and foreign Swedes is provided in a more recent study by Andrén and Andrén (2013) who fit a variant of the basic DREP model to the two groups separately using administrative data for the years 1991-1999. Estimates of $\lambda$ are substantially larger for foreign-born Swedes than native-born Swedes, and the authors report "marginal effects' of 12.5 percentage points and 4.1 percentage points for the former and the latter group, respectively (2013: Tables 2 and 3). Their marginal effect calculation is related to but not the same as the standard APE calculation, which is why the results are not included in Table 15 (see footnote 11 in Andrén and Andrén (2013) for the authors' definition of a marginal effect). 
Table 15. Estimates of raw and genuine state dependence in SA receipt in selected OECD countries

\begin{tabular}{|c|c|c|c|c|c|c|c|}
\hline \multirow{2}{*}{ Study } & \multirow{2}{*}{ Country } & \multirow{2}{*}{ Period } & \multirow{2}{*}{$\begin{array}{c}\text { Group } \\
\text { (adults of working age) }\end{array}$} & \multicolumn{2}{|c|}{$\begin{array}{c}\text { Raw state } \\
\text { dependence }\end{array}$} & \multicolumn{2}{|c|}{$\begin{array}{l}\text { Genuine state } \\
\text { dependence }\end{array}$} \\
\hline & & & & $\begin{array}{c}\text { RSD } \\
\text { (ppts) }\end{array}$ & PPR & $\begin{array}{l}\text { APE } \\
\text { (ppts) }\end{array}$ & PPR \\
\hline $\begin{array}{l}\text { Cappellari and Jenkins } \\
\text { (2008a) }\end{array}$ & Britain & $\begin{array}{l}1991- \\
2005\end{array}$ & all & 63.1 & 27.1 & 14.4 & 4.0 \\
\hline $\begin{array}{l}\text { Hansen, Lofstrom, Liu, } \\
\text { and Zhang (2014) }\end{array}$ & Canada & $\begin{array}{l}1993- \\
2010\end{array}$ & all & 80.2 & 43.2 & 35.4 & 12.1 \\
\hline \multirow[t]{2}{*}{ Königs (2013a) } & \multirow[t]{2}{*}{ Germany } & \multirow[t]{2}{*}{$\begin{array}{l}1995- \\
2011\end{array}$} & all & 65.0 & 21.0 & 14.1 & 3.3 \\
\hline & & & $\begin{array}{l}\text { women } \\
\text { men } \\
\text { natives } \\
\text { migrants }\end{array}$ & $\begin{array}{l}66.2 \\
63.5 \\
65.2 \\
63.6\end{array}$ & $\begin{array}{l}20.6 \\
21.3 \\
23.9 \\
12.8\end{array}$ & $\begin{array}{l}15.1 \\
12.6 \\
11.9 \\
23.2\end{array}$ & $\begin{array}{l}3.2 \\
3.2 \\
3.1 \\
3.4\end{array}$ \\
\hline \multirow[t]{2}{*}{ Königs (2013b) } & \multirow[t]{2}{*}{ Netherlands } & \multirow[t]{2}{*}{$\begin{array}{l}1995- \\
2009\end{array}$} & all & 82.1 & 43.6 & 28.3 & 7.3 \\
\hline & & & $\begin{array}{l}\text { women } \\
\text { men } \\
\text { Dutch-born } \\
\text { other EU-born } \\
\text { non-EU-born }\end{array}$ & $\begin{array}{l}84.9 \\
79.5 \\
79.5 \\
83.8 \\
84.9\end{array}$ & $\begin{array}{l}43.1 \\
43.6 \\
52.7 \\
27.1 \\
16.2\end{array}$ & $\begin{array}{l}27.8 \\
30.3 \\
27.7 \\
35.3 \\
27.5\end{array}$ & $\begin{array}{l}7.7 \\
6.9 \\
7.9 \\
6.1 \\
7.5\end{array}$ \\
\hline \multirow[t]{3}{*}{$\begin{array}{l}\text { Bhuller and Königs } \\
\text { (2011) }\end{array}$} & \multirow[t]{3}{*}{ Norway } & \multirow[t]{3}{*}{$\begin{array}{l}1993- \\
2008\end{array}$} & receiving SEA & 62.9 & 42.0 & 9.8 & 4.7 \\
\hline & & & receiving SEA, or TA & 66.8 & 40.6 & 17.6 & 7.5 \\
\hline & & & $\begin{array}{l}\text { receiving SEA, TA, or } \\
\text { HA }\end{array}$ & 74.0 & 50.0 & 20.5 & 7.6 \\
\hline \multirow[t]{6}{*}{$\begin{array}{l}\text { Hansen and Lofstrom } \\
\text { (2011) }\end{array}$} & \multirow[t]{6}{*}{ Sweden } & \multirow[t]{6}{*}{$\begin{array}{l}1991- \\
2001\end{array}$} & men: native-born & 61.3 & 56.7 & 6.2 & 5.4 \\
\hline & & & $\begin{array}{l}\text { men: non-refugee for- } \\
\text { eign-born }\end{array}$ & 62.8 & 24.3 & 12.9 & 4.0 \\
\hline & & & $\begin{array}{l}\text { men: refugee foreign- } \\
\text { born }\end{array}$ & 66.3 & 13.5 & 29.8 & 4.2 \\
\hline & & & women: native-born & 60.2 & 67.9 & 4.6 & 4.5 \\
\hline & & & $\begin{array}{l}\text { women: non-refugee } \\
\text { foreign-born }\end{array}$ & 58.2 & 35.8 & 7.6 & 3.8 \\
\hline & & & $\begin{array}{l}\text { women: refugee foreign- } \\
\text { born }\end{array}$ & 68.6 & 30.8 & 21.7 & 6.7 \\
\hline
\end{tabular}

Notes and Sources: 'ppts': percentage points. RSD, PPR and APE are defined in the main text. In all studies, estimates of raw state dependence were derived by pooling transitions from each year over full period (for Bhuller and Königs (2011) no such numbers had been reported in the original paper). Genuine state dependence was obtained using a basic DREP model estimated separately by subsample where applicable; Hansen and Lofstrom (2011) assume a random-effects logit (rather than probit) structure, Hansen and Lofstrom (2011) and Hansen, Lofstrom, Liu and Zhang (2014) assume mass-point rather than normal unobserved time-invariant heterogeneity. APE and PPR are (within-sample) averages.

Cappellari and Jenkins (2008a: 45): British Household Panel Survey, SA receipt measured at date of annual interview, all individuals in a family counted as recipients if at least one person in the family receives SA.

Hansen, Lofstrom, Liu and Zhang (2014: Tables 2 \& 5): Survey of Labour and Income Dynamics, SA receipt measured in terms of 'benefit year' (receipt counted for year if receipt within any month of the year by any member of the household).

Königs (2013a: Figures 2-3 and 5; Tables 3, 7-8, 11-12): German Socio-Economic Panel, SA receipt measured at date of annual interview, all individuals in a household counted as recipients if at least one person in the household receives SA.

Königs (2013b, Figures 4 \& 5, Tables 5-7): Income Panel Study, SA receipt measured in terms of 'benefit year' (see above).

Bhuller and Königs (2011: Figure 9, Table 9): FD-Trygd linked administrative record data set, SEA, Social Economic Assistance; TA, Transitional Allowance for Single Parents; HA, Housing Allowance. SA receipt measured in terms of 'benefit year' (see above).

Hansen and Lofstrom (2011: Table 3): LINDA linked administrative record data set, SA receipt measured in terms of 'benefit year' (see above), receipt of SA based on benefit payments recorded for the sampled individual. 
The Norwegian estimates highlight the potential importance of the definition of 'social assistance' for estimates of the degree of state dependence. Moving down the three rows for Norway in the table corresponds to a broadening of the definition - which raises not only the number of people in receipt of 'SA' at any point in time, but also the number of different groups of people who receive benefits, and the likelihood that somebody is counted as a recipient in successive periods. In particular the Transitional Allowance (TA) is for lone parents only and it is probably this factor which explains why the estimates of APE and PPR are larger for the broader second and third definitions of SA.

In sum, and taking the estimates from the studies discussed at face value, it is clear that there is genuine state dependence that exists over and above the spurious state dependence that is attributable to observed and unobserved differences across individuals. Moreover state dependence varies across groups within national populations, with a tendency for greater dependence for groups typically seen as more disadvantaged (e.g. lone mothers, immigrants, etc.) though the results for the Netherlands caution against overgeneralisation.

Annexes 4.A and 4.B provide a discussion of a number of issues concerning the reliability of these conclusions. While some of the potential complications that are mentioned may lead one to question the magnitude of particular estimates, they are unlikely to change the headline result that genuine state dependence is an empirical reality.

\section{Policy implications}

The previous subsection showed that there is strong evidence of genuine state dependence in SA receipt and provided some illustrations of estimates. If a period of SA receipt in the past causes current receipt, one of the first questions is for the behavioural mechanisms that underlie this link. Knowing these would presumably help the targeting and formulation of relevant measures. From what is currently known, there are a number of candidate mechanisms, but it is hard to pin down their specific contributions.

It is difficult to be specific for two reasons. First, state dependence in SA receipt that is identified by DREP models may reflect the impact of one or more of several types of dependence effects: The type of relation modelled in Equation (1), where current benefit receipt depends on the benefit receipt status in the previous period (and possibly a number of earlier periods) is referred to as Markovian state dependence. The probability of benefit receipt might however also be related to the duration of the current spell ('duration dependence': with increasing benefit duration, recipients may become more likely to remain a recipient), an individual's number of previous spells ('occurrence dependence': with increasing previous number of spells, recipients may become more likely to remain a recipient), or even the duration of a previous spell that has ended ('lagged duration dependence': e.g., with increasing benefit duration at a younger age, recipients may become more likely to remain a recipient). Annex 4.A. discusses the problems of distinguishing between Markovian state dependence and duration dependence given the nature of data that are currently available. The data issue needs to be stressed. Heckman and Borjas (1980) and Heckman (1981c) set out strategies for discerning between different types of dependence, but their methods rely on richer longitudinal data than are typically available for SA histories. For a recent analysis of duration and occurrence dependence in social assistance in Norway, see Bhuller, Brinch and Königs (2014). ${ }^{39}$

39 There exists another, more subtle identification problem: Observe that the basic DREP model for SA receipt summarised by Equation (1) is observationally equivalent to a basic DREP for SA non-receipt with lagged non-receipt as an explanatory variable instead of lagged receipt. The estimate of $\lambda$ may therefore partially reflect duration dependence in non-receipt, i.e. the fact that non-receipt probabilities maybe tend 
Rather than to link particular behavioural mechanisms with particular types of dependence, the literature to date has provided rather general explanations of 'why past receipt matters', and these explanations could be applied, e.g. to either duration dependence or Markovian state dependence. Also the review of potential mechanisms and their policy implications provided below is therefore relatively broad brush. Being able to attribute different behavioural mechanisms to each of the different types of dependence may not be feasible in any case, although it would clearly be of interest for policy purposes. Operationalising the measurement of 'duration dependence', and distinguishing it from state dependence, could help pin down policy-relevant 'threshold' values for spell durations. For instance, knowing the amount of time different groups of people can spend on benefits before 'scarring' effects become sizeable would enable policy makers to optimise the design and timing of interventions during the benefit spell.

The second reason preventing specific attribution is that, for working-age individuals, there is a close association between being 'in receipt of SA' on the one hand, and being 'unemployed', 'low paid', or 'poor' on the other hand. Whether an individual receives SA is the result of an administrative decision about eligibility where, by definition, eligibility depends on the income of the claimant's family or household. Low income arises from low pay or especially unemployment. Also, SA benefit levels in most countries would give SA recipients an income lower than or similar to the official poverty line, so most SA recipients are also poor (see Section 1). Furthermore, eligibility for SA also depends on household size and composition, so there may also be a role played by demographic changes. It is difficult to disentangle the extent to which state dependence in SA receipt reflects dependence in these other domains (with associated policy implications), and whether there are (also) factors associated with past SA receipt alone $?^{40}$

For working-age individuals, state dependence in unemployment is an obvious source of state dependence in SA receipt. Several reasons have been advanced for it, including: ${ }^{41}$

- Being without a job can mean that a worker's existing training, educational skills and experience ('human capital') may lose their labour market value and opportunities to update them on the job are unavailable. These effects in turn increase the likelihood of future unemployment. An analogous argument can be made for jobseeker's job readiness in terms of physical or mental health.

- State dependence may arise if employers screen potential employees on the basis of their unemployment histories (over and above other characteristics such as their education and skills). Past unemployment provides a cheap signal to employers regarding low labour productivity, with adverse consequences for the individuals concerned. (Evidence about such signalling is provided in a US field experiment by Kroft, Lange and Notowidigdo, 2013.) This aspect may be hard to distinguish from state dependence in low pay if there is significant cycling of workers between low pay and unemployment, and low-waged jobs - in addition to unemployment - do not maintain or enhance workers' human capital, or are used as a screening device by employers. ${ }^{42}$

to be greater, the longer the spell of non-receipt. The factors influencing duration dependence in nonreceipt however need not be the same as the factors influencing duration dependence in receipt.

These questions have been emphasised by Contini and Negri (2007). They use simulation evidence to demonstrate that "negative duration dependence in the exit rate from welfare may arise in environments where no corruptive effects of benefits are at work ... the observed pattern may be due to the effects of persistence in poverty or in unemployment" (2007: 21).

See inter alia Heckman and Borjas (1980), Arulampalam, Booth, and Taylor (2000), and Stewart (2007), and references therein.

See Stewart (2007). 
- It has been suggested that individuals' preferences change with the experience of unemployment: "individuals in unemployment may lower their reservation wage with the passage of time, and accept poorer quality jobs that are more likely to be destroyed, and for this reason may be more likely to experience unemployment in the future" (Arulampalam, Booth, and Taylor, 2000: 26).

- Effective intensive job search may be reliant on financial expenditure in addition to investments of time. Because unemployment leads to a substantial running down of financial assets and savings, past unemployment may affect the chances of finding re-employment possibilities. A similar argument can be made relative to health problems that may develop or worsen when people are without work or poor.

Arguably, the driver in the third and fourth cases might be poverty rather than unemployment (Contini and Negri, 2007) - in other words, it is a lack of economic resources more generally that can lead to poor quality jobs being taken or compromises effective job search.

Additional explanations for the change in preferences underlying a lowering of reservation wages over time might be what Bane and Ellwood (1994: Chapter 4) refer to as "expectancy" and "cultural" theories of dependence. In the context of the labour market, the former would refer to the adverse impacts of unemployment on individuals' confidence and feelings of self-control, motivation, and self-esteem which then have adverse effects on job-finding. (There might also be a deleterious feedback loop from lack of job finding to psychological factors.) The cultural theory refers to peer or neighbourhood effects, i.e. the idea that social groups can have powerful norms, which individuals within the group would find it difficult to deviate from. Thus, being unemployed among many unemployed people may be normal; getting a regular job may be abnormal. So, social pressures of various kinds may lead people to change their attitudes if they become unemployed.

As Bane and Ellwood (1994) comment, these sorts of arguments have greatest plausibility in the context of 'ghettos', i.e. communities with highly elevated concentrations of disadvantage. But even then it is difficult to claim even in principle that it is unemployment that is the principal driver, since ghettos are locations with an intense concentration of disadvantage of various kinds, including poverty and low paid work as well as unemployment and benefit receipt. ${ }^{43}$ It may be a neighbourhood culture of poverty or of benefit receipt, rather than or as well as unemployment which changes preferences. A different type of social group effect of unemployment might be its adverse impact on the size and nature of the circle of social contacts that help people find out about jobs or to get them. These effects are more likely the result of unemployment if the relevant contacts are typically found in a work environment; otherwise arguably similar effects might arise from a lack of income to afford to socialise.

Most of the discussion in this section has assumed that getting a job is the route off SA receipt. But so too may be living with someone if the combined family income is high enough to remove eligibility. The argument in reverse is that experience of welfare dependence or unemployment may reduce (re)partnering rates and hence raise the chances of future benefit dependence. This is mainly a US discussion concerning lone mothers: see e.g. Bane and Ellwood (1994), Blank (1989), Sandefur and Cook (1998). It is less likely to be relevant in Europe given that a large fraction of SA recipients live in marital partnerships.

There is little in the discussion so far to suggest that receipt of SA itself, rather than a history of unemployment (or low paid work) or poverty, is responsible for the observed state dependence in SA. However, one effect that clearly relates to the receipt of SA or related benefits is the possibility of significant finan-

$43 \quad$ Bane and Ellwood (1994) were discussing the reason for 'welfare dependence' in 1980s USA when the principal welfare (SA) benefit was Aid for Families with Dependent Children. AFDC recipients were mostly black lone mothers. 
cial work disincentives created by a combination of income testing and weak activation measures. When such disincentives exist, they can make it financially unattractive to take up or look for a paid job. Work disincentives would then make remaining on benefits more likely and give rise to a genuine type of state dependence. ${ }^{44}$ Studies of the empirical importance of work disincentives for employment decisions regularly find strong effects for low-income individuals in particular, so a form of 'pure' state dependence coming from SA is empirically plausible. These results, however, vary considerably between groups (e.g., employment is typically found to be much more responsive for women and, especially, lone parents; see Immervoll, 2012b, and the references cited therein).

It is generally difficult to distinguish pure SA receipt dependence from other forms of dependence. However, a more systematic comparison of SA state dependence for different population groups could present one possible avenue for further clarifying the relative importance of benefit dependence and other forms of 'scarring'.

\section{Main findings from Section 4}

A consistent finding from studies on SA dynamics is the very large difference between rates of persistence in benefit receipt, i.e. the probability for a recipient to stay on benefits from one year to the next, and benefit entry rates for non-recipients. Two alternative drivers of this observed 'state dependence' can be distinguished: (i) systematic differences in individual characteristics across recipients and non-recipients (e.g., lower education among recipients), and (ii) a possible 'causal' effect of current benefit receipt on the likelihood of benefit receipt in the next period. A significant degree of 'genuine' state dependence would indicate that benefit receipt is self-reinforcing, i.e. that there is a 'welfare trap'.

Drawing on a number of recent country studies (some of which initiated by the authors), this section has summarised available evidence on 'genuine' (or 'causal') state dependence in SA receipt in six OECD countries (Britain, Canada, Germany, the Netherlands, Norway, and Sweden). The main findings are:

- The degree of observed state dependence is substantial: In the six countries studied, the likelihood of receiving SA in the next period is 60 to 80 percentage points higher for someone who is currently in receipt than for someone who is not. The smallest value is observed non-refugee immigrant women in Sweden (58 percentage points) and the largest for women and non-EU migrants in the Netherlands ( 85 points).

- Empirical studies on state dependence that report results in a format comparable across countries also find statistically significant genuine state dependence. The estimated effect size is however substantially smaller.

- A majority of observed state dependence can be attributed to differences in personal and household characteristics across individuals, rather than to any causal effects of past benefit receipt as such.

- The magnitude of genuine state dependence varies strongly across countries, recipient groups, and benefit programmes. The smallest effects are reported for native women in Sweden (5

However, such disincentives can also increase entry rates into benefit receipt. Since state dependence is the difference in probabilities of receiving SA between someone who has and has not received SA in the period before, a higher entry rate compared to the (counterfactual) persistence rate would lower state dependence. 
percentage points), and the largest ones for Canada and non-EU born individuals in the Netherlands (35). Typically, state dependence appears to be higher for migrants than for natives.

- There exist numerous theoretical explanations of what might be the drivers of genuine state dependence in SA benefit receipt: financial work disincentives arising from benefit receipt, a loss of important labour market networks, adverse effects on individuals' motivation and feeling of selfcontrol, or the potential function of past benefit receipt as a negative productivity signal to future employers. To date, there is very little empirical evidence on which of these channels are likely to be the most relevant. It is likely, however, that a substantial part of state dependence in SA benefit receipt can be attributed to persistence in unemployment, poverty, or low pay rather than SA benefit receipt per se. 
Annex 1.A. Social Assistance programmes included in the recipiency statistics reported in Section 1

Table 16. Programmes included in the Social Assistance Category

\begin{tabular}{|c|c|}
\hline Country & Programme name \\
\hline AUS & $\begin{array}{l}\text { Special Benefit } \\
\text { Youth Allowance for full-time student and apprentice }\end{array}$ \\
\hline BEL & Integration income \\
\hline CZE & State Social Support: Social benefit \\
\hline DEU & Social Assistance \\
\hline DNK & $\begin{array}{l}\text { Unemployment (register): Recipients of social assistance } \\
\text { Social Assistance / Income Support }\end{array}$ \\
\hline FRA & $\begin{array}{l}\text { Minimum Income Guarantee - All schemes } \\
\text { Minimum Income Guarantee - RSA }\end{array}$ \\
\hline GBR & Income support (others) \\
\hline HUN & $\begin{array}{l}\text { Availability support } \\
\text { Regular Social Assistance }\end{array}$ \\
\hline IRL & $\begin{array}{l}\text { Supplementary Welfare Allowance } \\
\text { Carer's Allowance } \\
\text { Farm Assist } \\
\text { Guardian Payment non-contributory }\end{array}$ \\
\hline ISL & Single Parents Allowance (TR) \\
\hline ISR & Maintenance Payment (Guarantee of Payment) \\
\hline JPN & Social assistance (Livelihood assistance) \\
\hline LTU & $\begin{array}{l}\text { Social Assistance Benefit - Assistance for Socially Supported } \\
\text { Families }\end{array}$ \\
\hline LUX & $\begin{array}{l}\text { Guaranteed minimum income } \\
\text { Income for people with severe infirmity }\end{array}$ \\
\hline MLT & Social assistance programmes \\
\hline MEX & Human Development Program - Oportunidades (SEDESOL) \\
\hline NLD & WWB Work and Benefits Act \\
\hline NZL & $\begin{array}{l}\text { Emergency Benefit } \\
\text { Temporary Additional Support/Special Benefit }\end{array}$ \\
\hline POL & Social Assistance - Income support (Pomoc społeczna) \\
\hline PRT & Social Integration Income - Guaranteed minimal income \\
\hline ROU & $\begin{array}{l}\text { Scheme regarding guaranteed minimum income (GMI): guaran- } \\
\text { teed minimum income } \\
\text { Scheme regarding Minimum guaranteed social pension: PEN- } \\
\text { SOC }\end{array}$ \\
\hline SVN & $\begin{array}{l}\text { Financial social assistance - for limited period of time } \\
\text { Permanent financial social assistance }\end{array}$ \\
\hline SWE & Social allowance \\
\hline USA & $\begin{array}{l}\text { Food stamp assistance: Supplemental Nutrition Assistance } \\
\text { Program (SNAP) benefits }\end{array}$ \\
\hline
\end{tabular}

Source: OECD (2014), Social Benefit Recipient Database (SOCR), forthcoming 
Table 17. Programmes included in the Unemployment Assistance Category

\begin{tabular}{|c|c|}
\hline Country & Programme name \\
\hline AUS & $\begin{array}{l}\text { Job Seeker Allowance (Newstart and Youth allowance for non- } \\
\text { students) } \\
\text { Partner Allowance }\end{array}$ \\
\hline DEU & Basic income support for job seekers \\
\hline GBR & Jobseeker's Allowance \\
\hline $\mathrm{IRL}$ & Jobseeker's allowance (JA) \\
\hline MLT & $\begin{array}{l}\text { Special Unemployment Benefit (SUB), Unemployment Assis- } \\
\text { tance (UA) }\end{array}$ \\
\hline NZL & $\begin{array}{l}\text { Independent Youth Benefits } \\
\text { Unemployment Benefits - Student - Hardship } \\
\text { Unemployment Benefits - Training, Unemployment Benefits - } \\
\text { Hardship - Training } \\
\text { Unemployment Benefits, Unemployment Benefits - Hardship, }\end{array}$ \\
\hline
\end{tabular}

Source: OECD (2014), Social Benefit Recipient Database (SOCR), forthcoming

Table 18. Programmes included in the Lone Parents Category

\begin{tabular}{cl}
\hline country & \multicolumn{1}{c}{ programme name } \\
\hline AUS & $\begin{array}{l}\text { Parenting Payment Partnered } \\
\text { Parenting Payment Single } \\
\text { ABSTUDY scheme } \\
\text { Special assistance for immigrants }\end{array}$ \\
& Asylum seeker's waiting allowance - All schemes \\
& Single parent's benefit \\
FRA & Income Support for Lone Parents \\
GBR & Deserted Wife's Allowance \\
IRL & One Parent Payment \\
MSL & Careripal Income Support \\
MLT & Domestic Purposes Benefit-Sole Parent \\
NZL & Domestic Purposes Benefit-Woman Alone \\
& Emergency Maintenance Allowance \\
& Family Benefits - Lone parents \\
POL & Emergency allowances - state budget \\
ROU & Support Allowance for monoparental families \\
& Temporary Assistance for Needy Families (TANF) \\
USA & \\
&
\end{tabular}

Source: OECD (2014), Social Benefit Recipient Database (SOCR), forthcoming 


\section{Annex 4.A. Issues complicating assessments of state dependence: model specification}

The DREP model set out in Section 4.1 provides a comprehensive framework for identifying and assessing the importance of genuine state dependence. However, the extent to which it gives a reliable answer to the question whether the high rates of persistence in benefit receipt are indeed driven in part by 'structural' state dependence depends on the validity of the model. This Annex therefore discusses issues of model specification.

Consider, first, potential variations on the basic DREP model set out in Equation (1) of Section 4.1. Although normality is the most commonly used assumption concerning the distribution of the error components when modelling SA histories, some authors have assumed a logistic distribution for the timeinvariant individual effect instead (Hansen and Lofstrom 2011), and others have used a discrete mass-point distribution with two classes (Hansen, Lofstrom, Liu, and Zhang 2014). Unfortunately, the impact of the change in assumptions cannot be assessed because the authors do not compare the estimates from the model variants with those from standard DREP models.

Different assumptions about the error structure are considered by Andrén and Andrén (2013) in their DREP models of SA dynamics. In addition to the basic model, they consider a specification in which there is first-order autocorrelation in the idiosyncratic random error term $\zeta_{i t}$, and a more general model in which these errors have a constant variance over time but cross-time correlations are unrestricted. Comparing the estimates from the three specifications, Andrén and Andrén report that the basic DREP model "seems to be a relatively good approximation to the general structure" (2013: 12). They also state that the "general behaviour of the coefficient for structural state dependence [i.e. $\lambda$ ] is that it is biased upwards, and that the more restrictive the error structure is, the more the bias increases". However, the magnitude of the bias is difficult to assess because specific details are not provided.

The most substantial comparison of estimates from different variants of DREP models is by Stewart (2007, see especially Table IV). He models unemployment rather than SA (using British data) but, since the domains are closely related, his results should be informative, subject to the caveat that Stewart's models incorporate the impact of previous low pay in addition to previous unemployment. Stewart concludes that assuming a discrete mass-point distribution for the unobserved heterogeneity rather than normality leads to estimates of the coefficient on lagged unemployment (the analogue to $\lambda$ ) and its APE that are "similar" to those from the basic model (2007: 525). Moreover, retaining normality but allowing for first-order autocorrelation in the idiosyncratic random error term $\zeta_{i t}$, leads to estimates of the autocorrelation parameter that are not statistically significant from zero and a coefficient on lagged unemployment that is little different from that in the basic model but less precisely estimated. Stewart (2007) also fitted dynamic linear probability (DLP) models in order to estimate parameters without making a distributional assumption about the time-invariant individual-specific error components. This results in a larger estimate of the APE for lagged unemployment. Stewart states that "all the dynamic random-effects probit model estimators (as well as the GMM estimators of the DLP model) show a strong degree of agreement" (2007: 527).

Based on the evidence cited in the previous paragraphs, the relatively simple assumptions incorporated in the basic DREP model regarding the unobserved heterogeneity appear to be reasonable compromises, in the sense that estimates of key parameters such as $\lambda$ do not appear to be fragile to variations in specification.

A more substantial concern might be that all the models considered so far are random effects models and hence assume that observed and unobserved characteristics are uncorrelated with each other. Fixed effects models relax this assumption using estimators that do not depend on the unobserved individual-specific effects (see Honoré and Kyriazidou, 2000). As Biewen (2009) explains, these estimators may not work well in practice because estimation is based on histories with particular patterns and there are typically 
rather few of these. Usable histories are those with specific combinations of change in the outcome variable and (lack of) change in the explanatory variables over at least three consecutive periods. Inter alia, for $\lambda$ and $\gamma$ to be identified, the explanatory variables need to change over time but not too quickly. Note also that an APE for $\lambda$ cannot be calculated using the fixed effects approach. All in all, these problems, together with a lack of widely-available software to fit the models, mean that parameter estimates for fixed effects models of SA dynamics are rare. ${ }^{45}$

Another issue regarding specification of the basic DREP model is that genuine state dependence is assumed to be the same for all individuals: there is a single state dependence parameter, $\lambda$, common to all individuals. Heterogeneity in state dependence can straightforwardly be introduced in three ways. The first is simply to fit separate DREP models to each of several different sub-samples, where the sub-sample membership is defined by observable characteristics. (This procedure allows all model parameters to differ between groups, not only $\lambda$.) Examples of this strategy were discussed in Section 4.2.

A second approach is to fit one DREP model to the full sample but also to allow $\lambda$ to vary with observable characteristics. This is done by Andrén and Andrén (2013), and most systematically by Cappellari and Jenkins (2014) who interact every element of $Z_{i t-1}$ with lagged SA receipt on the grounds that this allows each characteristic to have a different impact on rates of entry into and exit out of SA receipt. ${ }^{46}$ The same procedure is also commonly used to examine whether state dependence varies with calendar time (see e.g. Bhuller and Königs (2011), Cappellari and Jenkins (2008a), and Königs (2013a)). A third approach is to allow for unobserved heterogeneity in the state dependence parameter. For example, Stewart's (2007) study of unemployment persistence considers the case in which dependence is normally distributed with a mean and variance estimated from the data. As it happens, the model's fit is unsatisfactory compared to the basic model, and Stewart does not consider it further. Bhuller, Brinch, and Königs (2014) combine the two approaches in their study of SA dynamics in Norway letting the effect of observed characteristics and unobserved heterogeneity vary with past benefit receipt status. The level of state dependence estimated from such a model is substantially higher than for the standard DREP model or a model that allows state dependence to vary only with observed characteristics.

A further potential area of concern about model specification is the way in which histories of past receipt are incorporated in the basic DREP model, viz. characterised solely by receipt in the previous period. This assumption is a convenient simplification that can be relaxed, for example to allow more years' history to have an influence, in which case the basic DREP model changes from being a first-order Markov model to a second- or higher-order one. However, there exist only few applications of such models to study SA dynamics. Andrén and Andrén (2013: Table 5) fit a third-order Markov model to Swedish SA histories and report that receipt two and three years ago has a statistically significant association with current receipt (in addition to receipt one year ago), but the effect size of past receipt declines sharply after the first lag. Bhuller, Brinch, and Königs (2014) find evidence of significant but weak higher-order state dependence in a monthly DREP model of SA dynamics for Norway.

One reason why researchers have not fitted higher-order Markov models more frequently may be that researchers may not be aware that it is possible to fit such models using readily-available software. Second, higher-order models require long runs of panel data and these data may not always be available. One might argue that first-order DREP models are sufficient to capture the key distinction between heterogeneity and

One exception is Chay and Hyslop (2014), who fit a fixed effects logit model together with a number of other specifications.

If $\lambda$ is the same for all individuals, each observed characteristic is constrained to have the same impact on the SA entry and exit rates. Cappellari and Jenkins (2014) focus on estimates of transition rates and do not report estimates of APE or PPR. 
state dependence as determinants of SA receipt histories - note e.g. the relative unimportance of secondand third-order lags cited earlier - but the veracity of this case has not been rigorously scrutinised. An additional complication arises from the fact that approaches for dealing with the initial conditions problem need to be adjusted when higher-order lags are added to the DREP model. Andrén and Andrén (2013) appear to simply rely on the Heckman approach for the standard first-order Markov model.

There are more fundamental issues concerning the way in which histories of past receipt are incorporated in the statistical model. The argument is that there are several different types of 'state dependence' and that state dependence identified by the DREP model's Markovian state dependence specification may in fact reflect one or more of the other types of dependence. Heckman and Borjas (1980) distinguish four types of state dependence in their discussion of whether unemployment causes future unemployment:

1. Markovian dependence (as in the DREP model).

2. Occurrence dependence: the number of previous spells affects the current probability of unemployment.

3. Duration dependence: the probability of leaving unemployment depends on how long an unemployed worker has been unemployed so far since starting the current unemployment spell.

4. Lagged duration dependence: the probability of leaving unemployment depends on the lengths of previous unemployment spells.

It should be noted that the different concepts were defined by Heckman and Borjas assuming a 'continuous time' environment rather than the 'discrete time' environment assumed so far.

In the continuous time case, one has detailed histories of SA receipt with the dates of transitions into and out of receipt, and hence spells of SA can be identified. In the discrete time case, exact dates of transitions are not available, only whether an individual is receiving SA or not within particular intervals of time (such as a month or a year, depending on the data source). In the discrete time case, spells of receipt may be defined in terms of groups of consecutive intervals in receipt, but the accuracy of measurement of spells depends on how short the interval is. If observation of receipt is only annual or at one point within a year, short spells of receipt may be missed altogether. If a 'benefit year' is defined (for data-related reasons) as receipt at any time within a given year, as commonly done (see Annex 4.B), there is an asymmetric treatment of receipt relative to non-receipt. Only one week of receipt is needed to generate $y_{i t}=1$ for a benefit year, whereas non-receipt requires a full 52 weeks of non-receipt. See Ellwood (1982, especially pp. 3623) for further discussion. ${ }^{47}$

How histories are measured in available data sources is therefore crucial to the type of modelling approach that is feasible. When sub-annual (monthly) data are available, researchers have typically modelled the length of spells of SA among individuals beginning spells of receipt and the concept of dependence examined is exclusively duration dependence (item 3 in the list above), see e.g. Grogger (2004) using US Survey of Income and Program Participation data. In a recent study based on monthly data for Norway, Bhuller, Brinch, and Königs (2014) test for different types of state dependence and find evidence for occurrence dependence in social assistance entries and for duration dependence both on and off benefits. However, most studies of SA receipt for other countries have SA receipt histories at the annual level and model bina-

47 To avoid these asymmetry problems, Ellwood (1982) suggests the use of point-in-time sampling rather than the use of concepts such as benefit years. (He also discusses the "continuing spell' issue cited in the next paragraph.) Point-in-time sampling is in effect what studies based on household panel surveys with annual interviews have done. 
ry sequences of receipt and non-receipt and they do not look at spells. ${ }^{48}$ For this reason, this paper focuses on DREP models and Markovian state dependence exclusively. (The definition of the time period is discussed further in Annex 4.B.) In sum, the nature of the data available prevents more detailed examination of which type(s) of state dependence are the most important in the context of SA receipt dynamics. Bhuller, Brinch and Königs find however that estimates of the level of state dependence can vary significantly with the level of time aggregation.

Some researchers fitting DREP models to annual unemployment histories have taken a practical approach to try and identify Markovian state dependence separately from duration dependence. For example, Arulampalam, Booth, and Taylor (2000) observe that among the working-age men in their sample who were unemployed at the time of an annual interview, around one-third were in an unemployment spell that lasted longer than 12 months (the average gap between annual interviews). ${ }^{49}$ For these cases, unemployment a year ago $\left(y_{i t-1}\right)$ refers to the same spell rather than a different spell; so the higher chances of unemployment for those with $y_{i t-1}=1$ may in part reflect the relatively long length of the unemployment spell to date. In order to check the sensitivity of the estimates of (Markovian) state dependence derived from their basic DREP model, Arulampalam, Booth, and Taylor fit two further model variants. In one, they simply drop all observations with an unemployment spell spanning two consecutive interviews and, in the other, lagged receipt refers to whether the respondent was unemployed two years ago (rather than one year ago). It turns out that the basic model and the second variant provide similar estimates of the coefficient on lagged unemployment (Arulampalam, Booth, and Taylor 2000: Table 3) but the first variant, in which cases with spells overlapping interviews are dropped, leads to rather lower estimates of the coefficient on lagged unemployment (but it remains statistically significantly different from zero). Stewart (2007) also compares estimates of state dependence from a basic DREP model and one from which continuing spells are excluded and finds an even larger decline in the effects of lagged unemployment than Arulampalam, Booth, and Taylor: the estimated APE falls from 13 to 3.5 (Stewart 2007: 522).

The issue of continuing spells of SA receipt has been little addressed by researchers fitting DREP models to SA histories. One reason for this is that, as discussed in Annex 4.B, data on SA benefit receipt are often measured in 'benefit years', which means that a measurement of spell durations is not possible. Cappellari and Jenkins (2008a: 58) account for the issue, pointing out that on average around two-thirds of the individuals observed to receive SA at an annual BHPS interview were also in receipt at the previous annual interview without any intervening months of non-receipt. They re-estimate their basic DREP model excluding individuals with continuing spells and report that the estimate of the coefficient on $\lambda$ falls from above 1 to around 0.5 and the corresponding APE is less than one-third of the APE estimated when individuals with continuing spells are included. Thus, how one treats the continuing spells issue has a major impact of estimates of the extent of genuine state dependence.

Cappellari and Jenkins also observe that the prevalence of continuing spells is strongly associated with observable characteristics. For example, almost one-third of those with such spells are lone parents. They suggest that models which allow for heterogeneity in state dependence (as discussed earlier) are useful in the continuing spell context because the problem of separately identifying state and duration dependence is then restricted to the subgroups for whom the prevalence of continuing spells is high. For example, fitting a model in which $\lambda$ is allowed to differ between lone parents and other adults, Cappellari and Jenkins (2008a: Table 7) find that the estimated coefficient on lagged SA receipt is substantially higher for lone parents.

$48 \quad$ One exception is Hansen's (2009) study of SA spell lengths using annual data for Norway.

49 The authors use the British Household Panel Survey. BHPS questions ask not only about whether respondents are unemployed at the time of the annual interview, but also about their unemployment in each month prior to the interview, back to 1 September of the calendar year preceding the current interview year. 
In sum, these analyses suggest that the dependence identified by fitting DREP models to SA histories reflects a mixture of genuine Markovian state dependence, duration and possibly occurrence dependence, and it is difficult to separate out these factors. This issue is reflected in the discussion of the policy implications in Section 4.3.

The final specification issue that should be mentioned concerns whether the model needs to be extended to take account of the potential endogeneity of the explanatory variables. The question arises because derivation of unbiased estimates of the DREP model parameters relies on the assumption that all the explanatory variables included in $Z_{i t-1}$ are 'strictly exogenous'. As Biewen (2009: 1096) puts it, it is "assumed that the regressors and the dependent variable are dynamically unrelated in the sense that outcomes of the dependent variable do not influence future outcomes of the regressors". This assumption is relatively innocuous for factors such as measures of labour market tightness such as local unemployment rates or measures of benefit generosity. More debatable is the supposition that the impacts of shocks in individuals' SA receipt on where they live, the type of housing, or their household composition, are sufficiently small that they may be ignored.

This is a model specification issue because endogeneity issues can be addressed in principle by extending the basic DREP specification to also model the determinants of endogenous factors jointly along with the model of SA receipt. For an example of a DREP model of poverty dynamics in Germany extended to allow for feedback effects on household composition and labour force participation, see Biewen (2009). Biewen (2009: Table IV) reports that the estimate of the APE for lagged poverty status from the extended model is roughly half that of the corresponding APE for the basic DREP model (0.31 compared to 0.61). Thus, different assumptions can make a substantial difference to the estimates. However, fitting DREP models that incorporate feedback effects is difficult, especially since software modules to fit them are not widely available and, in any case, identification of model parameters is hampered by a lack of plausible instruments. 
Annex 4.B. Issues complicating assessments of state dependence: data and definitions

Methodological concerns extend beyond the choice of the 'correct' model specification to questions of data and definitions. Getting definitions right is important not only for intrinsic validity, but because having different definitions in different studies hampers cross-study comparisons of estimates. Additional empirical issues that may have an impact are the length of the panel, whether the panel is 'balanced' (i.e. whether all individuals in the sample are observed in each time period), and sample drop-out.

Any empirical analysis of the dynamics of SA receipt requires definitions for three components: ${ }^{50}$

\section{The benefit-receiving unit}

2. The income sources included in 'social assistance' benefits

3. The time period over which the benefit(s) are received.

In many countries (e.g. Britain), the assessment of eligibility for SA benefits is based on the income of the nuclear family, referring to a single person or a couple living together with or without dependent children. The 'family' unit differs from the 'household': a household may contain several benefit-receiving units. Examples of this are a non-dependent child living with his parents (two benefit units), or three single adults sharing a house (three benefit units). Although only one individual within a family is the benefit claimant, the family-based means test all the individuals within a family are assumed by the benefit system to gain from the income provided by a social security benefit. That is, there are multiple recipients within each family or household (other than within single adult benefit units).

Families and households cannot be followed over time in any consistent manner. Families and households change their composition over time as individuals arrive (e.g. via birth of a child or marriage) or depart (e.g. via a child becoming non-dependent or leaving home, death or divorce). And these types of change are common (see e.g. Jenkins, 2000). Thus one can only follow individuals over time, though of course one can characterise individuals in terms of their family's characteristics including receipt status at a given point in time. There are, however, practical issues for empirical analysis concerning the tracking of recipient and non-recipient individuals over time. When modelling the dynamics of receipt of SA, should each family at a particular point in time be represented in the data set by one individual (and, if so, which one), or should there be as many observations as there are family members?

On the one hand, if one is interested in modelling persistence in receipt to learn about changes in the number of claimants over time, this suggests that one should focus on one individual per benefit unit, viz. the claimant, in so far as he or she can be identified from the survey data, or another key individual such as the 'family head' (defined below). On the other hand, researchers are more commonly interested in longitudinal patterns of benefit receipt. The state dependence hypothesis, for example, concerns whether past receipt of benefit causes current receipt. Taking the receipt persistence perspective implies that every member of a family should be represented in the data set.

The distinction between recipient and claimant is complicated by the fact that a person may become a claimant or stop being a claimant separately from whether or not the person's family is in receipt. For example, consider a lone mother who is a benefit claimant (and in receipt) in year $t$. At $t+1$, she re-partners with a man and it is he who is now the benefit claimant (and family head). He was also the head of a (separate) family in year $t$, though his family was not in receipt then. The woman's receipt status has not changed, but her claimant status has. The man's receipt status has changed, but he has remained a family 
head and potential claimant. In the example described, a longitudinal data set should track both the woman and the man over time, and count her as remaining in receipt and him as moving into receipt.

In sum, the ideal may be to track individuals over time, and to characterize each individual's receipt status at each point in time in terms of whether anyone in their benefit-receiving unit was receiving SA benefits at that time. At the same time, specific groups of individuals should be excluded. One would want to track only adults over time and not dependent children precisely because children are dependent: their benefit receipt status at a particular time depends entirely on their parents. Children would contribute SA histories to the analysis database only when they become non-dependent, i.e. adults in their right. In addition, and depending on context, one is likely to restrict analysis to the groups of adults that are eligible for different types of SA benefit, and this choice is likely to vary from country (see also Section 1 and below). For example one might focus on persons of working age who are economically active, thereby excluding older and retired persons or full-time students. Whether to include disabled individuals is a more moot point and the answer may be country-specific, e.g. depending on whether the primary benefit for the income support of disabled people is SA benefits or separate disability benefits. Persistence in benefit receipt is likely to be larger for disabled people than other groups.

The definitions proposed mean that a multi-adult family contributes multiple observations on benefit receipt status at a given point in time. This induces a lack of independence between observations and this, in turn, means that the precision of parameter estimates is over-estimated. Because individuals are clustered in families, the amount of information provided by the data is not as large as the nominal sample size (in terms of individuals) would suggest. However, the size of the problem is not known as it has apparently not been investigated in the context of DREP models. On the one hand, this is likely to be because adjustment for such clustering is not available in the software typically used to fit DREP models. ${ }^{51}$ On the other hand, the issue arises in practice only with studies based on household panel surveys. In samples from administrative record data, the probability that any two sample members belong to the same household is small.

Following adults over time is the most commonly-used practice in the literature to date, but there are subtle differences in practice between studies in terms of which adults are followed and in the definition of benefit receipt, where the variations are closely related to what is possible with the longitudinal data that are available.

First, there are the studies using what is referred to as the 'ideal' above. In Cappellari and Jenkins's (2008a) study based on data from the British Household Panel Survey, all working-age adults are tracked over time, with each adult attributed with SA receipt in a given year if any adult in their family is in receipt. Essentially the same procedure is followed by Bhuller and Königs (2011) using data from a Norwegian administrative database and by Königs (2013a) using data from the German Socio-Economic Panel (SOEP), except that receipt is defined within households rather than within families.

Second, by contrast, only one adult per benefit-receiving unit is tracked in other studies from Germany, Sweden, and Canada. Wunder and Riphahn (2014) use data from the SOEP as Königs (2014a) does but they use a fully individualised definition: SA recipients are the individuals who report that they personally received some form of SA benefit. In a follow-up paper (Riphahn \& Wunder, 2013), the same authors only track the benefit receipt status of the household head (as identified by the survey) and remove all other individuals in a household from the sample. Andrén and Andrén (2013) analyze SA dynamics over the

A similar issue arises in the modelling of individual unemployment dynamics where the estimation sample includes both men and women, though the issue does not appear to have been explicitly discussed or addressed in this context. For instance, Stewart (2007) modelled men's and women's unemployment dynamics using BHPS data, and some of the men and women in his sample lived together in a marital partnership. 
period 1990-1999 using the Swedish Income Panel, a register-based panel data set based on a random sample of the Swedish working age population in 1990. Because the sample is of individuals rather than households, their data set does not include all the individuals from the household of each sampled individual in each year. So, the nature of the data means that Andrén and Andrén have to define SA receipt in terms of whether the person sampled received SA.

Hansen, Lofstrom, Liu, and Zhang (2014) use the Canadian Survey of Labour and Income Dynamics (SLID), a rotating panel to compare SA benefit dynamics across Canadian provinces. They state that each household is represented by one person at each point in time: "Given the practical challenges of incorporating household complexity, we opt for letting the survey response person (defined by Statistics Canada) represent the household." (p. 84), and the "response person does not change during the panel meaning that a household is always represented by the same person" (endnote 10). "A household is defined as a welfare participating household, in any given year, if any person belonging to the household received any SA at any time during that year" (p. 85). Throughout their paper they however refer to tracking households over time (note for instance the model specification on page 90), but household demographic change is not accounted for (see the earlier discussion).

Hansen and Lofstrom (2011) compare SA receipt dynamics for Swedish natives and immigrants using LINDA, a register-based data set consisting of a large panel of individuals, and their household members, which is representative of the Swedish population from 1960 to 2001. Analysis is of men and women between the ages of 18 and 65, excluding students and retired individuals, tracked between 1991 and 2001. However, it appears that benefit receipt is defined on an individual basis rather than household basis (as in the Andrén and Andrén (2013) study): "We classify a person as a welfare/UI recipient if he or she received welfare for at least a month and/or received more than one-half of the so-called basic amount, SEK 18,100, in unemployment benefits during the year" (Hansen and Lofstrom 2011: 421). One situation where the distinction between the family and the individual adult does not matter is when the two coincide. The leading example of this is the former Aid for Families with Dependent Children (AFDC) in the USA, a SA benefit that targeted lone parents.

The second definitional issue concerns the specific income sources that are counted as 'social assistance', a topic discussed in Section 1 of this paper. In some contexts, this is straightforward. For example, prior to its abolition in 1996, AFDC was the only SA benefit in the USA, remained in much the same form for a long period of time, and was targeted on a relatively narrow client group. In many other rich countries, there are a number of SA benefits, they have changed their nature over time, and eligibility is more universal.

An illustration of the cross-time complications is provided by Cappellari and Jenkins (2008a) in their discussion of the British situation in the 1990s and 2000s, a period when the benefit system was reformed substantially. Building of a consistent SA benefit series over the period as a whole required linking benefits that had changed their names and nature over time. Königs (2014a) describes similar issues for Germany, where SA benefits were also substantially reformed. A related issue concerns which types of benefits should be included in the 'SA' benefit variable and how to identify SA benefit receipt separately from receipt of other benefits. Cappellari and Jenkins (2008a) identify four main types of SA benefit in Britain during the 1990s and 2000s. However, the group receiving unemployment-related SA benefits substantially overlapped with the group receiving housing costs-related SA benefits, and Cappellari and Jenkins argue that the choice of whether to include HB in the definition of SA benefits is of little practical importance. An additional complication was that there were both contribution-based (social insurance) and meanstested (SA) benefits for unemployed workers. However the majority of individuals receiving social insurance also received SA top-ups as well. Ideally one would like to identify only the individuals and families receiving SA (or SA top-ups to insurance benefits) but this turns out to be impossible in practice. British surveys do not ask respondents to distinguish the benefits (because of the difficulty of doing so) and even 
official statistics stopped classifying unemployed recipients by the type of unemployment benefit received. Cappellari and Jenkins's (2008a, 2014) analysis therefore has to examine SA receipt defined in terms of receipt of either benefit in order to derive a consistent longitudinal series. Similarly, Hansen and Lofstrom's (2011) analysis of the dynamics of SA receipt in Sweden includes receipt of some unemployment benefits in the definition of SA.

The third definitional issue concerns the time period of receipt, an aspect already referred to in the Annex 4.A. Individuals receive benefits over periods of time. In any given calendar year, an individual may have no receipt, a single spell of receipt, or multiple spells of receipt, and any of these spells may overlap calendar years. Hence, and as illustrated in Sections 2 and 3 of this paper, the 'dynamics' of receipt are potentially very complicated. Most empirical work to date has taken a simpler approach.

Much previous analysis has defined the time period of receipt in terms of 'a SA year', a leading example of the case of discrete time data discussed earlier. For example, in Andrén and Andrén's (2013) analysis, receipt in a given calendar year is based on whether the sample person received SA at least once during that year. (Their data set provides no information about the sequence of SA received during the year, only the number of months.) Hansen and Lofstrom (2011) applied a similar definition to a different Swedish administrative data source. And Hansen, Lofstrom, Liu, and Zhang's (2014) and Königs' (2013b) definition of receipt of SA benefits in a given year refers to receipt at any time during that year in Canada and the Netherlands, respectively. In all three cases, it is apparently straightforward to characterise the 'year' over which receipt may occur. This is largely because of the nature of the data sources: the Dutch and the two Swedish studies are based on administrative record data from income tax sources and the SLID, used by Hansen and Lofstrom (2011), also utilizes administrative record linkage as the source for income for many respondents. (Income and taxes are assessed over a one-year reference period.) The 'continuing spell' issues discussed in the previous section cannot be addressed, however.

Interview-based surveys like the BHPS or the SOEP collect benefit receipt information differently as discussed briefly above in Sections 2 and 3. As a consequence of wishing to minimize measurement error and respondent burden, the survey organisation places most emphasis on the collection of detailed information about the income sources received at the date of the interview. Some histories of benefit receipt are collected relying on the respondent's retrospective recall, which cover the prior year including the previous year's interview. This means that the retrospective benefit histories from successive interviews provide two reports for each of the months for which the reference years overlap.

In principle, the data could be used to derive either SA histories on a monthly basis (and hence a spellbased analysis) or a 'benefit year' basis. In practice, there are major impediments to both approaches in household panels. In particular, as already mentioned in Section 3, the retrospective histories show an implausible number of transitions at the 'seam' where successive between-interview histories are spliced together. There is an additional complication because SA receipt should be defined in terms of whether any individual in a person's benefit unit is in receipt (see above). To do this for each 'social assistance year' requires information about receipt for every individual who was present in the respondent's benefit unit within each month of the relevant year. However, for adults who left the benefit unit after the last interview and before the current interview, there is no history of receipt over the reference period prior to the current interview. ${ }^{52}$ (By definition, they are not interviewed.) Receipt over the year defined in terms of receipt by any person within the individual's benefit unit may therefore be under-reported. As a result, analyses based

52 The same problem is likely to arise with annual administrative data, where family composition is recorded once per year. 
on household panels model receipt sequences where receipt is measured at the time of interview. ${ }^{53}$ This is the procedure followed by Cappellari and Jenkins (2008a) for Britain, and Königs (2013a) for Germany.

The richness of the Norwegian administrative data panel used by Bhuller, Brinch and Königs (2014) allows them to explore the use of three definitions of the time unit: monthly, point-in-time (receipt during one specific month during the year, as in the household panel-based studies), and the 'benefit year'. By construction, the rate of benefit receipt obtained from using the 'SA year' approach is larger than the comparable rate calculated at any single point in time. The difference of the two gives an idea of the turn-over in benefit receipt as discussed in Section 3. Since both entry and persistence rates will be higher under the SA year approach, the effect on state dependence of using this approach rather than the time-of-interview approach is ex ante unclear. Bhuller, Brinch and Königs (2014) find that state dependence is higher for the SA year approach, which might explain why state dependence in Canada and the Netherlands is estimated to be so high (see Table 15).

In sum, the definition of SA benefit receipt is not straightforward. The choice depends on country-specific factors such as the structure of the social security benefit system and how it changes over time. Also important are the data sources available: the longitudinal histories of SA receipt that can be constructed from household panel data and linked administrative records typically use different definitions.

This note finishes with a discussion of the length of the panel and related issues such as attrition. In principle, a DREP model can be estimated using only two consecutive observations for each individual but, other things being equal, a longer panel is better because a larger sample size provides more precise estimates, especially of parameters like the variance of the time-invariant unobserved individual effect (or a firstorder autocorrelation parameter). Moreover, the longer the panel is, the longer the period that is spanned in calendar time, the more likely that one can investigate calendar-time-specific events such as benefit reforms or business cycle peaks and troughs. The main issue concerning longer panels, at least those derived from household panel surveys, is that the longer the panel the more likely is that sample drop-out (attrition) means that the sample providing benefit histories is a non-random sample of all respondents because the probability of drop-out is correlated with the probability of receiving SA.

Related to this point is the issue of whether the panel is 'balanced' or not - whether each individual contributes benefit histories of the same length. The main argument for balancing is that some of the estimators for DREP model were originally developed assuming a balanced panel (with the start date of the histories being common across individuals). However, the Orme (2001) and Wooldridge (2005) estimators can be applied to unbalanced panels if it assumed that sample dropout is ignorable - the unobservable determinants of attrition are not correlated with the unobservables determining SA receipt. The main arguments against balancing are that its enforcement may introduce potentially non-representative samples (because a specific type of sample drop-out is being imposed by the researcher), reduce sample size, and coverage in calendar time.

Andrén and Andrén (2013) and Hansen, Lofstrom, Liu, and Zhang (2014) use balanced panels. Hansen and Lofstrom (2011: 419) also used a balanced panel to derive the estimates reported, but state that they also estimated the model with an unbalanced panel as a sensitivity check, and no major differences are reported. To derive most of their results, Cappellari and Jenkins (2008a) use an unbalanced panel in which the majority of the benefit histories begin in 1991 but some start in later years (the maximum sequence length is 15 years). However, they also examine the sensitivity of their findings by re-running their basic DREP model on (i) an unbalanced panel in which all individuals' histories begin in 1991 and (ii) a balanced panel in which every individual contributes 15 years of data (which reduces sample size substantially). Cappellari and Jenkins report that "[r] eassuringly the estimates $[\ldots]$ are broadly consistent with each other $[\ldots]$ in

53 This is the point-in-time sampling approach recommended by Ellwood (1982). 
terms of the point estimates and their statistical significance. [...] The state dependence is [also] similar" (2008: 54). They remark that the main impact of using the different samples is on the estimated impact of factors that vary with calendar time. Estimates are more imprecise with the smaller-sized samples.

The use of sample weights is commonly recommended in longitudinal analysis to counter the selectivity of sample drop-out. However, they are rarely applied by researchers fitting DREP models to SA histories. The only existing applications are Hansen, Lofstrom, Liu, and Zhang (2014) and Königs (2013a), likely because most commonly-available software for fitting DREP models does not allow weights. 


\section{Bibliography}

Adema, W., D. Gray and S. Kahl (2003), "Social Assistance in Germany", OECD Labour Market and Social Policy Occasional Papers, No. 58, OECD Publishing, Paris, http://dx.doi.org/10.1787/338133058573

Akay, A. (2012), "Finite-sample comparison of alternative methods for estimating dynamic panel data models", Journal of Applied Econometrics, 17, pp. 1189-1204.

Andrén, T. and D. Andrén (2013), "Never give up? The persistence of welfare participation in Sweden", IZA Journal of European Labor Studies, 2:1.

Arulampalam, W. and M.B. Stewart (2009), Simplified implementation of the Heckman estimator of the dynamic probit model and a comparison with alternative estimators, Oxford Bulletin of Economics and Statistics, 71(5), pp. 659-681.

Bane, M. J. and D.T. Ellwood (1994), Welfare Realities: From Rhetoric to Reform, Harvard University Press, Cambridge, MA.

Bane, M.J. and D.T. Ellwood (1986), "Slipping into and out of Poverty: the Dynamics of Spells", The Journal of Human Resources, 21(1), pp. 1-23.

Bane, M.J. and D.T. Ellwood (1983), The Dynamics of Dependence: The Routes to Self-Sufficiency, Report prepared by Urban Systems Research and Engineering, Inc. for the U.S. Department of Health and Human Services. June 1983.

Bargain, O., H. Immervoll and H. Viitamäki (2012), "No Claim, No Pain. Measuring the Non-Take-up of Social Assistance using Register Data", Journal of Economic Inequality, 10 (3), pp. 375-95.

Barrett, G. F. and M.I. Cragg (1998), "An Untold Story: The Characteristics of Welfare Use in British Columbia", Canadian Journal of Economics, 31(1), pp. 165-188.

Bhuller, M. and S. Königs (2011), The dynamics of social assistance receipt in Norway, unpublished report, Statistics Norway.

Bhuller, M., C. Brinch and S. Königs (2014), Time Aggregation and State Dependence in Welfare Receipt. Statistics Norway Research Department Discussion Paper, 771.

Blank, R.M. (1989), "Analyzing the Length of Welfare Spells", Journal of Public Economics, Vol. 39, Elsevier Science Publishers, pp. 245-273.

Blank, R.M. and P. Ruggles (1994), "Short-Term Recidivism among Public-Assistance Recipients", The American Economic Review, Vol. 84, No. 2, Papers and Proceedings of the Hundred and Sixth Annual Meeting of the American Economic Association, pp. 49-53.

Buhr, P. and A. Weber (1998), Social Assistance and Social Change in Germany, In L. Leisering \& R. Walker (Eds.), The Dynamics of Modern Society - Poverty, Policy and Welfare, The Policy Press, Bristol, pp. 183 - 198.

Cappellari, L. and S. P. Jenkins (2014), "The Dynamics of Social Assistance Benefit Receipt in Britain", In Carcillo, S., Immervoll, H., Jenkins, S. P., Königs, S., and Tatsiramos, K., editors, Research in 
Labor Economics: "Safety Nets and Benefit Dependence", Vol. 39, 41-79. Emerald Group Publishing Limited.

Cappellari, L. and S. P. Jenkins (2008a), "The Dynamics of Social Assistance Receipt: Measurement and Modelling Issues, with an Application to Britain", OECD Social, Employment and Migration Working Papers, No. 67, OECD Publishing, Paris, http://dx.doi.org/ 10.1787/236346714741.

Cappellari, L. and S. P. Jenkins (2008b), "Estimating low pay transition probabilities accounting for endogenous selection mechanisms", Journal of the Royal Statistical Society, Series C (Applied Statistics), 57(2), pp. 165-186.

Cappellari, L. and S. P. Jenkins (2004), "Modelling low income transitions", Journal of Applied Econometrics, 19(5), pp. 593-610.

Chamberlain, G. (1984), Panel data, In Z. Griliches and M. Intrilligator (eds.), Handbook of Econometrics, Amsterdam: North-Holland.

Chay, K. Y. and D. Hyslop (2014), "Identification and estimation of dynamic binary response panel data models: empirical evidence using alternative approaches", In Carcillo, S., Immervoll, H., Jenkins, S. P., Königs, S., and Tatsiramos, K., editors, Research in Labor Economics: "Safety Nets and Benefit Dependence", Vol. 39, 1-39, Emerald Group Publishing Limited.

Contini, D. and N. Negri (2007), "Would declining exit rates from welfare provide evidence of welfare dependence in homogeneous environments?", European Sociological Review, 23 (1), pp. 21-33.

Eardley, T, et al. (1996), Social Assistance in OECD Countries: Synthesis Report, OECD, Paris and Department of Social Security, Her Majesty's Stationary Office, London.

Ellwood, D. T. (1982). Teenage unemployment: permanent scars or temporary blemishes, In: R. B. Freeman and D. A. Wise (eds), The Youth Labor Problem: Its Nature, Causes and Consequences, University of Chicago Press, Chicago.

Eurostat (2012). Population by sex and age groups on 1 January, http://epp.eurostat.ec.europa.eu/portal/page/portal/region_cities/metropolitan_regions/ data metro/database sub3 (accessed in June 2013).

Finnie, R. and D. Pavlic (2013), The Dynamics of Social Assistance Receipt in Canada. unpublished working paper, University of Ottawa.

Fitzgerald, J. M. (1995) "Local Labor Markets and Local Area Effects on Welfare Duration", Journal of Policy Analysis and Management, 14(1), pp. 34-67.

Fitzgerald, J. M. (1991), "Welfare Durations and the Marriage Market: Evidence from the Survey of Income and Programme Participation" The Journal of Human Resources, 26(3), pp. 545-561.

Fortin, B., G. Lacroix and S. Drolet (2004), "Welfare benefits and the duration of welfare spells: evidence from a natural experiment in Canada", Journal of Public Economics, 88, pp. 1495-1520.

Gottschalk, P. and R. Moffitt (1994), "Welfare Dependence: Concepts, Measures, and Trends", The American Economic Review, 84, pp. 38-42. 
Gregory, R. G. and E. Klug (2003), A Picture Book Primer: Welfare Dependency and the Dynamics of Female Lone Parent Spells, Australian National University Working Paper.

Grogger, J. (2004), "Welfare transitions in the 1990s: the economy, welfare policy, and the EITC", Journal of Policy Analysis and Management, 32(4), pp. 671-695.

Gustafsson, B., et al. (2002), Paths through (and out of) social assistance, In: Saraceno, C.(ed), Social Assistance Dynamics in Europe: National and Local Poverty Regimes, Policy Press.

Gustafsson, B. and W. Voges (1998), Contrasting Welfare Dynamics: Germany and Sweden, In L. Leisering \& R. Walker (Eds.), The Dynamics of Modern Society - Poverty, Policy and Welfare, The Policy Press, Bristol, pp. $243-261$..

Hansen, H.T. (2009), "The Dynamics of Social Assistance Recipiency: Empirical Evidence from Norway", European Sociological Review, 25(2), pp. 215-231.

Hansen, J. and M. Lofstrom (2011), "Immigrant-native differences in welfare participation: the role of entry and exit rates", Industrial Relations, 50(3), pp. 412-442.

Hansen, J., and M. Lofstrom (2008), "The Dynamics of Immigrant Welfare and Labor Market Behavior", Journal of Population Economics , 22 (4), pp. 941-970.

Hansen, J., and M. Lofstrom (2003), "Immigrant Assimilation and Welfare Participation - Do Immigrants Assimilate Into or Out of Welfare?", The Journal of Human Resources, 38(1), pp. 74-98.

Hansen, J., M. Lofstrom and X. Zhang (2006), State dependence in Canadian welfare participation, IZA Discussion Paper No. 2266.

Hansen, J., et al. (2014), "State Dependence in Social Assistance Receipt in Canada", In Carcillo, S., Immervoll, H., Jenkins, S. P., Königs, S., and Tatsiramos, K., editors, Research in Labor Economics: "Safety Nets and Benefit Dependence", Vol. 39, 81-105, Emerald Group Publishing Limited.

Harris, K. (1996), "Life after Welfare: Women, Work, and Repeat Dependency", American Sociological Review, 61(3), pp. 407-426.

Harris, K. (1993), "Work and Welfare among Single Mothers in Poverty", American Journal of Sociology, 99(2), pp. 317-352.

Heckman, J. J. (1981a), "Heterogeneity and state dependence", in Rosen (ed.), Studies in Labor Markets. University of Chicago Press.

Heckman, J. J. (1981b), "The incidental parameters problem and the problem of initial conditions in estimating a discrete time-discrete data stochastic process", In: C. F. Manski and D. McFadden (eds.), Structural Analysis of Discrete Data with Econometric Applications. MIT Press, Cambridge, MA.

Heckman, J. J. (1981c), "Statistical models for discrete panel data", In: C. F. Manski and D. McFadden (eds.), Structural Analysis of Discrete Data with Econometric Applications, MIT Press, Cambridge, MA.

Heckman, J. J. and G. J. Borjas (1980), "Does unemployment cause future unemployment? Definitions, questions and answers from a continuous time model of heterogeneity and state dependence", Economica, 47, pp. 247-283. 
Hernanz, V., F. Malherbet and M. Pellizzari (2004), "Take-Up of Welfare Benefits in OECD Countries: A Review of the Evidence", OECD Social, Employment and Migration Working Papers, No. 17, OECD Publishing, Paris, http://dx.doi.org/ 10.1787/525815265414.

Hoynes, H. and T. MaCurdy (1994), "Has the Decline in Benefits Shortened Welfare Spells?", American Economic Review, Papers and Proceedings of the Hundred and Sixth Annual Meeting of the American Economic Association (May, 1994), 84(2), pp. 43-48.

Immervoll, H. (2012a), "Minimum-Income Benefits in OECD Countries: Policy Design, Effectiveness and Challenges", in: D. J. Besharov and K. A. Couch (eds.), Counting the Poor. New Thinking About European Poverty Measures and Lessons for the United States, Oxford University Press.

Immervoll, H. (2012b), "Reforming the benefit system to "make work pay': Options and priorities in a weak labour market", IZA Policy Paper No. 50, www.iza.org/en/webcontent/publications/policypapers.

Immervoll, H. (2010), "Minimum Income Benefits in OECD Countries: Policy Design, Effectiveness and Challenges", OECD Social, Employment and Migration Working Papers, No. 100, OECD Publishing, Paris, http://dx.doi.org/ 10.1787/218402763872.

Immervoll, H. and M. Pearson, M. (2009), "A Good Time for Making Work Pay? Taking Stock of InWork Benefits and Related Measures across the OECD", OECD Social, Employment and Migration Working Papers, No. 81, OECD Publishing, Paris and IZA Policy Paper No. 3, http://dx.doi.org/ $10.1787 / 225442803245$ and www.iza.org/en/webcontent/publications/policypapers.

Jenkins, S. P. (2000), "Modelling household income dynamics", Journal of Population Economics, 13, pp. $529-567$.

Kazepov, Y. (1999), "At the Edge of Longitudinal Analysis. Welfare Institutions and Social Assistance Dynamics", Quality \& Quantity, 33, pp. 305-322.

Königs, S. (2012), "The Dynamics of Social Assistance Benefit Receipt in Luxembourg - a descriptive analysis", INET Working Paper, University of Oxford, www.emod.ox.ac.uk/sites/emod.ox.ac.uk/files/Konigs_2012.pdf (accessed January 2015).

Königs, S. (2013a), "The Dynamics of Social Assistance Benefit Receipt in Germany", OECD Social, Employment and Migration Working Papers, No. 136. OECD Publishing, Paris, http://dx.doi.org/ $10.1787 / 5 \mathrm{k} 3 \mathrm{xwtg} 6 \mathrm{zknq}-\mathrm{en}$.

Königs, S. (2013b), "The Dynamics of Social Assistance Benefit Receipt in the Netherlands", unpublished report.

Königs, S. (2014a), State Dependence in Social Assistance Benefit Receipt in Germany before and after the Hartz Reforms, In Carcillo, S., Immervoll, H., Jenkins, S. P., Königs, S., and Tatsiramos, K., editors, Research in Labor Economics: "Safety Nets and Benefit Dependence", Vol. 39, Emerald Group Publishing Limited, pp. 107-150.

Königs, S. (2015), The Micro-Dynamics of Social Assistance Benefit Receipt - Evidence from 4 European Countries. Statistics Norway Research Department Discussion Paper, forthcoming

Leisering, L. and S. Leibfried (1999), Time and Poverty in Western Welfare States: United Germany in Perspective, Cambridge University Press. 
Kroft, K., F. Lange and M. J. Notowidigdo (2013), "Duration dependence and labor market conditions: evidence from a field experiment", Quarterly Journal of Economics, 128 (3), pp. 1123-1167.

Marchal, S. and Van Mechelen, N. (2013), "Activation strategies within European minimum income schemes", GINI Discussion Paper Series, Amsterdam Institute for Advanced Labour Studies, forthcoming.

Mundlak, Y. (1978), "On the pooling of time series and cross section data", Econometrica, 46(1), pp. 6985.

OECD (2008), Growing Unequal? Income Distribution and Poverty in OECD Countries, OECD Publishing, Paris.

OECD (2007a), "Special Feature: The Tax Treatment of Minimum Wages", in: Taxing Wages, OECD Publishing, Paris, pp. 22-34.

OECD (1999), The Battle against Exclusion, Social Assistance in Canada and Switzerland, Vol. 3, OECD Publishing, Paris.

OECD (1998a), The Battle against Exclusion, Social Assistance in Australia, Finland, Sweden and the United Kingdom, Vol. 1, OECD Publishing, Paris.

OECD (1998b), The Battle against Exclusion, Social Assistance in Belgium, the Czech Republic, the Netherlands and Norway, Vol. 2, OECD Publishing, Paris.

O’Neill, A., Bassi, L.J., and Wolf, D.A. (1987), "The Duration of Welfare Spells", The Review of Economics and Statistics, Vol. 69(2), MIT Press, pp. 241-248

Orme, C.D. (2001), Two-step inference in dynamic non-linear panel data models, Unpublished paper, University of Manchester, http://personalpages.manchester.ac.uk/staff/chris.orme/documents/ Research\%20Papers/initcondlast/pdf.

Pavetti, L.A. (1993), The Dynamics of Welfare and Work: Exploring the Process by which Women Work their Way off Welfare, $\mathrm{PhD}$ thesis, Harvard University.

Peck, J. and N. Theodore (2000), Commentary, "Work first: workfare and the regulation of contingent labour markets", Cambridge Journal of Economics, 24, pp. 119-138.

Riphahn, R., and C. Wunder (2013), State Dependence in Welfare Receipt: Transitions Before and After a Reform, CESifo Working Paper No. 4485.

Riphahn, R., and C. Wunder (2012), "Patterns of Welfare Dependence Before and After a Reform: Evidence from First Generation Immigrants and Natives in Germany", Review of Income and Wealth, 59(3), pp. 437-459.

Sandefur, G. D. and S. T. Cook (1998), "Permanent Exits from Public Assistance: The impact of Duration, Family, and Work", Social Forces, 77(2), pp. 763-787.

STAKES (2008), “Social Assistance 2007”, Statistical Summary 37/2008.

Stewart, M. B. (2007), "The interrelated dynamics of unemployment and low pay", Journal of Applied Econometrics, 22(3), pp. 511-531. 
Tseng, Y.-P., H. Vu and R. Wilkins (2008), "Dynamic Properties of Income Support Receipt in Australia", Australian Economic Review, 41(1), pp. 32-55.

Tseng, Y.-P. and R. Wilkins (2003), "Reliance on Income Support in Australia: Prevalence and Persistence", Economic Record, 79(245), pp. 196-217.

Wilson, M. (1999), "The Duration of Benefit Receipt: New Findings from the Benefit Dynamics Data Set", Social Policy Journal of New Zealand, 13.

Wooldridge, J. M. (2005), "Simple solutions to the initial conditions problem in dynamic, nonlinear panel data models with unobserved heterogeneity", Journal of Applied Econometrics, 20(1), pp. 39-54.

World Bank (2013), Latvia GMI Program: Main Design Characteristics and Comparison with Minimum Income Schemes in Other EU Member States, World Bank Report, www.lm.gov.lv/upload/aktualitates/lv gmi note 270513.pdf (accessed June 2013).

Wunder, C. and R. Riphahn (2014), "The dynamics of welfare entry and exit among natives and immigrants", Oxford Economic Papers, 66, pp. 580-604. 